\title{
Questioning Many Mysteries
}

\author{
Sara F. Martin 1
}

Received: 31 October 2014 / Accepted: 9 March 2015 / Published online: 3 April 2015

(C) The Author(s) 2015. This article is published with open access at Springerlink.com

\begin{abstract}
The first section of this memoir queries my formative years. Indirectly I address the question, did my childhood and early years make a difference in my choice of career? Why and how did I begin my journey to becoming a scientist? Did I choose the field of solar astronomy or did circumstances dictate it for me? In the second section, I travel through my work environments and experiences, talking about interactions and aspects of being a scientist that do not appear in our research papers. What parts of my research were happenstances and what parts did I plan? What does it feel like to be on scientific quests? Using examples in my journey, I also turn to questions that have intrigued me throughout my sojourn as a solar astronomer. How do scientific discoveries come about? What factors lead to little discoveries? And what factors lead to major exciting discoveries? Are there timely questions we do not think to ask? How can small, seemingly scattered pieces of knowledge suddenly coalesce into a deeper understanding - what is called the "Aha!" experience - the times when our mental light switches on, and with child-like wonder we behold a "big picture"?
\end{abstract}

\section{What Led to My Career in Solar Research?}

\subsection{Childhood and Earliest Family Influences}

According to my mother, I was always content to amuse myself. Before I was one year of age, she could put me in my crib or on the floor and I would soon find a way to keep myself occupied for long periods of time. In contrast, my two brothers, one older and one younger, were incessantly teasing and provoking each other into retaliation. When Mother came to put a stop to the ruckus, they both would claim "He started it!" She would respond with "It takes two to start a fight and two to keep it going!" If they still would not give her any peace of mind, she would simply punish both of them. Through her actions, our mother instilled in me and my siblings a sense of justice, truthfulness, and that our actions

S.F. Martin

sara@helioresearch.org

1 Helio Research, 5212 Maryland Ave., La Crescenta, CA 91214, USA 
Figure 1 With brothers, Alan James (left) and John Harvey (right), companions, and playmates during my formative years. We had been cleaned-up and dressed by our mother, Emily, for a family gathering at the small farm of our grandfather, Elba Roy Higgins and grandmother, Grace Irene Higgins, the parents of our father, Harold Harvey Higgins.

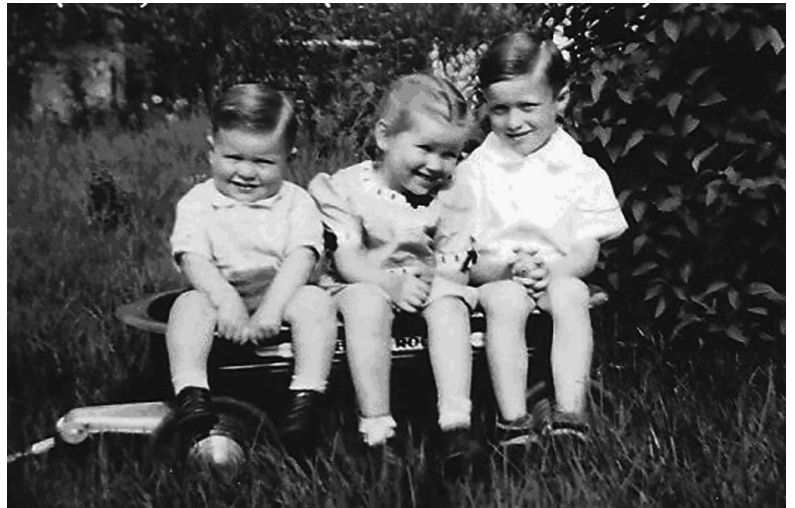

have consequences. These virtues have value in any profession, but their absence would be particularly detrimental to a career in research.

We oldest three of four siblings in my family had distinctly different personalities from the start of our lives (Figure 1). The same was true of our much younger sister, who arrived in our family when we were teenagers. There do not seem to be any shared traits I could cite as predictive of our occupations, but there does seem to be a common thread in our choices. My older brother went into mathematics; I went into solar research, and our little sister into biology. My younger brother studied chemistry and physics in college, and then diverged into music but maintained a lifelong side interest in the sciences. Possibly we influenced each other. Our parents had little or no background in science, nor did they encourage any of us to choose careers in science.

\subsection{Home Influences}

My two brothers and I lacked any real concern for the fact of being a financially poor family. However, our father's occasional periods of being unemployed must have been of grave concern to our grandparents and to our mother, to whom working hard for everything was an expected part of life. In my earliest memorable years from age five to eleven, we lived in the country, on or next to our paternal grandfather and grandmother's small farm in Michigan. I recall moving into their single car garage, converted to living space by our grandfather. There was no space for indoor plumbing. Bunk beds for my brothers and a small closet occupied one end of the one-room "cabin" as we called it. I slept on a sofa bed, and our parents on a roll-away bed that was stored in the closet in the daytime. A small dining table separated the "kitchen" end of the cabin, which had barely sufficient room for our mother to turn around 360 degrees. Without taking a step, she could turn to reach the cupboard, a two-burner electric plate, the water bucket, the table for preparing and eating meals, and the garbage pail. Food that could spoil was stored in our grandparent's icebox. Water was brought in a bucket from a tall pump out near the barn. From prior visits to the farm, we were already accustomed to using the outhouse and washing our hands at the barnyard pump.

A large semicircular driveway enclosed the cabin, our grandparents' small house and a large grassy yard.

Outside of the driveway was a small orchard, the barn, chicken coop, and a big garden that provided a large part of our food, along with the eggs gathered daily from the chickens. Behind that were the pasture and a wheat field, and then a little wooded valley with a creek running through it. We quickly became emancipated children, spending most of our time 
in the great outdoors. We were free to roam our local countryside if we reported to our mother where we wanted to go and returned at the expected hour. I feel this setting, with our freedom to explore, was a big factor in several of my later life and career decisions.

My brothers and I walked a mile into town to school. We were good students, although I was quiet and shy and did not talk much with my peers, or even my brothers. What we did outside of school is more memorable. We spent a lot of our summertime and school year weekends wandering in the woods behind our grandfather's farm. We waded in the little creek, caught polliwogs and snakes, picked wildflowers, ate and brought berries home to our mother from patches of wild strawberries, climbed trees, and occasionally played ball in the horse pasture. Winter was for ice-skating, sledding, making snowmen, and snowball fights. On rainy days we stayed inside and played board games.

Being the middle child between two brothers was a big factor in establishing my confidence and self-esteem. We were continuously testing ourselves against the world and alternately competing and cooperating with each other. I never, ever had any doubt about the equality of girls and boys or women and men, because I could do anything about as well as or better than my brothers and vice versa. Overall, we were on par with each other.

Our mother's skills were clearly as important as our father's, but different. She made many of our clothes, cooked, did the laundry, managed the meager family finances, and later took various jobs outside the home. At different times she was a door-to-door salesperson for the Real Silk Hosiery Co, an assistant in bank accounting, but her favorite job was becoming a medical transcriptionist because she was good at spelling and liked learning the root meanings of words. Our father mostly worked in department stores where he made boring jobs more interesting with artful displays and advertising. He was minimally helpful around the house, and largely ignored us children. Very often he would have classical music playing on the radio while he was absorbed in his writing on a typewriter.

We kids always complained about, but eventually complied with various chores assigned by our mother. Mostly we experienced a life of freedom with mild, but definite, constraints. Along with our independence and self-sufficiency, we learned cooperation and the ability to do innumerable practical tasks. I absorbed a great variety of skills by doing gardening, feeding animals, mowing grass, helping my mother with cooking, and with canning food for winter, doing laundry, ironing clothes, and many other tasks. The influence of the required family work was definite. At relatively early ages, my brothers and I learned self-discipline and to complete any task begun.

When I was eleven, our father was out of work. Eventually he found a job in a department store in another town in Michigan. We left the idyllic countryside and moved to the small town of Owosso. Our mother was the one who found a house to rent that was not in very good condition. She negotiated with the landlord to keep the rent low by volunteering to paint the interior of the house. Over the next few months, my older brother and I helped her with a lot of the painting. While our parents had moved a couple of times previous to our starting school, this move was our first big lesson in adapting to a new environment. My brothers and I, in grades five, six, and seven, made new friends in school, and we found new sports to play. We learned that life is full of changes and responsibilities, both big and little. This move was our first important lesson in meeting and accepting change, out of one's control, with a positive attitude, something I had to repeat several times in later life.

\subsection{Middle School Influences}

Around age 13, I was fortunate to have an extraordinary English teacher for both the seventh and eighth grades. From Mrs. French I learned the roles that various words play in our 
speech and writing and in the structure of English by diagramming sentences. She illustrated how long sentences can easily become illogical, and how to arrange words to convey even complex ideas. Her writing assignments were challenging and interesting. No other teacher so skillfully provided the practical knowledge and tools that I would apply almost unconsciously the rest of my life. The jumble of words we all learn by rote memory and association came together in the bigger picture we call language. It was my first conscious realization of how small pieces of something could fit together to make a meaningful whole. At that point, I subliminally knew what it meant to "get an education".

This revered teacher once gave our class the assignment of picking a life work and writing a page about our choice. The assignment included describing the personal qualifications and characteristics that one would need for our chosen career. My girlfriends discussed whether to write about becoming a nurse, school teacher, secretary, airline hostess or a homemaker, but none of these options appealed to me. I was not of a mind to limit my choices to the "acceptable" careers for women in the US at that time. I strongly felt I would find something different and exciting. I wanted to be an explorer or a pioneer - but that was not regarded as a career option.

On the weekend before the assignment was due, I walked across town to the public library. No one in my family used the library much, nor encouraged us to, so this was a new experience, probably suggested by the teacher. I quietly looked around without going to the librarian. Eventually, I found some books on careers and began leafing through them and reading bits. I came across the heading "Scientist" and began reading. A scientist needed to be curious, to like math, to have a logical mind, and especially to have patience and perseverance. The self-identity clicked. That was me! I checked out a book from the library and wrote my essay on the qualifications needed to become a scientist. My girlfriends were surprised at my choice, and asked why I would choose something so difficult and uninteresting. I gave some offhand answer about it being just another assignment at the time. However, when I returned the book to the library, I found a book about atoms and later another fascinating book about the life of Madam Curie. My interest was silently strengthened, although my period of extra reading did not last long. No one else engaged me in further discussions about what career I would like.

At that time young women, unlike young men, were expected to "get married and raise a family" - not to have a career. When the question of a career did come up, it was generally phrased as a choice: Do you want to have a career or raise a family? For me the only answer was: Both. I was interested in expanding my options, not limiting them. My mother was both working and taking care of the family; she was already the example that one need not be compelled to make a choice, even though her work was not considered to be a "career". She set a positive example in personal values and work ethics but I wanted to find much more interesting work. In that respect I consciously sought to be different from her.

\subsection{Parental Influences}

The limitations imposed by our father's low income, and interspersed with periods of being without a job, became obvious. We never took a family vacation; our only trips were to family reunions. My parents did not own a car until I was in junior high school and my father took a job as a car salesman. The financial limitations on our personal freedom were seeping deeper into my consciousness. With my mother's encouragement, I became determined to get a college education to overcome these limitations.

While I was selecting a college prep curriculum in high school, my father once said to me that he thought I should take more vocational courses, as it was unlikely that we would 
be able to afford college. His good intentions made me secretly angry! I silently rejected his advice. I saw college as my path to financial freedom, and that would lead to freedom to see the world and to choose my own destiny. Work permits for students could be obtained at age fourteen. I got a job at a dime store on Saturdays, primarily to begin saving money for college. From that time onward, I always had some kind of low-paying part-time job on weekends and throughout the summers.

\subsection{Religious Influences}

Most religious influences on scientists and budding scientists are negative ones. Their exposure to religion often causes them to reject it as illogical, man-made stories and beliefs based on the fear of death, or an unfulfilled emotional dependence.

My experience was the antithesis; my choosing a religion became a big and positive factor in my choosing science as a career. To explain, I should briefly tell the story of how my mother adopted a new, little known religion, and how it eventually impacted me. When Mother was in her early twenties and single, she joined a young people's group at a local Christian church in Flint, Michigan. The president, Harold H. Higgins, liked to invite guest speakers from other religions to speak to the group. One time he invited a member of the Baha'i Faith to speak. My mother and several others in the group found its precepts refreshing and enlightening. It was their first experience in hearing of a religion that espoused the concept that all of the broadly known religions were from the same God, ... that the founders of the world's great religions were inspired by the same God... and taught essentially the same spiritual principles, such as the Golden Rule. Discovering the Baha'i Faith was the "Aha!" experience of my mother's life.

This introduction spurred her and a small group of her friends to seek all opportunities to learn more. They would meet to discuss the teachings of Baha'u'llah and would eagerly drive for hours to hear other Baha'i speakers. My mother's study and adoption of the Baha'i Faith exemplify how my mother was a woman who thought for herself, as did her mother. In this way, I followed in their footsteps.

Among the principles of Baha'i Faith, is the harmony of science and religion. Both are regarded as essential and complementary pathways to the meanings of life. I was strongly influenced by the poetic metaphor that science and religion are like the two wings of the bird of truth. Without the wing of science and its applications, mankind will not intellectually progress. Without an equally strong wing of spiritual values, science cannot prevent man from destroying rather than building an ever-advancing civilization. Why have we been watching them flap out of sync, rather than together, for so long?

More than any other single influence in my life, the life and deeply inspired writings of Baha'u'llah (1923) prompted my independence. Also a few kind, thoughtful Baha'i people in my life encouraged my interest in the physical sciences. These were the lights that kept me on the path to becoming a scientist.

\subsection{Planning for College}

Midway through high school, we moved again; this time to Pontiac, Michigan, our father's newest place of employment. Pontiac's public high school was huge; I was one of more than 2500 students in comparison to the few hundred in my previous schools. I looked forward to taking physics and chemistry. I soon learned physics classes were exceedingly unpopular, largely due to an uninspiring teacher with a strong German accent. Notably, there were only three women students, two in my physics class and one in a second physics class. Learning 
Figure 2 Picture taken in

Michigan during my last year in high school, circa 1956-1957, when I was 18 or 19 with my sights set on beginning college at Michigan Tech.

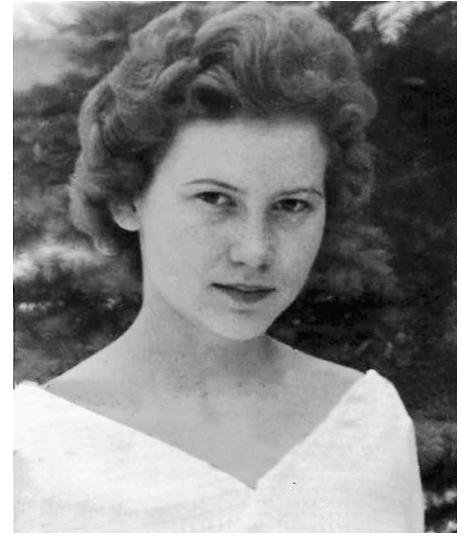

about the periodic table of elements was deeply satisfying. Another revelation was finding out about the electromagnetic spectrum. I was amazed to learn X-rays, light, and radio waves were different parts of a continuous spectrum.

At one point, I became intrigued with the idea of entering a science fair and building a Van de Graaf generator. Thinking that the teacher might give some helpful advice, I explained my interest after class one day. He was completely disinterested; he tried to discourage me by pointing out that the "boys" who would win those science fair contests would have vastly more experience than me. I went away disappointed, without a single encouraging word. I dropped the idea for doing a science project; however, my interest persevered. I still thought studying physics would be a good preparation for many possible kinds of interesting work.

A picture of me taken some time during my last year in high school, 1956-1957, is in Figure 2. Uppermost in my mind, as I began my final year in high school in 1956, was deciding where to go to college. The public library had catalogs from schools everywhere. I compared the costs and availability of scholarships to the technical institutes and universities in interesting places in the US. It quickly became obvious that an in-state school would be much cheaper than paying a high out-of-state tuition. The least expensive was the Michigan College of Mining and Technology (Michigan Tech). The college was the biggest remaining "business" in the former mining town of Houghton, in the Keewenaw peninsula, which juts northward from upper Michigan into Lake Superior toward the southern border of Canada. Early in the 1900s, logging and copper mining boom towns grew there, and they made it a natural location for what was originally the Michigan College of Mines. The school remained after copper mining was no longer profitable, and morphed into the Michigan College of Mining and Technology.

Michigan Tech was state-supported; there was no tuition per se, only a fee of $\$ 100$. My direct expenses would be room and board, the $\$ 100$, plus books. The huge difference in cost compared to the University of Michigan or Michigan State made Tech an easy choice. In addition, Michigan Tech offered one scholarship per high school covering the $\$ 100$ fee. From a school counselor, I learned there were only two other students in my senior class of several hundred "college prep" students who had expressed interest in Michigan Tech. I eagerly applied for the scholarship. My ability to earn good grades in school finally paid off. I won the $\$ 100$ scholarship and that meant I only had to earn enough money to pay for the dormitory, food, and books. I would soon be happily headed off to college to study physics! 
The end of my last summer of earning money for college came, and I bought a one-way bus ticket to Michigan Tech. My mother drove me, an old trunk, and a large box to the bus station. It was an exciting day for me, but my mother could not muster even a bit of elation. She broke into tears a few minutes before I boarded the bus. The little college in "Copper Country" was over 500 miles from where we lived in Pontiac; I would not be coming home on weekends on my budget.

\subsection{Major Challenges of My Undergraduate Years}

I arrived in Houghton in the middle of the following day. I struggled with my clumsy baggage until a seldom-seen taxi happened by and took me the remaining half mile to my academic residence for the next two years. All of the women students from outside the local area were required to live in a college dormitory; it was the large, elegant, old, 3-story Smith House. The house mother was taken aback at my sudden appearance without family, and asked a bunch of questions before welcoming me into the house. The women students had doubled that year to 25, compared to the population of around 1200 in the two men's dormitories.

There were also a few students from local Finnish families who commuted daily from their homes and some of these became my good friends. Among these, Kathy Hellman was first to introduce me to the real Finnish sauna and Finnish family life in this remote region of the US. Among the local families, as in my extended family, almost no one thought we women enrolled at Michigan Tech to "get an education" in spite of the fact that most of us were sincere in that goal. Smith House girls had to be in by $10 \mathrm{pm}$ and the penalty for breaking the rules was expulsion from the college. There was one daring young woman who tested the rules during my second year; not long after that, she was gone. The house-mother hen literally ruled the roost!

I was assigned a room on the second floor with my roommate Georgina, whose parents lived in the country a few miles from the college. She had a full scholarship that allowed her to live on campus rather than to commute from home in winters with an annual snowfall of 25 to 30 feet. Gina was a soft-spoken, blue-eyed, blond Finnish girl with a wonderfully pleasant disposition that exuded a natural femininity and concealed her genius. Not only was chemistry her major, she also had a personal chemistry that automatically attracted male students. She played the flute with marvelous beauty, could write well, and was academically at the top of her high school class. As naturally and easily as she did everything else, Gina helped me become more social and less shy. We enjoyed each other's company, but did our endless studying individually.

The extremely low ratio of women to men students was actually a disadvantage, in the sense that we were not necessarily viewed as normal women. The men students were afraid we were too smart, too aggressive, or lacking in femininity because we had chosen to compete with them for grades at Michigan Tech, and then jobs in male-dominated professions. Initially we were more avoided than befriended. Being assigned Georgina as a roommate was one of my luckiest personal circumstances. When we wanted a short break, we would walk to the coffee shop in the student union building together. We soon found that two young women together was the ideal social combination. Guys were often too shy to try to strike up a conversation with a single woman. They feared razzing from the other male students. Three or four women students together also scared them away; two was just right. Within minutes of our arrival at the coffee shop, two or more men students would find an excuse to come talk with us. Gina frequently dated; she was well known locally as well as at the college. Dates and social occasions were rarer for me but I did get invitations to occasional 
fraternity parties. However, class assignments were demanding even for the best students like Gina, and our social life was minimal. We were busy with studies and assignments day and night.

College for me was a time of great change and challenges - academically and financially as well as socially. I had earned enough money before college to get through one semester without working. After that I got a job in the school cafeteria that almost earned me enough to complete the first year. When home on spring break, I asked an uncle to loan me $\$ 125$, a request he did not greet with pleasure, pointing out he had children of his own to put through college. However, he did give me the money. I worked all summer as a waitress, successively in two small restaurants. Besides saving some money for my return to college in the fall, I completely surprised my uncle with a letter thanking him for his help, and a check including some interest on money he assumed forever gone. This earned some family respect among my mother's brothers. Respect from my mother's side of the family was not something I was seeking, but it served to put my mother a notch higher in esteem among her six brothers. She was proud!

My dire financial condition wore me down during my second year. I continued working in the college cafeteria. A college counselor told me about a small scholarship that helped. I got a second job at the college telephone switchboard, and sometimes I did babysitting for married students. My grades were far from tops; working and a full load of 16 units of classes was too much, but I was determined to continue. I had no second thoughts about having chosen physics as my major but the idea of taking longer than four years to graduate was not in my personal equation, as I did not see how I could continue supporting myself. In hindsight, taking longer to complete my degree would have been a better choice; I surely would have found the financial means. All was not doom and gloom. The occasional down feelings alternated with some very positive experiences. By the end of my second year at Michigan Tech, a remarkable summer employment opportunity opened up for two successive summers.

\subsection{Discovering McMath-Hulbert Solar Observatory}

During Thanksgiving holiday break that year, my brother Alan noticed an article in the Pontiac Press about McMath-Hulbert Solar Observatory. We were immediately curious, but the article only described its location as "at Lake Angelus", a little north of the city. We borrowed the family car the next day, and drove out to find this intriguing place. We took a gravel road off the main highway in what we thought was the right direction, past a few small country houses and into a stretch with woods close on both sides of the road. There were no signs, but we spotted a little one lane dirt road that went off to the left through a small ravine and disappeared into the trees in our estimated direction of the hidden lake. Coming up out of the ravine, we came into a parking lot with chain link fence on three sides and a big oak tree in the middle. There was an academic-looking, concrete, two-story building to the east, a large grassy lawn to the west. To the south was a small observatory dome on a tower sticking up a little higher than the surrounding trees! We had found it!

We got out of the car, and while we were wondering whether we dared open the gate in the fence, a little gray-haired woman came out of the building. Without a word of welcome, she asked why we were there. We introduced ourselves as college students, mentioned the newspaper article, and asked if we could be allowed to see the telescopes. She went to find a man named Cliff Bennett, who gave us a guided tour of the telescopes in each of the three domes in Figure 3; he explained what they did and answered our many questions. Alan and I were both enchanted with this mysterious place for observing the Sun. At the end of the 
Figure 3 McMath-Hulbert

Observatory viewed facing north.

The observatory image was taken much earlier than the photo below of the staff during the summer of 1959. Front row, left to right: Professor Orren Mohler (assistant director), Dr. R. Jay Anthan (scientist), Mr. Fred Stuart (data analyst),

Dr. Helen-Dodson Prince (scientist), Miss Sara Higgins (student), Mrs. Joan Koster (secretary), Miss Ruth Hedeman (scientist). Second row:

Mr. Charles Martens (student), and other staff assistants: W.G. Olsen, Mr. John Brody (photo processing and general assistant), Mr. Andrew Erkaroeld (observer), Mr. Cliff Bennett (observer), Mr. James Kline (machinist), Mr. J.W. Troy (janitor). Two other summer students not in this picture were Gerald Newsom and Roger Kopp.

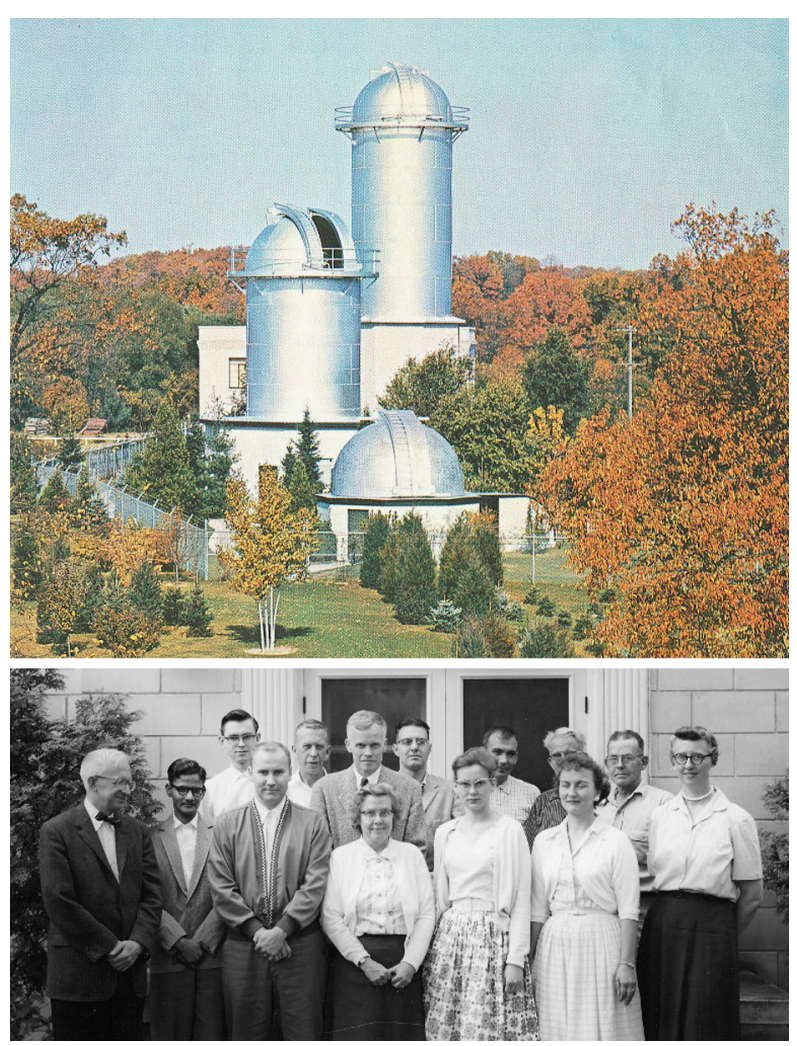

tour, my last question to Mr. Bennett was whether I could apply for a summer job. He said that I should talk with Dr. Prince, whom we had met in the parking lot. She informed us they had only hired students from the University of Michigan. However, when I was home for Christmas break I wrote a letter applying for summer employment at the Observatory. I got a polite answer thanking me for applying but informing me that all the summer positions had been filled with students from the University.

When I was home on spring break, I nonetheless went out to McMath-Hulbert Observatory again, by myself. Dr. Prince was off on a trip, but Dr. Orren Mohler was there, and also Miss Ruth Hedeman, who collaborated with Dr. Prince. Dr. Mohler was assistant director to the aging former owner, amateur astronomer, and auto industry tycoon, Dr. Robert McMath. I asked again about summer employment. Dr. Mohler told me that Dr. Prince would be getting another grant and might be hiring one more student. I immediately wrote to her as he instructed, and this time I got the job! No words could express my elation!

By the time summer came, my mother and little sister had gone to join my father, who had taken an extended trip to Richmond, Virginia, and decided to stay. Dr. Prince kindly found a neighbor down the road about a mile from the Observatory who rented me a room for the summer of 1959. They were nice people, but not academically inclined. They had a high school age son who had a summer job and spent most of his spare time working on his sports car. It was a little uncomfortable living with a family with whom I had so little in common. I sensed they thought I was a strange young woman; I was not interested in watching TV with them in the evenings, preferring to read or take a walk, and had almost no other social life. 
My first summer at McMath-Hulbert Observatory was a unique experience. At that time, Dr. Robert McMath, though not in good health, still came to work part-time and occupied the elegant Director's Office. Although Dr. Prince and Miss Hedeman were staunch figures in the operation of the observatory, attitudes about women were still very traditional. I followed their custom of always wearing a dress or skirt and blouse to work. I was never asked to participate in the observing although I very much would have liked to gain observing experience. On the other hand, my summer position was a highly privileged one of being the only student working all of the time for Dr. Helen Dodson-Prince, one of the famous solar astronomers of that time. I enjoyed it immensely. Although it was routine data processing, I was daily becoming familiar with the images recorded in the recent days. Dr. Prince would occasionally talk about something that had happened or was presented at a meeting, or would comment on the contents of a research paper that was relevant to her. She was always accommodating in answering my questions.

At the end of my first summer, Dr. McMath called me to his office to bid me farewell and offer some fatherly advice. He suggested that if I were to continue in the field, I should cut my hair which I had let grow much longer than in previous years as in Figure 2; indirectly he was saying that I should wear it short like Dr. Prince and Miss Hedeman. His implication was that long hair gave the wrong impression about one's competence, but you could also say he was really telling me that women in the workplace should not be distracting. I thanked him but did not take his advice; in fact, he had just convinced me to do the opposite and keep my hair at the shoulder length. The length of my hair was independent of my work, and in no way, an encumbrance. Although Dr. McMath's advice was surprising, it was helpful on an unintended level: In a roundabout way he was saying that men found me to be attractive something I needed to hear at that time to counter my extreme shyness.

Such conservatism ruled the attitudes of the day. Noticing that Jim, in the Observatory machine shop, did not participate in lunches upstairs, I would return his morning greeting and stop to chat. He was obviously lonely and he was pleasant to talk with. Sometimes, he would give me useful bits of information about people's attitudes or other miscellaneous information. One morning as I came to work, Jim did the "wolf whistle" that we rarely hear these days. It was just a friendly bit of flattery coming from him. I just let it pass and went in as usual to chat briefly. Then later in the day, I was informed by Dr. Prince that I should not stop to talk with Jim anymore.

It would clearly not have been wise for me to ignore this unfortunate advice. There was no need to explain to Jim; he knew why I only waved as I went by and did not stop to chat any more. It is still a sad commentary on people that someone at the observatory, not necessarily Dr. Prince, was so uptight they made an issue of his harmless whistle at me. Probably that person thought they were doing the right thing. I never knew who, and I never asked. Still, I wish I would have had the skills to gracefully counter that bit of social injustice. In spite of these stories revealing outdated attitudes, the McMath-Hulbert Observatory was a great learning experience. I very much wanted to work there again the following summer. Luckily, Dr. Prince had funding for a student assistant the next summer, and I was welcomed back.

Back at college in my third year, my physics advisor, Professor Donald Yerg, was very pleased to learn of my summer position at McMath-Hulbert Solar Observatory. He later offered me a job on a project he was doing in ionospheric research. It was not as fascinating as my job at McMath-Hulbert Solar Observatory because the nature of the data was not as obvious. Nevertheless I was pleased to be working at anything that had to do with research. I also continued working in the cafeteria, which had been transferred to a new wing in the men's dormitory. I could finally see my way to the end of college, and applied for a National student loan to cover my expenses for my final year at Michigan Tech. That enabled me to concentrate almost completely on the courses required to graduate. 
When I returned for my second summer at McMath-Hulbert Solar Observatory, Dr. McMath had been replaced as Director by the quiet, soft-spoken Dr. Orren Mohler. He also had duties at the University in Ann Arbor, and Dr. Prince was in charge when he was away. She was a diligent and thoughtful researcher, with a colorful personality. She would become very excited when one of the observers came to the office building to report there was a solar flare taking place, and hustle over to the observatory with me tagging along to see what the welcome excitement was all about. The research was very much focused on active regions and solar flares. Solar active regions, whose sunspots had decayed and disappeared, were of great interest to the two lady scientists because some of the largest solar flares with geomagnetic effects sometimes occurred in them. A student from the University of Michigan, Roger Kopp, whom I had met the year before, also returned for a second summer. He later became a professional friend and colleague and is best known for the Kopp and Pneuman theory of solar flares.

That second summer I roomed with an elderly woman, Rose, who had a small house close to the observatory and who had twice become a widow. We got along famously. She lived contentedly in her small country home tending her garden, chickens and geese. She would induce me to tell my stories about college and my work at the observatory, which was a curiosity to the people in the country neighborhood. She would tell me comical stories about her former husbands, the first one whom she had loved and the second one whom she had come to despise for his verbal abusiveness. It seemed that my presence made her happy - someone else to cook for and to talk with over breakfast and dinner. I enjoyed the quiet evenings to go for walks and read about solar astronomy. For a short time, I borrowed a small night-time telescope that was stored at the observatory and got my first experience in visually observing objects in the night sky - until informed that I had not properly requested permission to use it.

In my fourth year at Tech, senior women students were allowed to live off campus. My roommates, Bonnie and Mary, and I found a top floor apartment in a building only a block from campus. One night during the spring semester of my senior year, I became sick to my stomach. An upset stomach was nothing to be concerned about but, for peace, I gave in to Bonnie's insistence on her walking with me to the infirmary before she would go to her classes. The nurse wisely sidestepped the dismissal of my case by the college doctor and called a city doctor. The second examination quickly resulted in an order for an emergency appendectomy and more extraordinary kindness from the nurse who took me to the hospital while my condition rapidly degraded. I awoke the next day grateful to have been saved by my roommate, the astute nurse, and conscientious doctor from a potentially worse, lifethreatening disaster.

Luck, guardian angels, or whatever appeared a third time. Months earlier and for the first time, I had purchased a student health insurance package for only $\$ 12$. It covered essentially all of my expenses for the surgery and nearly a two-week stay in the hospital in Hancock! Upon my release, I walked ever-so-slowly home, greeted my surprised roommates, and fell into bed exhausted. I learned the body does not heal from surgery as fast as one would like. It put me far behind in my homework and I dropped a couple of my easier classes that I could finish during the summer quarter. I recovered and was allowed to participate in the spring graduation ceremonies with my classmates. The real diploma was held until the end of the summer term when my remaining requirements for my Bachelor of Science degree were met. 


\subsection{Formal Entry into the Field of Solar Astronomy}

During the fall of our senior year, professional recruits for various companies and government agencies came to campuses like Michigan Tech for a specified week to interview students. Most of the companies were seeking graduates in engineering fields, but also interviewed students in the sciences. The top students were usually offered further interviews and a trip. A few received immediate job offers. Older students, who had entered college after military service, were preferred candidates by the interviewers. I signed up for a few interviews, but I soon learned that women were at the bottom of preferred interviewees. One interviewer from industry actually told me he was instructed not to hire any women. In other cases, that was obvious by the way the interview proceeded.

I found only two entries on the list of interviewers that were specifically interested in graduates in physics. They were the National Security Agency (NSA) and the Central Intelligence Agency (CIA). I wound up on a list to be offered a trip to Washington DC to see the NSA facilities and be interviewed a second time. The CIA also communicated but in more interesting ways. No letter had a return address. The content was specified as confidential as were the extensive applications forms and a telephone call about further interviews.

On my own, I also wrote to Dr. Prince about possible employment at McMath-Hulbert Observatory. She replied that they did not have grant funds to even consider such a possibility. However, she recommended that I write to a man at an aircraft company in Texas, whom she had met at a meeting. He never replied, so I assumed that lead was a dead end. I also wrote to the Director of the Mt. Wilson Observatory, knowing that solar astronomy was important there. The response was also negative. I began envisioning a secret CIA job at some exciting place in the world, as opposed to the huge, faceless laboratories of the NSA.

Then one day in April I was studying in our apartment when a man called and identified himself as Mr. Gail Moreton from the Lockheed California Company. He said he had gotten my name from the man I had written to at the aircraft company in Texas, and asked if I was still interested in a position. I said yes, and he promptly offered me the position of Associate Scientist on Lockheed's solar research team at about $\$ 6900$ a year, a good salary at the time. We settled on a beginning date in September of 1961, after I completed the classes that I needed to finish in the summer session at Tech. Mr. Moreton told me that I would receive their formal offer in the mail, and our conversation came to a close.

After hanging up the phone, I did my best to study while trying to believe what had just happened. Mercifully, the offer arrived just a few days later. All thoughts of Washington and the CIA flew out the window, and sunshine flooded in. I was going to California to do solar research!

\subsection{My Transition from College to Work}

My final summer at college was a welcome change of pace, a peaceful retreat to complete healing from the appendectomy while knowing a job awaited me in early September in faraway Southern California. I especially enjoyed a creative writing class which inspired me to write poems in the styles of different authors. However, writing and social sciences seemed too easy from my immature perspective and, at that time for me, did not hold the challenge and intrigue of the physical sciences.

For two years I had been communicating occasionally with a student, Joe Smith, whom I had dated during the latter part of my sophomore year. He graduated with a degree in chemical engineering that year and had gone to Seattle. As a consequence of being in the college ROTC program, he had the opportunity to fulfill his military service via a government program that allowed engineers to be assigned to governmental organizations or those 
with military contracts. During my last year in college, Joe had been assigned to an engineering department at the Jet Propulsion Laboratory, roughly 20 miles from Burbank where I would begin my work in the solar group at Lockheed. While neither of us had contemplated a relationship beyond friendship upon his graduation, neither of us had developed any other binding romantic relationship in the next two years. The attraction between us had increased during a brief summer visit and re-acquaintance at his parent's home before returning to my college in the Upper Peninsula for my final summer at Michigan Tech. Joe proposed marriage and I accepted. We would get married as soon as I finished my degree requisites at the end of the summer of 1961.

My grandfather and grandmother Higgins assented to Joe and I being married at their small farm near Clio, Michigan, a suitable central location for our parents and families to meet. We had a simple, outdoor Baha'i ceremony followed by a homemade picnic with our extended families and a few friends. Then we flew straight to California, full of idealism and eager for adventure.

\section{My Career in Solar Research}

\subsection{Lockheed - My First Professional Position}

When I first read a couple research papers by George Ellery Hale in my early career, I was struck by the way his writing style conveyed enthusiasm about his investigations, an element that is absent in our current, purely technical scientific literature. His early papers are part of my inspiration to talk about my personal history and feelings about my career in solar research. In casual discussions, on the other hand, various people have told me about the early days of solar astronomy at Mt. Wilson. Thus I found that Hale would not hire a woman for any position associated with the science or business of the observatory. As one professor put it "Even his secretaries were men!" And, indeed, later I found that the "Hale attitude" toward women in science still prevailed in the 1960s, which I did not realize initially because it was disguised by my solar colleagues with opposite attitudes. Nevertheless, culturally as well as scientifically, I was extremely lucky to have been hired for a position of "associate scientist" in the new solar astronomy group at Lockheed.

I must thank the solar group director, Mr. Gail Moreton, posthumously for the opportunity to jump straight into research as a full-fledged solar astronomer, although I was little more than a fledgling fresh from the college nest. Mr. Moreton introduced me to Mr. Harry Ramsey, the chief observer, Mr. George Carroll, the Lockheed telescopes engineer, and Dr. Kim Malville, a new graduate from the University of Colorado. The prime movers in bringing Moreton's dream of a new Lockheed Solar Observatory into reality were Carroll and Ramsey, with a big assist from Dr. Lewis Larmore, Director of Pure Research at Lockheed. Dr. Larmore had acquired data for his Ph.D. thesis using a $15-\mathrm{cm}$ solar telescope at the Climax Solar Observatory in Colorado. Dr. Larmore was instrumental in negotiating the loan of their 6-inch aperture telescope to Lockheed. George Carroll, in Figure 4a, refurbished it and a replacement telescope shown in Figure 4b. Harry Ramsey had been using these telescopes to take time-lapse observations in hydrogen light for only a few years when I arrived at Lockheed in September of 1961. Harry Ramsey, his wife Joanne and children had come to California from Sacramento Peak Observatory in New Mexico, where Harry had participated in the startup of that facility and was a presiding observer for many years (Ramsey, 1997). George Carroll was an aircraft mechanical and electrical engineer, famous among amateur as well as professional astronomers for designing and building elegant telescopes 

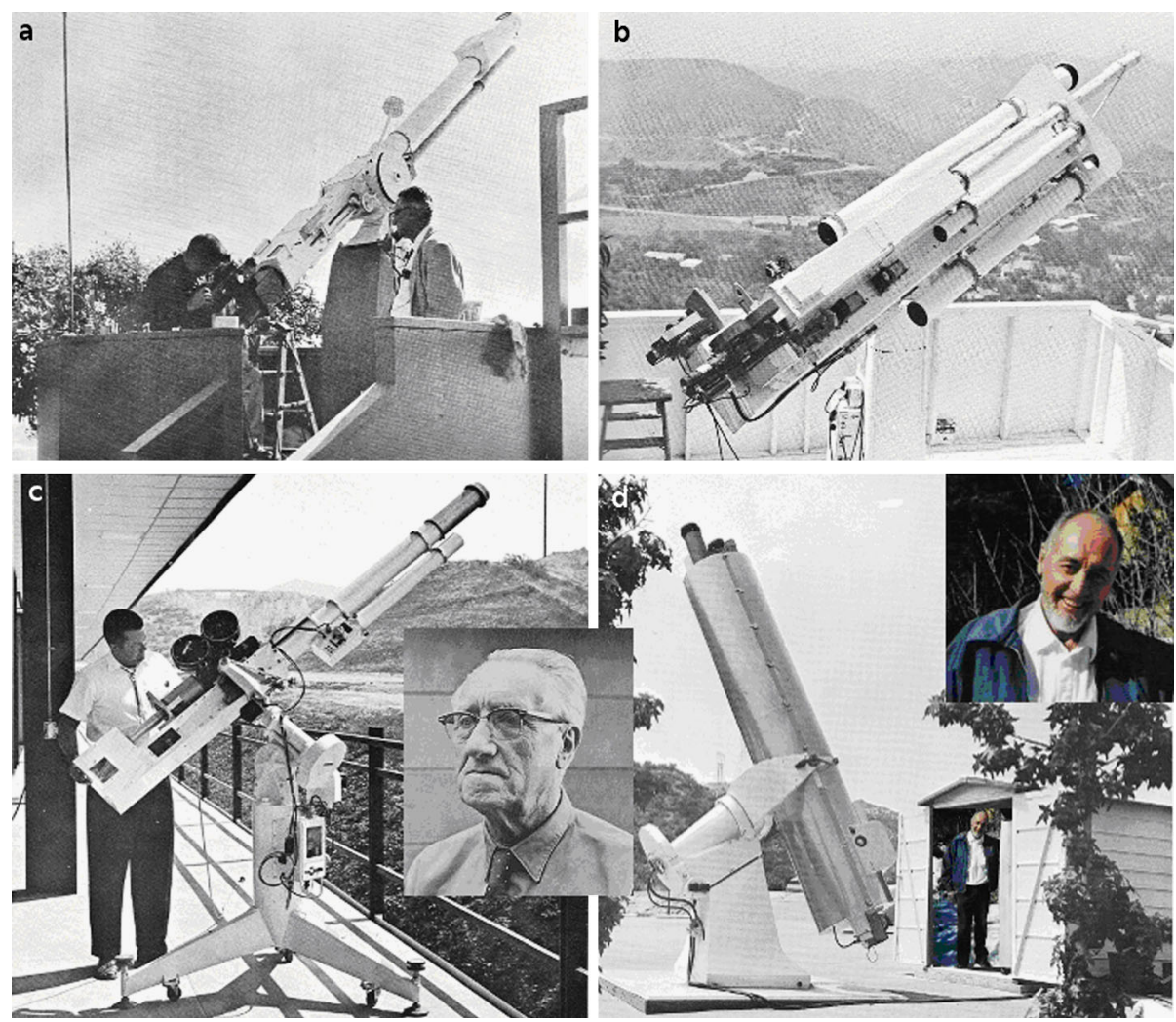

Figure 4 First four telescopes used by the Lockheed Solar Observatory group. (a): George Carroll stands by the first telescope located at Briar Summit which he had refurbished upon its loan from the High Altitude Observatory in 1958. Gail Moreton peers in the eyepiece. (b): Replacement telescope at Briar Summit on temporary loan from HAO in 1959. (c): Full-disk, transportable solar telescope designed by George Carroll (shown in the inset overlapping (c) and (d)); Gail Moreton stands next to the transportable telescope at the Lockheed Rye Canyon Research Center in 1964. (d): New Lockheed telescope at Rye Canyon designed by George Carroll. All of the telescopes were operated by Harry Ramsey shown in the insets in (d). These images, excluding the insets, are from Solar Filtergrams of the Lockheed Solar Observatory by Nolan, Smith, and Ramsey (1970). The inset photograph of Harry Ramsey was provided by Joanne Ramsey.

in his spare time. One of several transportable, solar full-disk telescopes, designed and built by George is shown in Figure 4c. A new one specific for our research is in Figure 4d.

The initial Lockheed solar observing site was in the Hollywood Hills, an informal designation for the east end of the Santa Monica Mountains. The telescope was about $4 \mathrm{~km}$ west from the famed Hollywood sign. But I was not there to view the stars of Hollywood; I was enchanted with watching our day-star, the Sun, visible through the telescope eyepiece. The image quality and detail (Smith, 1963) exceeded any that I had seen during my summer jobs in Michigan.

Kim Malville invited me to join him in research for a paper on the properties of solar flares which partially covered the umbra of sunspots. We compiled data for this study by systematically searching through copies of $\mathrm{H} \alpha$ movies. We completed our paper in a few months and submitted it to the Journal of Geophysical Research (Malville and Smith, 1963). Kim then announced that he was leaving Lockheed for a position in Boulder Colorado with 
the High Altitude Solar Observatory. He encouraged me to present our paper at the next meeting of the Astronomical Society of the Pacific. While disappointed in Kim's leaving Lockheed, I was grateful that he had initiated me into the process of producing and presenting a research paper. Indeed, I was full of eagerness to pursue analyses of other fascinating activity I had seen in the solar films.

Instead of setting up a film lab at Lockheed, Harry Ramsey had arranged for our 200-ft rolls of 35-mm pictures of the Sun to be developed once or twice a week by Pathe Laboratories, a movie studio in Burbank. We always looked forward to the days when Harry brought the processed rolls to our temporary office and lab space in Burbank. As at McMath-Hulbert Observatory, we had a 35-mm projector for looking at the originals and making measurements directly when needed, but it could only run about 5 frames per second. While at Sacramento Peak, Harry had begun the practice of also getting a 16-mm copy, to run on a smaller but more versatile projector at the movie speed of 30 frames per second. The expendable 16-mm copies allowed us the luxury of watching movies of the solar flares, erupting filaments, surges, and other solar activity visible through the narrow-band hydrogen alpha $(\mathrm{H} \alpha)$ filter. A whole new world of exploration opened before my eyes!

I spent many rewarding hours in the film-viewing room in amazed study of the dynamic activity featured in our films. Successive days of observations enabled tracking the more stable active regions and filaments as solar rotation carried them across the Sun. Over time, this let me see nearly all solar phenomena from many different viewing angles, and thereby deduce their three-dimensional structures. This included short-lived phenomena such as the flares and surges that repeatedly occurred at specific locations within an active region. There was no place in the world I would rather have been working. I sometimes felt inadequate when faced with giving presentations at professional meetings, because I had not gone to graduate school - not yet understanding that my daily experience learning from and along with my colleagues was an ideal equivalent. I was left completely and mercifully unaware of the publish-or-perish syndrome that existed elsewhere; I thought research papers should be packed with significant new information that was well demonstrated, no matter how long it took to achieve a good result.

We used a birefringent filter with a half-width of $0.5 \AA$ that could be manually tuned up to $1 \AA$ into the blue or red wing of the $\mathrm{H} \alpha$ line in the solar spectrum. Harry Ramsey set the filter passband for the red or blue wing on alternate days. This yielded increased contrast on sunspots, fibrils and filaments. I could see that the images were also superb for identifying patterns in the Doppler shifts in filaments before they erupted and chose that topic for my next research project. Harry was also keenly interested in filaments from his years of observing, and he agreed to work with me (Smith and Ramsey, 1964). The research environment was wonderfully innovative. Gradually I realized from reactions to my presentations at meetings that no other solar observatory was producing such a large quantity of high-quality, time-lapse solar images for immediate study in the form of movies. Harry often happily commented on how many more days and continuous hours of clear weather and with much better "seeing" (conditions with stable air allowing higher-quality imaging) than he had previously experienced in the mountains of New Mexico.

Now in 2012, I am blessed to witness "history repeat itself", in a most favorable way. In this era of the internet, researchers in solar astronomy all over the world now share the excitement of daily viewing of the Sun's dynamic phenomena in digital movie format. Thanks to current solar satellites imaging solar activity at ever higher data rates (SOHO, SDO, STEREO), even school-age children can share in the delights of observing our awesomely dynamic Sun. Some satellites enable observing events on the back side of the Sun relative to the side seen from Earth. 
One surprising development, however, is that in my early days it was generally thought that observations would have to be taken from space to eliminate the distorting effects of the Earth's atmosphere. We could not anticipate the reverse. Now, due to new methods of taking and processing solar images, the highest-quality observations from the ground can exceed the resolution and imaging rates of most of our instruments on satellites. Our spacebased instruments complement, rather than replace, our ground-based observations. Now, it is mainly international economic and political challenges that stand in the way of coordinating and maintaining uniform, high-quality, multi-wavelength solar observations from the ground for nearly 24 hours per day.

Early in 1962, our solar group moved from Burbank to a modern, new building at Lockheed's Rye Canyon Wind Tunnel and test facility near Saugus (now part of Santa Clarita). Shortly thereafter, funding for a new 25-cm limited-field solar telescope designed by George Carroll, was approved. The new telescope was temporarily set up in a corner of the parking lot outside of the moat of vegetation around our new building (Figure 4d). To everyone's amazement, the atmospheric stability at Rye Canyon proved to be as good as at the site in the Hollywood Hills. The telescope, on one corner of the asphalt parking lot, was so convenient and the results were so astoundingly good that no effort was made to find a new site.

\subsection{Flare Waves and Harry Ramsey}

Before and after the move to Rye Canyon, Gail Moreton and Harry Ramsey were focused on the detection of large-scale flare waves in the chromosphere, a phenomenon Harry discovered by first manually tuning the filter into one wing of the $\mathrm{H} \alpha$ line and then taking automated time-lapse movies. Harry was initially unsuccessful in convincing Gail to allow him to observe in the wings instead of the center of the line, where flares were more completely seen. However, invisible propagating disturbances had much earlier been inferred from the sudden disturbance of filaments outside of the active regions of a few bright flares at least as early as 1949 (Dodson, 1949 and review in Smith and Harvey, 1971). When Gail was away on a trip in 1960, Harry could not resist his instinct to experiment by taking timelapse images in the wings of the $\mathrm{H} \alpha$ line. By the time Gail returned, Harry had made his first wing movie of the effects of a flare-associated shock wave rippling through the chromosphere in a large arc propagating away from the core of the flare. Gail was very excited and fueled-up to make trips advertising these new results, while Harry continued observing in each wing on alternate days. This ironically led to other scientists in the field calling Harry's newly observed phenomenon "Moreton waves", instead of Ramsey getting the credit for the discovery. Years later, having learned about fascinating coronal effects concurrent with the chromospheric waves and with Harry's full concurrence, Karen Harvey and I agreed to henceforth call the phenomenon "flare waves" (Smith and Harvey, 1971). We all strongly preferred not to name any natural phenomena after a person.

The chromospheric flare waves were a spectacular discovery and it was certainly appropriate for Gail (Moreton 1961, 1964; Athay and Moreton, 1961) to make them known. As the leading edge of an invisible shock wave in the corona spread across the face of the Sun, a corresponding huge arc of the fibril and spicule structure of the chromosphere was temporarily depressed and then quickly sprang back upward after the shock wave passed. The chromospheric wave was damped within two oscillations, whereas filaments in the path of the invisible flare wave sometimes exhibited several oscillations (Ramsey and Smith, 1966). These, in the earliest papers, had been called "winking" filaments (Dodson, 1949). As new examples were observed, they continued to be seen only with the brightest flares, whether 
small or large. It was eventually established that the threshold for detection of flare wave effects, observed at $193 \AA$ in the corona by the SOHO EIT experiment, was much lower than for $\mathrm{H} \alpha$. Also, they were invariably associated with CMEs (Cliver et al., 2005). Now, the several effects of the flare shock waves are commonly observed in coronal images from the SDO and the STEREO A and B satellites.

Even after all that has been learned about flare waves since then, a question remains in my mind as regards the explanation of the hazy bright emission front that is observed in the core of the $\mathrm{H} \alpha$ line as a flare shock wave passes through the corona. The emission front accompanies but does not exactly mimic the wave in the wings of $\mathrm{H} \alpha$ and can be broader in the direction of propagation. Karen and I (Smith and Harvey, 1971) clearly pointed out the reasons that the bright emission cannot be a chromospheric effect and must be in the corona. This intriguing mystery is still lying dormant three solar cycles later. What is the mechanism that temporarily results in $\mathrm{H} \alpha$ emission in the corona? Why has no one become interested in searching for the physical explanation to resolve this intriguing paradox?

At a meeting on Solar Flares organized by Peter Sturrock, I once suggested in a presentation that the emission might represent something happening within a CME (Sturrock, 1980). I pointed out the possibility of the emission front being coincident with an associated CME that would not otherwise be seen against the disk. The participants in the discussion were adamant that coronal temperatures were too high for anything about CMEs to be visible in $\mathrm{H} \alpha$. There was the polite negative attitude I have encountered over the years implying that observers do not understand physics. Among the valuable lessons learned from getting dismissive answers, I hope I have learned to pose questions more astutely. Now I ask: What interesting effects could result from a flare shock wave passing through its associated $\mathrm{CME}$ or from electrons and protons from the flare reconnection site also passing through the CME?

Flare waves in the chromosphere could have been discovered long before Harry's observations. My mentor, Helen Dodson-Prince, had reported 14 years earlier, on the disturbances and oscillations in filaments. Dodson discussed their unique association with solar flares, and inferred the existence of a "propagating disturbance" from the flare to distant filaments and beyond (Dodson, 1949). Other examples were observed by Bruzek (1951), Ohman and Ohman (1953) and Ohman, Lindgren, and Lindgren (1962). However, no one anticipated that major observable effects on the chromosphere would be detectable by taking pictures in the wings of the $\mathrm{H} \alpha$ line. The simplest question might have been: If filaments oscillate so readily, do other structures in the chromosphere respond similarly?

Harry continued to take images in the wings of the $\mathrm{H} \alpha$ line and was thinking about better ways to observe the flare waves and other flare-associated features in two or more wavelengths simultaneously. Then one day in the fall of 1963 he recognized a strongly Doppler-shifted filament visually through the telescope eyepiece and knew that an eruption was about to happen. Lacking any better means, Harry manually tuned the filter to the red wing, center-line, and blue wing wavelengths every 10 seconds for hours as the eruption proceeded. He could not know until the film came back from Pathe Lab if his effort was rewarded. In the blue and red wings of the line, the eruption was accompanied by a spectacular flare-wave rippling across the chromospheric face of the Sun in a broad arc. In addition, the event revealed hazy bright propagating emissions in the core of the line, the triggering of tiny, point-like brightenings in the chromosphere, and oscillations in a filament distant from the source-site of the wave (Moreton, 1964).

Harry worked with his contact at Pathe Lab to separate the three wavelengths into individual false-colored movies, which they then recombined into a single 3-color movie. Harry made a black and white illustration of a few images for a paper presented at an AAS meeting (Moreton, 1964). This event is among those studied by Karen and I (Smith and Harvey, 
1971). However, the three-color movie was never published or publicly shown in its full glory. Years before his death, Harry passed the original on to me for safe keeping. He and I hoped a future means would be found to have this beautiful film record copied and made broadly available as an educational solar movie. This still remains a personally important goal.

Less than four years after I was hired, Gail Moreton succeeded in "promoting" himself out of his job at Lockheed. The final straw for the management was his repeated failure to get his travels approved beforehand. To his credit, Gail made the Lockheed Solar Observatory known around the world. We were stunned by his departure, but we continued to function well as a research group, including bringing in more funding via research grants than any of the other four pure research groups started and supported by Lockheed. Harry became our natural leader. In effect, he was the mentor for all who came into our group, whether for long or short periods of time. I would feel remiss if this memoir did not include more mention of this man who so greatly influenced the direction of our research and acted as if his role was nothing.

Although someone else was always the formal director of the Lockheed solar group, it was in name only; they wisely allowed our research group to operate for at least a decade under Harry's informal leadership. Harry encouraged everyone at what they were doing and steered the highly productive solar group with a natural ease. Harry welcomed newcomers into the group. Among those who stayed for various lengths of time were Barry Nolan, Marshall Ogne, Dean Canfield, Don Carson, Bob Smithson, and Alan Title. Jack Harvey, Karen Angle, Gary Phyllis, and Doug Rabin were among the students Harry brought into our group. In contrast to this outgoing part of his nature, Harry was self-effacing, and not keen on making research presentations, but would occasionally give a talk in an informal setting. If it was really important to him, he would initiate a paper, such as the one we did on the oscillations of filaments impacted by the flare shock waves (Ramsey and Smith, 1966). But Harry always insisted that he was not a writer, and would convince me to do a lot of the analysis and the writing. However, he would pause in his work on the telescopes and filters, and take time to discuss results and methods of analyses and also make photographic illustrations and edit our papers.

Harry encouraged me to attend meetings and to work on research papers and proposals. Attending a professional meeting usually carried the unwritten requirement of making a research presentation. Being relatively inexperienced, I looked forward to professional solar meetings to become acquainted with people from other solar observatories and to learn whom to contact about proposals that we anticipated writing. It was not long before this led to acquaintance with Dr. Robert (Bob) Howard, who was responsible for all of the solar research being conducted at Mt. Wilson. Among his many accomplishments at Mt. Wilson was the modernization of its famous magnetograph. Bob, Harry, and I were all interested in comparing the high-quality $\mathrm{H} \alpha$ observations from Lockheed Solar Observatory with these unique magnetograms from Mt. Wilson.

As this was before the evolution of desktop computers, Bob suggested that the magnetograms on film would be easier to compare with other data sets if they were first converted to isogauss contour maps. The magnetic signal was represented by slim slanted rectangles, like large diagonal pixels, whose brightness was proportional to field strength. The rectangles representing positive and negative polarities were at 90 degrees to each other. This format made it difficult to see how the magnetic field was changing over time. Bob set up a system to project the original film magnetograms onto large paper Stonyhurst disks. I went to Mt. Wilson every morning for an extended period of time to convert the original magnetograms to hand-drawn isogauss contours. Bob eventually hired a person specifically to 
do that repetitious task, and we were joined by his visitor, Dr. Václav Bumba, in publishing them in an Atlas (Howard, Bumba, and Smith, 1967). The maps in the Atlas became the basis for several research papers. The first three were: "Large-Scale Patterns of Solar Magnetic Fields" (Bumba, Howard, and Smith, 1964), "The Classification of Active Regions" (Smith and Howard, 1968), and "The Sun as a Magnetic Star" (Bumba, Howard, and Smith, 1967). Another was "Flare Positions Relative to Photospheric Magnetic Fields" (Smith and Ramsey, 1967).

The latter paper contained two main results. One was our finding that filaments invariably occur at boundaries between opposite polarity magnetic fields. It was an exciting confirmation and extension of the initial finding by Babcock and Babcock (1955), first for a single polar crown filament and then for quiescent filaments in general. We had the thrill of finding that their result also applied to all filaments in active regions as well as intermediate cases. Our second major finding was that solar flares always straddled lines of zero line-of-sight magnetic flux. These early studies were eye-openers for me. It was amazing to begin to see how well-organized solar activity was. The highly organized fibril structure of active regions and along filaments was obvious in Harry's first $\mathrm{H} \alpha$ filtergrams, of higher spatial resolution and more limited field-of-view than full-disk images (Smith and Ramsey, 1966; Smith, 1968).

I learned about the observing equipment slowly from watching and talking with Harry and occasionally George. I had longed to do observing myself since my student days at McMath-Hulbert Observatory but that was not practical with such expert observers already doing that work. At Lockheed, everyone voluntarily did what they could do best for the group according to interest, ability, and the needs of the group. I knew I was needed for analyzing the data, authoring or co-authoring papers, and writing proposals so that the research could continue. This role involved me deeply in the research planning.

Barry Nolan comes to mind as a typical example of how our research group functioned well as a cooperative group with indirect leadership. Barry Nolan was a creative handyman in our group introduced to us by Jack Harvey. Barry got the idea to put all of the illustrations that we had made for proposals and papers into a picture book describing all the types of solar activity that we observed in $\mathrm{H} \alpha$. After getting us enthused about his idea, he asked Harry to organize the materials, and me to write the captions, while he voluntarily did all the rest, including convincing the Lockheed management to publish a limited edition of 100 copies of our 80 page book, Solar Filtergrams of the Lockheed Solar Observatory (Nolan, Smith, and Ramsey, 1970).

Various aspects of solar flares were a common topic of study in our research. Harry Ramsey told me he was convinced that the basic structure of solar flares were systems of loops. He also told me that it was rewarding and fun to be an observer because observers were usually the first to learn new things about the Sun, and indeed he deserved recognition for quite a number of our findings. In addition to the flare waves mentioned earlier, he was the first to detect dark flare points in the D3 line of He I. He did early comparisons between prominences observed in $\mathrm{H} \alpha$ and the D3 He I line, and he also made photographic magnetograms in $\mathrm{H} \alpha$ and in the $5324 \mathrm{Fe}$ I line for comparison with $\mathrm{H} \alpha$ structure.

With a wealth of new material available for us to work on, unfortunately, I did not further formalize quite a few findings beyond doing a presentation or publication in conference proceedings. We were always working toward our next results. Along with family priorities, I often did not take the extra time that would have been necessary for more formal publication of our findings. Also, we did not think to publish many things we learned, simply because they seemed obvious or not adequately significant. 
I did not get much personal experience using a telescope until I joined the Stony Ridge Observatory, Inc. in 1967. A group of 15 men, amateur astronomy associates of George Carroll, built this observatory, including all the optics and mechanics of its 30-inch telescope - at that time the largest telescope ever built by amateur astronomers. With the honored George Carroll as my sponsor, I was accepted as the first woman member. Observing at night at Stony Ridge was convenient; it was only a 50 minute drive into the San Gabriel Mountains from my home, at that time in La Canada. My required training at the Observatory was surprisingly rapid. In half a night, a Stony Ridge member, Roy Ensign, taught me how to open the Observatory, point the 30-inch telescope to find objects, do knife-edge focusing on point sources, and process short rolls of film. I was then given a key and was free to sign up to observe at Stony Ridge whenever I wished. Of my experiences at Stony Ridge, the most thrilling was personally recognizing and observing the break-up of Comet West over multiple nights.

Along with the opportunity to work with Bob Howard on the Mt. Wilson magnetograms, of great interest to me was Harry's idea to make a photographic magnetograph for the $\mathrm{H} \alpha$ line, and later, for the Fe line at $5324 \AA$. While I took on the task of writing proposals to get funding for this experimentation, Harry began disassembling one of the two birefringent filters in order to optimize it for this purpose. Harry also invited an eager student, Jack Harvey, to work with him on several projects, including using the modified magnetograph for observations in the Fe line at $5324 \AA$ A. Jack later went to graduate school and did his $\mathrm{Ph} . \mathrm{D}$. thesis on solar magnetic fields.

Karen Harvey also got her start in the field at the Lockheed Solar Observatory. She first came as a student, Karen Angle, from UCLA. She planned to go to graduate school and was temporarily at the University of Hawaii before returning and obtaining her Master's degree at UCLA. Karen and I found many common research interests, which initially became manifest in the first comprehensive paper on flare waves (Smith and Harvey, 1971). During this period, major changes took place in both of our lives.

Joseph Smith and I divorced in December 1968 and I was single again for three years. Meanwhile Karen Angle was enticed away from Lockheed by a proposal of marriage by Jack Harvey who, upon receiving his Ph.D. at the University of Colorado, accepted a position at Kitt Peak National Observatory. Karen then left our group and became a guest astronomer at Kitt Peak, but we continued to work together remotely.

\subsection{A New Solar Telescope at Lockheed}

After about 12 years of my employment at Lockheed, our solar group was the only surviving pure research group in our building. The others had all been replaced by research applications groups, and there was uncertainty about pure solar research continuing under the Lockheed California Co. I am not sure who first expressed the idea that our group should become affiliated with the successful Research Laboratory of the Lockheed Missiles and Space Company in Palo Alto. Initially, the idea was not for us to physically move, but rather, to make us a remote solar group under the direction of Loren Acton. Loren was a highly successful experimentalist in solar X-ray observations and was responsible for building early instruments flown on rockets. It seemed a logical association and was implemented. Loren would visit us at irregular intervals, but was too busy with his own flight experiments to engage in our day-to-day operation. However, no one was unhappy with this situation except Loren; we continued our work as usual and were pleased to see Loren when he could visit.

Around 1972 I had many discussions with Harry Ramsey about the virtues of time-lapse imaging versus spectral observation. From this, the idea came to me for a new instrument, 
a multi-slit spectrograph that would combine the best features of time-lapse filtergrams with time-lapse spectra. It would be very useful for studying the dynamics of flares, erupting filaments, surges and any other rapidly changing solar features. It would be easier with such an instrument to record the range of velocities in the features observed in the filtergrams. Yet, it would still have the advantages of high spatial resolution, at that time 0.8 to 1 arc second. No such instrument was in operation at any observatory in the world. I calculated the basic instrument parameters: overall dimensions, number of slits, and spectral band that seemed to be the best combination to record spectra of the same type of events we were already studying from filtergrams alone.

Harry and George liked the concept, and encouraged me to write a proposal for funding the new instrument and its initial operations. However, a new telescope would be needed for the multi-slit spectrograph. One discussion was sufficient to interest George to begin its design. It was quickly decided that the multi-slit spectrograph was to be incorporated into the upper half of a second new Carroll Solar Telescope at the Rye Canyon facility. During one of Loren Acton's early visits to our lab, I presented our scheme for a multi-slit spectrograph to him. After some questions and discussion with all of us, Loren became quite delighted with this innovation and readily approved our writing of the proposal for it and for building the new telescope.

The new telescope was to be larger in diameter, with hinged exterior panels so the components inside could be easily worked on. We also planned for new filtergraphs in the lower two quadrants. Harry and I were interested in exploring other lines than hydrogen alpha. For the multi-slit spectrograph, we also proposed a birefringent filter for the infrared line of Ca II at $8542 \AA$ from Spectra Optics, the new company of Douglas Martin, former manager of the optics and thin films division of Spectrolab. Our proposal succeeded and the new telescope with the multi-slit spectrograph went into operation around 1974. Harry, George, Doug, and I then collaborated on a paper on the concept of the multi-slit spectrograph (Martin et al., 1974).

In the fall of 1971, I married Douglas Martin, whom I had gotten to know while he was serving as optics and filter consultant to our group at the invitation of Harry Ramsey. Doug's experience making optics and interference filters and knowledge from his background in geology enabled Harry's and his mutual success in the art of polishing calcite for birefringent filters. In his own business, Doug went on to build a series of birefringent filters. The first was for Professor Robert Leighton for a video-magnetograph being built by his graduate student, Robert Smithson. The second was the $0.25-\AA$ pass filter at $8542 \AA$ for our multi-slit spectrograph at Lockheed, and a third was the $1 / 8$ - $\AA$ element specified by Jacques Beckers for use in conjunction with the universal birefringent filter at Sacramento Peak Observatory. In all, he designed and built six birefringent filters, each taking at least 6 months of time to construct, exclusive of his growing business in producing thin-film filters.

\subsection{Work with Karen Harvey}

Before Karen's move to Tucson, full-disk magnetograms were becoming available on a daily basis from the National Solar Observatory at Kitt Peak. Karen and I were both struck with how many small bipolar "ephemeral active regions" were forming and disappearing every day. While working on the first paper solely on this topic (Harvey and Martin, 1973), we became fascinated with their role with respect to the solar cycle. We did not suspect that big chunks of our respective careers would be devoted to these questions, first together and later, independently. We continued to work together remotely and on our next two papers on ephemeral active regions (Harvey, Harvey, and Martin, 1975; 
Martin and Harvey, 1979). Much later, we contributed work on ephemeral regions to a paper on the overlap of successive solar cycles with Peter Wilson, Richard Altrock, and Hershel Snodgrass (Wilson et al., 1988). We were showing that the period of overlap of successive solar cycles is 6 to 8 years instead of $0-4$ years as previously thought. This was an intriguing property difficult to reconcile with the prevailing dynamo theory of the solar cycle. Dick Altrock continued to pursue the topic of overlapping solar cycles using coronal data and the solar cycle became the subject of Karen's thesis (Harvey, 1993) for her doctoral degree under Cornelius ("Kees") Zwaan at the University of Utrecht.

Using an enormous statistical sample, Karen demonstrated extremely well how ephemeral active regions are numerically the main population of the solar cycle, and large active regions with sunspots are an integral part of a distribution of active regions of increasing size and decreasing number. In other words, the active regions with sunspots, conventionally considered to be representative members of the solar cycle, could more clearly be seen as simply the tail of the continuous distribution of active region magnitudes. Our early work and Karen's momentous statistical result raised the question to me: Was the current dynamo theory a hypothesis of "the tail wagging the dog?"

Karen's thesis also spurred my continuing to question the nature of the solar cycle and this interest is ongoing. Currently, ephemeral regions play no role in the main dynamo theory of the solar cycle. Such small active regions are thought to extend no deeper than their short surface dimensions, whereas the classical dynamo theory assumes the larger active regions originate at the base of the solar convection zone. However, if the majority of the population of active regions is shallow in origin, is it not then logical to think the larger members of the population might also be relatively shallow in origin?

There is more evidence that favors a shallow origin for the entire population of active regions, including ephemeral regions. The source sites of new active regions consist of small discrete bipoles called "elementary bipoles" (Martin, 1990c). The elementary bipoles appear to be approximately of the same magnitude. If elementary bipoles are quantized, the size to which an active region grows is dependent primarily on the number of these bipoles that successively appear in it. Large ephemeral regions form from one to several elementary bipoles. Small active regions consist of a fountain of tens of elementary bipoles, while large active regions consist of several of these local fountains of elementary bipoles. Another feature discussed by Karen and me is that a single cluster of elementary bipoles usually does not exceed the average size of a supergranule and the interval of appearance of new flux within a cluster of elementary bipoles rarely, if ever, exceeds the duration of a supergranule. From these observations, I see reasons, but no compelling reasons, to assume that large active regions are any deeper than the top layer of supergranules. For one inclined to questioning, the nature of the solar cycle continues to be one of the most challenging unresolved problems in solar astronomy. Is it a mystery hidden in plain sight?

\subsection{The Transition from the Lockheed Solar Group to California State University Northridge and the San Fernando Observatory}

After a couple of years of being the group head, Loren Acton felt he could not spend enough time with our group and asked us to find a replacement. Harry took the lead this time. He proposed Alan Title and argued effectively for his suggestion. Alan was interested in instrumentation and had received his Ph.D. under Robert Leighton at Caltech. Alan would be innovative and had a common interest with Harry in optically designing more efficient birefringent filters with partial polaroids. After becoming the head of our group, Alan foresaw a brighter future in instrumentation at the LMSC lab and initiated steps for the group 
to physically move and join the research group in Palo Alto. Lockheed's California Co. no longer professed interest in pure research. However, for solar astronomy, the space age was just beginning and the Lockheed Missiles and Space Co. in Palo Alto had an important role to play.

By the time the group was preparing to move to Palo Alto in 1976, Doug and I had two sons, and his optics business was well established in La Crescenta where we lived. We elected not to make the move to northern California. The Lockheed telescopes and equipment were packed and shipped to Palo Alto, but the Lockheed Solar Observatory was never re-established there as initially suggested. The solar group continued under the able leadership of Alan Title, but changed its focus to observational experiments on satellites along with applying for time on existing large telescopes. I continued to work remotely for Lockheed from our residence and also remotely with Karen Harvey. With a growing family, I had little time for the question of how would I continue in longer-term work in solar astronomy.

Soon after the Lockheed group moved to Palo Alto, news spread that the Aerospace Corporation was seeking to divest itself of the San Fernando Solar Observatory it had built during the early heyday of the space age. Its location, on the north side of the Van Norman Reservoir in the north end of the San Fernando Valley, had proven to have seeing comparable to the Lockheed sites. The closest university was the California State University at Northridge (CSUN). I went there to meet Professor Paul Richter, who was interested in acquiring the Observatory for the University. I helped to write a proposal for the telescope to be transferred to CSUN. That led to spawning a plan with Paul Richter and the CSUN office of sponsored research for me to work at the San Fernando Observatory, if our proposal was successful. No other institutions competed with our proposal and it was accepted. Paul Richter became the director and hired the mechanic, William (Bill) Mott who had worked at the Observatory for Aerospace Corporation. The main 24-inch telescope had been damaged in an earthquake, but two smaller telescopes were ready to use. The telescope on the small tower in the right side of Figure 5 was called the "steam whistle", and the other was in a small dome on a short but sturdy mount.

I was appointed an Adjunct Professor at CSUN, a position that only paid a salary if I either taught a class or was an investigator on a successful proposal. I was highly motivated and began writing proposals to take and analyze data beginning with the smaller telescopes. Supported by a few intriguing, early results from the initial Lockheed multi-slit spectrograph, we proposed building an improved model, which would be adapted to the telescope mount in the small dome. We proposed that the new instrument would be for $\mathrm{H} \alpha$ instead of the infrared Ca line at $8542 \AA$ and that it be designed and built by my husband, Douglas Martin, at his business, Spectra Optics; he had provided the slit assembly and optical design for the successful original version of the multi-slit spectrograph at Lockheed.

Our proposal pointed out what was yet to be learned about the Doppler shifts observed in flares, surges, and erupting filaments, as time-lapse observations in the wings of the line were still relatively uncommon. At that time there was always a trade-off between high spatial resolution and observing a large area of the Sun at lower resolution. The steam-whistle telescope's field of view was about $4 \times 5$ arc minutes, and the multi-slit spectrograph was designed for a similar field of view in order to match the spatial resolution of approximately 1 arc second on our half-frame 35-mm time-lapse cameras.

When news came that our proposal would be funded, I began looking for an observer to assist me in running the small telescopes presumed to be a prelude to using on the main 24-inch aperture telescope that was proposed for repair. Fortunately, a highly skilled observer at McMath-Hulbert Observatory, William (Bill) Marquette, was recommended to me. He was available because the University of Michigan was no longer planning to maintain the McMath-Hulbert Observatory where I had first worked as a student. With a high 
Figure 5 Upper picture: Telescopes at the San Fernando Observatory: (1) the 24-inch telescope with clam-shell dome, (2) small dome that then contained the 10-inch imaging telescope and multi-slit spectrograph and (3) the steam-whistle 6-inch telescope with a motorized housing and roof that rises upward and covers the telescope. Lower: I am beginning a student tour of the telescopes and facilities.
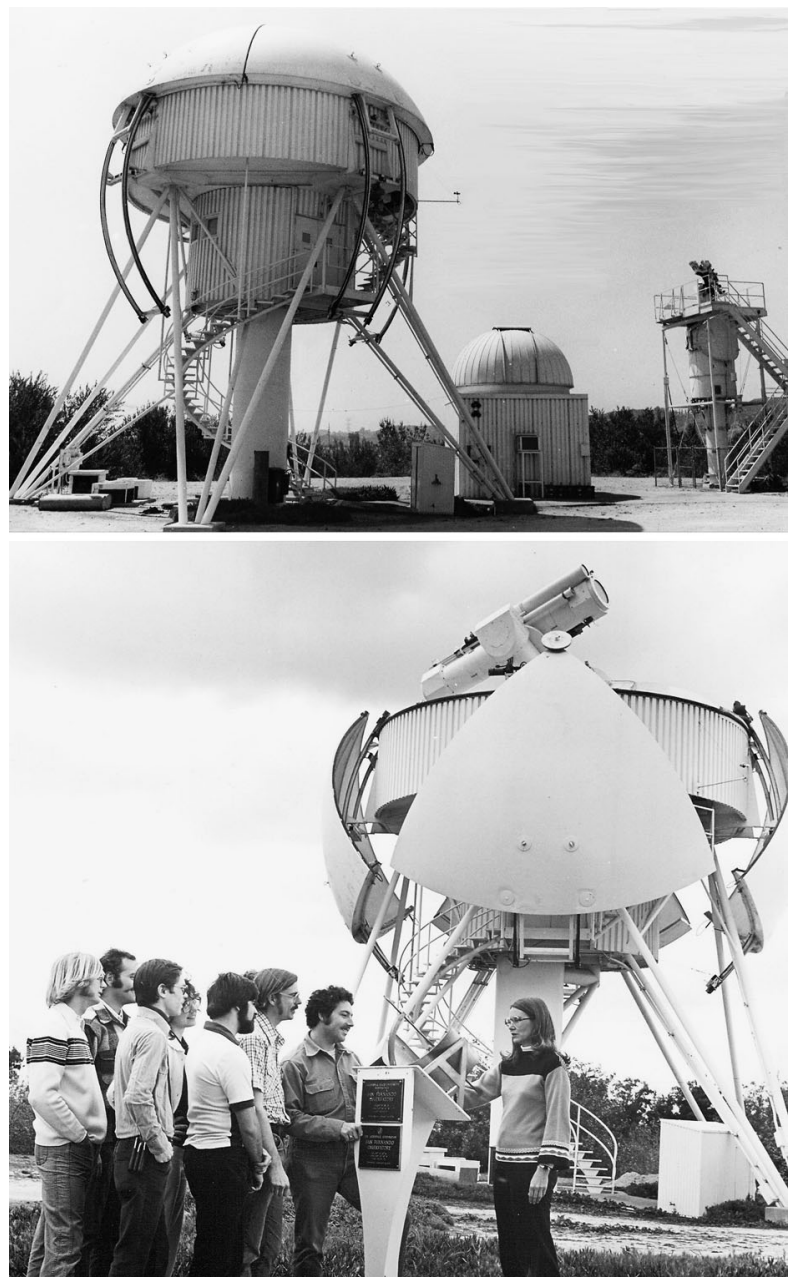

recommendation from Dr. Helen Dodson Prince, I hired Bill as chief observer. I also had the funds to hire undergraduate students from CSUN to help with the observing so we could run the telescopes 7 days per week. We began the new observational programs in 1979. We worked up to running three instruments daily: the second generation multi-slit spectrograph, filtergrams on the steam whistle, and a 6-inch full-disk $\mathrm{H} \alpha$ telescope newly installed south of the small dome. The site of the latter telescope is hidden from view behind the small dome in Figure 5.

\subsection{Predicting Filament Eruptions}

Working for San Fernando Observatory of CSUN gave me my first experience working with and overseeing observers and student employees. Both men and women students were always eager to have the opportunity to work at San Fernando Observatory. Some were self-starters and learned a lot by asking a lot of questions; these were clearly the potential scientists. Others performed their jobs as instructed but did not seem to know how to formulate questions and get the most out of their work experience. In addition to trying to motivate 
the students to ask questions, I felt I needed to do something to enable those who worked with me to feel involved as a group and committed to a common research goal.

The idea came to me that trying to forecast erupting filaments in real time would provide the incentive and common goal that was needed. There were two types of observations that could potentially allow one to forecast erupting filaments. One was the finding by Bruzek (1952) that a specific linear relationship existed between the emergence of a new active region and the time to eruption of filaments whose center was within 40 heliographic degrees of the new active region. Our forecasting procedure would be to watch for the emergence of a new active region, plot its distance to the adjacent filaments, and immediately make a forecast of the nominal eruption time of the filaments based on the curve in Bruzek's paper. After making about 20 such forecasts, we would then compare our forecasts with what actually occurred. Because about one major active region formed somewhere in the solar active region belts per day, we would be able to accrue a sufficient sample of such trial forecasts in a couple of months.

A second type of forecast would be based on the Doppler shifts in filaments since we had the capability to manually shift the filter passband. In my experience and previous studies at Lockheed, I knew that any filament whose Doppler shifts exceeded $0.5 \AA$ into both the red and blue wings were the ones most likely to erupt. A question to be answered was: What threshold in Doppler shift in each wing would yield the highest ratio of positive to negative forecasts? By observing the Doppler shifts and noting their magnitudes and time until eruption, we would learn how to improve our forecasts. We would also learn how frequently activations of filaments occurred that did not lead to an eruption. Therefore, I chose to begin the project with the relatively low threshold of $0.5 \AA$ as the starting criterion. To further simplify the task, we would forecast based on only the two patterns of Doppler shifts which most frequently precede eruptions: 1) an asymmetric pattern in which one end of a filament becomes red-shifted and the other end blue-shifted and 2) symmetric eruptions in which two ends became red-shifted with blue shifts between them (Martin et al., 1979). The observer's daily task was to first survey all filaments on the Sun and choose one to record continuously on film. Also the observer would visually monitor the Doppler shifts in the selected filament approximately every 30 minutes for the remainder of each day to see whether our criteria were met and a forecast could be made.

Initially, my staff and students were all exceedingly uncomfortable with the idea of making forecasts. They were afraid of failure in making incorrect forecasts. Instead of treating our forecasts as tests of filament behavior, they reacted as if it was a test of their ability to make forecasts. Seeing this reaction, I had to explain, repeatedly, that a properly designed research experiment enables testing a physical phenomenon against chosen criteria; if well designed, it would not be a test of the experience or skill of the person carrying out the experiment. Still the observers were reluctant. It was only by finding that I was happy with all outcomes and eager to have them help make presentations at meetings that they could settle into enjoying the project (Hermans, Martin, and Marquette, 1980; Dunn and Martin, 1980; Martin, 1980).

We learned over the course of three years that many filaments exhibited activations that did not lead to eruptions. Therefore, forecasts based on relative Doppler shifts were not likely to be of interest to the Solar Forecasting Center at the National Oceanic and Atmospheric in Boulder, Colorado. However, if a scientist wanted to have a higher probability of observing an erupting prominence than by random choice of a filament, our forecasting experiment demonstrated exactly that possibility. We learned that one could increase the chances of observing an eruption by about a factor of 2 to 5 over random selection of a filament, simply by choosing active filaments with Doppler shifts greater than $0.5 \AA$ in both wings (Martin et al., 1979; Dunn and Martin, 1980; Hermans, Martin, and Marquette, 1980). 
Our testing of the relationship found by Bruzek, yielded results far beyond my hopes of confirming or not confirming what he had found. We statistically demonstrated that the success of forecasts based on the Bruzek relationship depended on: 1) the magnetic flux of the active regions, 2) the inverse of the magnetic flux density associated with the coronal magnetic fields that form an arcade over a filament, and 3) weakly, the distance of the new active region from the filament. We worked out a graphical way of showing all three results in one three-dimensional diagram. We concluded that new active regions often served to catalyze the eruption of a filament. However, this was not a fundamental reason why filaments erupted, because most filaments end their life cycle by erupting, even if no new active regions develop in their environment.

Our forecasting experiments continued as the multi-slit spectrograph was installed and we began using it on a daily basis. In 1979, we captured a classic erupting prominence and flare, which clearly confirmed the value of the multi-slit spectrograph as a research tool. A paper on the whole event is in Webb et al. (1980). I presented my part of the results at the 1980 Colloquium on Solar Flares and participated in the working group on preflare topics (Webb et al., 1980 Appendix; Sturrock, 1980, Chapter 1).

Common interest in the eruption of filaments led to other friendships and meaningful collaborations. During my days at Lockheed, I had met Richard and Shirley Hansen who both worked for the High Altitude Observatory. Richard was a long-time colleague of Harry Ramsey since their early days of working together at Sacramento Peak Observatory, where they had both observed many erupting prominences. While I was at San Fernando Observatory, Richard Hansen contacted Einar Tandberg-Hanssen and me to invite us to co-author a paper. Richard had collected details supporting his enlightened understanding that "flare sprays" were really just fast erupting prominences. It was my pleasure to work on this paper although the largest part of this clarifying work was done by Richard. While Richard was a good writer, he wished more for the results to be accepted than to be the first author. Somehow he convinced Einar to write the first draft and, by tradition, become the first author (Tandberg-Hanssen, Hansen, and Martin, 1980). Einar's first book, Solar Prominences (Tandberg-Hanssen, 1974) was already well known. Indeed, Einar's second book on solar prominences (Tandberg-Hanssen, 1995) contains an updated and well-considered amplification, describing flare sprays as having their likely origin in filaments (prominences) in active regions. The term, flare spray, has now largely become outmoded, in keeping with Richard's initial insight and desire to advance the field.

We have Einar to thank for devoting a large fraction of his life to the difficult task of collating and trying to make sense of the huge diversity of observations and concepts of about prominences in his two books. In his memoir, Einar capped these huge achievements with more historical perspectives on prominences along with additional comments on their physical nature (Tandberg-Hanssen, 2011). How meaningful would our detailed studies be without the more complete picture he continuously strived to assemble?

\subsection{Transition from San Fernando Observatory to Big Bear Solar Observatory}

After four years of promoting the San Fernando Observatory, Paul Richter decided to pass the directorship on to someone with more experience in solar physics. Dr. Gary Chapman, who previously worked at the San Fernando Observatory, was selected as his successor. When the research grants for our initial projects were in their final year, I became discouraged about my prospects for contributing significantly to the future of the major 24-inch telescope. It was time to consider other alternatives.

In the summer of 1982, Professor Harold (Hal) Zirin at Caltech hired Bill Marquette for the position of Observatory Superintendant and Chief Observer of their Big Bear Solar 
Observatory (BBSO) at Big Bear Lake. That fall Zirin offered me a position as Scientist and Member of the Professional Staff, with the agreement that I would continue to write research proposals and be a contact to federal agencies that supported solar research. It was a smooth transition. I remained an Adjunct Professor for the California State University at Northridge in name only for several years. At the time of my transition to the Big Bear Solar Observatory, I had thought a time would come when I could propose to operate the multislit spectrograph again. That was not to be. However, it remains my firm opinion that the multi-slit spectrograph was a practical type of instrument that could be further improved. The concept could be redeveloped into an advanced digital tool for studying the spectra of various types of mass motions in filaments, flares, surges, and eruptive solar events, in conjunction with Dopplergrams of the same features at various wavelengths from other telescopes. When would I or any other colleague have the right circumstances to put such an instrument into operation again to solve many remaining problems about the dynamics of solar events?

At the time I was hired, the Big Bear Solar Observatory group consisted of 12 to 15 scientists and staff. This included engineers, technicians, secretarial or administrative assistants, and a few graduate students and post-docs. As a first priority, I began writing proposals, which soon successfully covered more than my salary. Hal Zirin readily approved my requests to travel to make presentations of research papers at meetings and trips to funding agencies regarding proposals. More exciting to me was surveying the BBSO solar film archives, analyzing data, deciding on new research projects, becoming familiar with the telescopes, and participating first hand in special observations for our research grants.

Hal Zirin's friendly and cooperative group of scientists included Gordon Hurford doing solar radio astronomy at the Owens Valley Radio Observatory (OVRO), and Frances Tang and Margaret Liggett working on data. Jeff Nenow was the photographer responsible for film processing and other photographic needs. Rich Goeden was the engineer. Simon Groez was an electronics technician. At Big Bear Alan Patterson was the BBSO Scientist in Charge. In a few years, Dale Gary came as a second radio astronomer and Dennis Dingley as an electronics technician at Big Bear. Randy Fear was hired as an observer and John Varsik initially came as a programmer and observer. Nora Knicker was the secretary and administrator. In addition, at Caltech there were often graduate students and one or more post-docs in the group. Two of the students who stayed on as post-docs, Jongwoo Lee and Haimin Wang, became well-known professional solar astronomers. Another post-doc who became a strong contributor to the field was Haosheng Lin.

Bill Marquette came to BBSO as an observer from San Fernando in 1982 and later became the BBSO Manager. He is shown in Figure 6 with the BBSO telescopes and observatory as they were in the 1980s and 1990s. Bill and I discussed solar activity and observing goals frequently, as we had done at San Fernando, but often by telephone as the offices and the data were at Caltech rather than at BBSO. During the summers, I would rent a house in the Big Bear area, and hire a baby sitter for work days. My husband, Doug, was occupied with his business, but he joined me and our boys, Daniel and Duncan, on weekends until school began in the fall and we returned to our home in La Crescenta. We very much enjoyed the summers at Big Bear, and after a few years built a second home on a lot we had fortuitously purchased there many years before I had any thought of working at Big Bear.

BBSO observers took daily observations with the 25-cm (10-inch) and 65-cm (26-inch) telescopes, and a video magnetograph (Figure 6) that had initially been the project of Bob Smithson when a graduate student under Robert Leighton. Hal generally chose the observing targets, but sometimes relinquished the telescopes to others for intervals of a few days to a couple of weeks for a specific project. The light beam of the $25-\mathrm{cm}$ telescope was successively diverted to three optical benches by means of automated flip mirrors. Exposures 

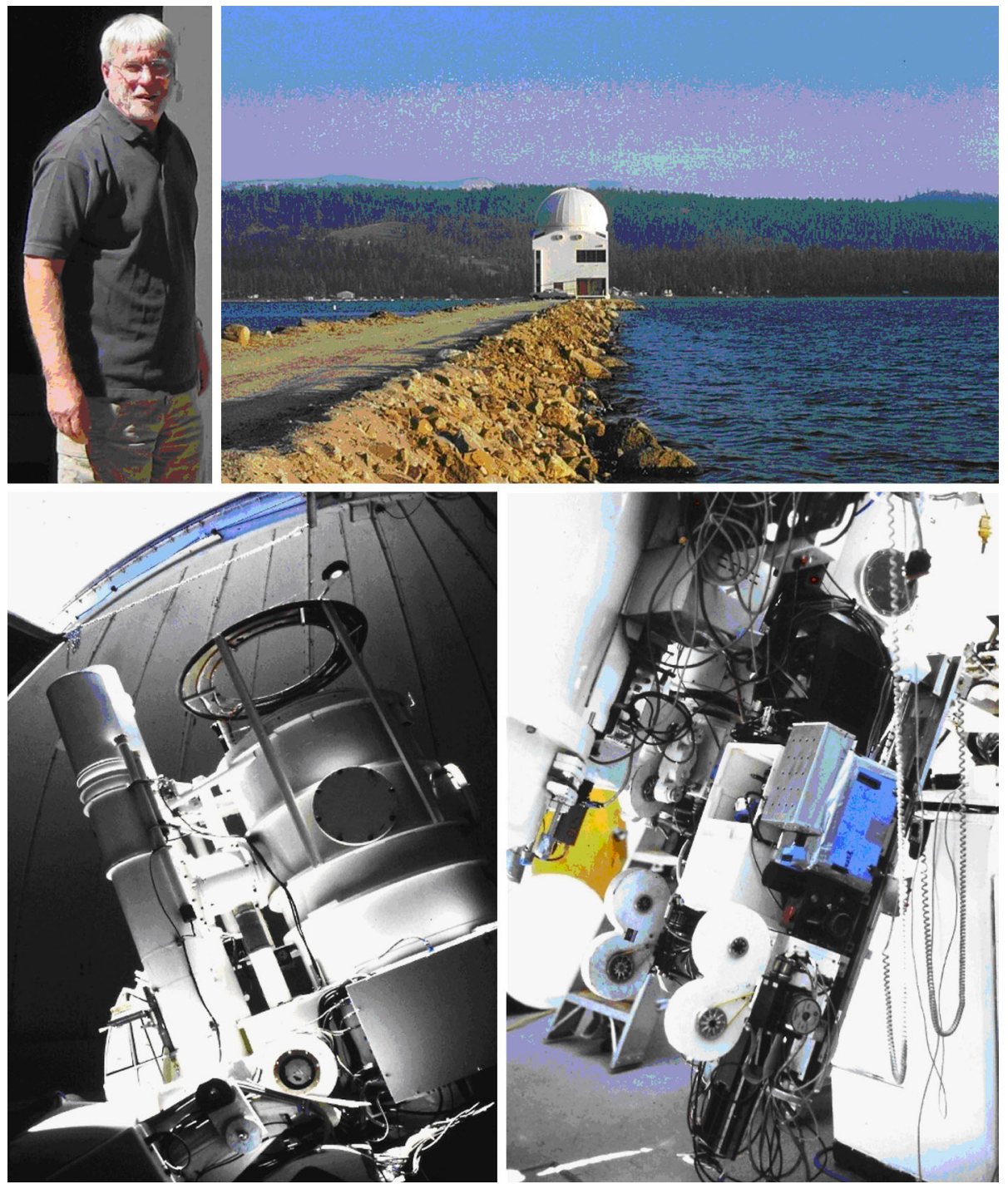

Figure 6 Upper left: Bill Marquette, observer and manager of BBSO 1981-2005. Upper right: The observing building and dome are shown before installation of new dome and new 1-meter telescope in 2010. Lower left: the 8-inch Singer telescope tube and the 10-inch telescope tube (in back of 8-inch) were mounted in the space beneath the larger tube of the 26-inch telescope and above the fork of the telescope mount. Lower right: The nearly circular parts of the film magazines for the 10-inch east and west benches are seen in the lower half of the image. The white box contains parts of the videomagnetograph mounted between the 10-inch east and west benches. The video camera is obscured by the 10 -inch $\mathrm{W}$ filament magazine. A Zeiss tunable filter is in the blue protective jacket on the 10-inch west bench. A real-time display of the videomagnetograms and various other real-time read-outs were located close to the dome wall west of the telescope.

were taken through an $\mathrm{H} \alpha$ Zeiss filter on the "west bench", on the video magnetograph on the "middle bench", and through another filter on the "east bench" as shown in Figure 6 (lower right). The filters, most used for daily observations, were the Zeiss filter for center- 
line observations, a Halle filter for observations in one wing of the $\mathrm{H} \alpha$ line, and either a Halle filter tuned to the opposite wing from the first, or another Halle filter for the Ca II line at $3933 \AA$. The telescope was set up such that one could view the Sun in the eyepiece during the time-lapses between taking images without interrupting the sequence. The videomagnetograph had a real-time display in the dome. A separate 8-inch refractor provided a nice-quality full-sun image. With these visual capabilities, we could watch especially interesting solar activity as it was being recorded. The Big Bear telescopes were providing more high-resolution, time-lapse images at that time than any other solar observing site in the world.

The 10-inch telescope with the videomagnetograph, Zeiss tunable filter, and one of the Halle filters got most of my attention because this array of instruments offered the most opportunities for capturing complete dynamic events and doing unique new research projects. Viewing the Sun with a superb 10-inch telescope again was delightful, bringing back memories of the last George Carroll telescope we used at Lockheed. The seeing was often as good in the summer and fall as at San Fernando Observatory or the former Lockheed Observatory. From my experience, the good seeing in southern California is primarily associated with high pressure zones common to the whole area and only secondarily to specific local conditions such as the presence of the lake at Big Bear. Regarding the initial site survey to locate Caltech's solar observatory, John Cowley, the site testing person, acknowledged to me personally that a lowland valley site on Lake Elsinore had on average a few more good seeing days than Big Bear - but Big Bear was by far the more comfortable place to work during the hot summers of southern California.

\subsection{Recognizing Canceling Magnetic Fields}

The developed BBSO films were delivered to Caltech about once a week. Caltech had a viewing room that could be completely darkened, and equipped with $16-\mathrm{mm}$ and $35-\mathrm{mm}$ projectors where, as in my previous positions, I spent hours studying the time-lapse films and making notes about what could be seen, measured, and analyzed. One Friday in 1983, I was alone viewing 35-mm images of the quiet Sun from the video magnetograph. The magnetic features were relatively few and isolated, and not all that interesting. Then I noticed two separate small features of opposite polarity drift together, with no obvious change until they collided - and then the majority of magnetic flux of both of them shrank steadily until the smaller one vanished completely! I was astounded! I went back and forth through the movie again and again. The colliding poles were part of mixed polarity background magnetic fields - not the poles of a single ephemeral region; the opposite polarity poles of ephemeral regions rarely move back together. There were some other disappearing features, but none that were so far apart at the beginning of the day's images as the two that captured my attention. I knew I was viewing something very significant. This was something other than magnetic flux welling up and down from convection. Then the significance hit me ... Aha! There had to be a lot of energy released when magnetic fields collided like this! Aha! My mind raced with excitement. I could not think of anything else the rest of the day. Over the weekend, every minute I was free from family and household issues, my mind returned to the images and questions and mental pictures. The "quiet Sun", as we called it, was not quiet! There was more going on than just boiling, convecting plasma!

I already knew a fair amount about the quiet Sun from doing the papers on ephemeral regions with Karen Harvey, and viewing many beautiful movies of spicules and fibrils in my years at Lockheed. But until that day, the quiet Sun had been boring in comparison with the flares, and dynamic filaments and surges. I was experiencing one of the most rapid 
changes in scientific perspective in my life. The quiet Sun had suddenly become completely fascinating! I was full of questions about the so-called "quiet Sun", and my mind brought up visions of many, many stored images and started feeding me possibilities....

The outstanding disappearing feature had to be at the boundary of a supergranule cell and I knew that spicules typically occurred around the boundaries of the cells. I saw a movie in my mind of continuous little colliding features, causing rapid energy releases and spicules with every collision! This would be happening with each and every spicule all over the Sun. Aha! Spicules had a reason for occurring! It could be that these little collisions released bursts of energy! What else? Convection alone did not operate on the same time-scale as the spicules. The familiar 5-minute solar oscillations were much too benign and not sufficiently localized. Small discrete releases of energy were needed to create spicules and repeated spicules from nearly the same locations. The colliding and disappearing features could be providing that energy. And such releases of energy should be accompanied by heating. The ubiquitous, small brightenings at the base of spicules were one signature of heating. Aha! Here was a possible mechanism for heating the solar corona!! Not the visible brightening itself, but rather the energetic particles or little shock waves that could be released when these brightenings occurred.

The spicules came back to mind; I pictured a fast stream of invisible particles preceding the tips of each spicule. Aha! If this was happening in coronal holes, as I knew would likely be the case, then here too was a source for the solar wind. Elsewhere on the Sun the high speed particles from the spicules would go into coronal loops, remained trapped in them and emit faintly from the many collisions that would have to take place. But in coronal holes, or any open-field configuration, a sporadic wind would be continuously emanating into the interplanetary space and this dovetailed well with the existing knowledge that coronal holes were the primary locations from which the solar wind emanated.

One Aha! experience puts one into a delightful natural "high". A series of so many big Aha!'s, proven or not, was overwhelming. What does one do in this state? I tried to explain that I had found something extraordinarily exciting to Doug. He listened politely, but his questions were extraneous to the ones I wanted to address, and our discussions were often naturally interrupted by the children and weekend home tasks that needed doing.

I naturally wanted to share my excitement, but I was not sure with whom to discuss my finding of colliding and disappearing flux at work. Hal Zirin's response would be his usual "Write it up", and of course, I would do that. I did not immediately find any person in our group that shared my enthusiasm over these disappearing magnetic features, but I could at least get the interest of my good friend Bill Marquette even if some of the ramifications were beyond his experience. As it turned out, my Aha! experience did not become an Aha! experience for anybody else at the time. I took that in stride and began studying every quiet Sun image sequence I could find that might bear on the flood of questions in my mind. Indeed, the only thing to do was to start a paper describing and illustrating the details of the colliding features, and suggest their importance. The next meeting where this personal discovery would be relevant was the Summer Workshop at Sacramento Peak Observatory.

When I presented the paper (Martin, 1984), there were the usual questions from the audience but no one seemed at all excited about these new observations. One question gave me a clue that most of the audience thought the colliding features were probably little loops of flux bobbing up and then sinking and disappearing. I had not conveyed an important detail - that the disappearing features could not be the two ends of the same loop. That would have to be proven, which would not be easy. Prior to this time, Ken Marsh, then in the Big Bear group, wrote a paper (Marsh, 1978) that I think correctly described the interactions matching the picture in my mind and that I had often sketched for myself on paper. Many 
people have thought of this same interaction; scientists often independently come up with the same concepts. The interaction in Ken's paper has been "rediscovered" many times, and is generally known as "interchange reconnection".

During my sustained enchantment with the quiet Sun in 1984, a woman astronomer, Silvia Livi, had come from Brazil with her husband, Rogerio Livi, who was working with a physicist at Caltech. She had inquired in the Stellar Astronomy Department about also doing research, but found no one in the department who was interested in her working with them. However, she was referred to Hal Zirin in the process, who introduced her to me. I in turn introduced Silvia to the solar data. She was an experienced researcher, and extraordinarily happy to be learning something new. Also, Jingxiu Wang and his graduate school advisor, Dr. Shi, came soon thereafter for an extended visit from China, and were eager to do something. They all joined me in studying the magnetograms of the quiet Sun. As Jingxiu and Silvia learned about the solar activity they saw in the BBSO movies, they began to share in my excitement over the colliding and disappearing magnetic fields. Giving these phenomena a name soon became a topic in our discussions. We did not want to just call them "disappearing flux" because magnetic flux can disappear just by a change in the quality or intensity of the magnetograms. As an observational purist, I did not want a name that implied any mechanism, because several possible mechanisms could be invoked. I thought we should avoid suggesting any particular mechanism until we figured out the correct one or ones. In addition to wanting a simple observational name, I was quite adamant about finding a name that would catch on and never be changed.

After much discussion, we consulted the dictionary and settled on "canceling magnetic features". Silvia and Jingxiu put in an enormous effort day and night. We found a relatively new BBSO movie of a medium sized active region, which covered the whole evolution of the region from its formation to its disappearance. It was extraordinary, because it showed the disappearance of flux being accompanied by a succession of little filaments forming, growing, and culminating in eruptions accompanied by small flares. The association of filament formation and evolution with canceling magnetic fields was very clear, both for the filaments in small active regions and mini-filaments on the quiet Sun. Aha! Canceling fields somehow created filament spines! That was why filaments always coincided with polarity reversal boundaries!! Aha! What is now called "head-to-tail" magnetic reconnection appeared to fit the configuration of $\mathrm{H} \alpha$ structure of filament channels. Prior to joining the solar group at Caltech, I recall a discussion with Ron Moore on such reconnection as a means of building filaments. But that was long before we discovered the canceling magnetic fields consistently accompanying filament formation.

Jingxiu, Silvia, and I decided on two papers for the forthcoming IAU Symposium on Solar Magnetic Fields. One would be on Canceling Magnetic Fields in an Active Region (Martin, Livi, and Wang, 1985). The second would be on Canceling Magnetic Fields on the Quiet Sun (Livi, Wang, and Martin, 1985). The meeting was dedicated to the scientist Ron Giovanelli who had recently passed. It was my good fortune to have met Giovanelli on a few occasions at Lockheed, Caltech, and Sacramento Peak. He exuded enthusiasm over solar research as does his small book on Solar Astronomy.

The audience reaction to my second presentation on the canceling magnetic fields was very different from my initial presentation at the prior Summer Workshop. The audience was unusually quiet. As everyone began the usual clapping at the end of my presentation, my friend Dave Rust yelled out "Bravo! That inspired some whistling, more clapping, and then, to my amazement, the whole audience stood up and gave a standing ovation. I was dumbfounded! The cool reactions to my previous presentations made this reaction completely unexpected. And the excitement carried over to the second presentation by Jingxiu 

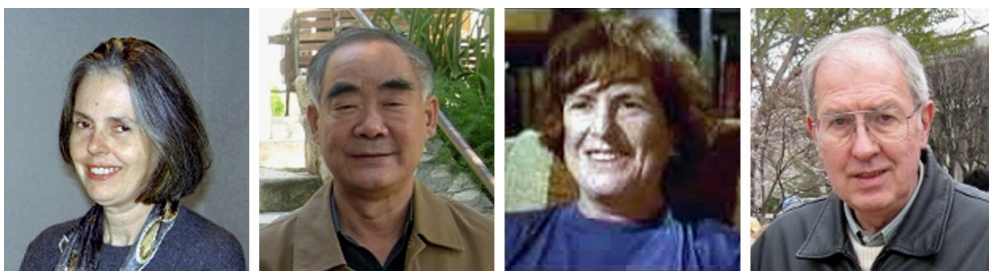

Figure 7 Left to right: Silvia Livi, guest stellar astronomer at Caltech and BBSO from Porto Alegre, Brazil; Jingxiu Wang, guest scientist from National Academy of Sciences, Beijing, China; Joan Feynman, Jet Propulsion Laboratory; David Rust, Johns Hopkins Laboratory.

and throughout the remainder of the meeting. There were many questions. It was a wonderful, spontaneous affirmation of the success of our collaboration. Pictures of Silvia and Jingxiu are shown in Figure 7 along with two subsequent collaborators, Joan Feynman and David Rust.

We continued working on the interpretation of canceling magnetic features. Anticipating the possibility that flares would be erroneously attributed to canceling magnetic fields, I thought we should further clarify our understanding of the observed relationships. In our next paper, we tried to carefully show the evidence that the association of canceling fields with filament formation could prove to be a direct cause and effect, whereas the connection with flares was necessarily indirect. Filaments formed directly from the canceling fields, as they extended precisely from the canceling boundaries of opposite polarity network fields beneath the spine. Although flares also straddled canceling-field boundaries, flux cancellation occurred in the absence of flares, and before, during and after flares. Due to this lack of any close temporal association or spatial association as exact as that of filaments, we deduced that any association of flares with canceling magnetic fields was indirect at best. However, we also pointed out that canceling fields could be associated with a reconfiguring of the magnetic fields such that energy would be stored in filament channels which could later be released in solar flares. The evidence for this storage and release concept are, initially, the gradual changes of implied magnetic structure from fibrils and filaments along a filament channel before a flare, and, secondly, the sudden appearance of flare loops straddling a channel (Livi et al., 1989). This effort did not serve its intended educational purpose of dissuading premature publication of the opposing conclusion that canceling fields directly cause flares. Should I be surprised?

\subsection{The Numerous Effects of Canceling Magnetic Fields}

My fascination with the "quiet" Sun continued and led me to classifying canceling magnetic fields and continuing their study after Jingxiu and Silvia went back to their respective countries and Silvia's later return associated with another project of her husband Rogerio. By 1988 , I had become sufficiently familiar with the quiet Sun that I could recognize its components and patterns. It was amazingly simple. There were only three components: network fields, intranetwork fields, and ephemeral active regions, and I summarized my understanding in a couple of papers (Martin 1988, 1990a). Briefly I also worked with a visitor, Carolus (Karel) Schrijver, who led the way in an interesting method of following the lifetimes and dispersal of features from day-to-day around the periphery of an active region (Schrijver and Martin, 1990).

Around the same time, Giannina Poletto invited me to write an article for a special symposium publication in honor of a colleague. By that time I had begun noticing how some of 
the ephemeral regions were a succession of two or more tiny bipoles instead of being just a single bipolar unit. Then we observed an example of a small active region during an interval of very good seeing. The magnetograms revealed how the new magnetic flux appeared in the form of successions of tiny bipoles in tight clusters. Three of these clusters formed the complete active region. It was immediately obvious that these tiny bipoles were occurring beneath the arch filaments of the active region. From my previous work with Karen Harvey, I knew well that the active region spectrum included ephemeral regions. I saw the tiny clusters of tiny bipoles as one more piece of evidence that linked the ephemeral regions to their larger counterparts. It was fascinating how the little elementary bipoles of opposite polarity would collide and cancel just like any other opposite polarity fields on the Sun. Then I could guess why little active regions were often bright and had so many tiny flares. These little elementary bipoles would be a worthwhile topic on which to write a paper in response to Giannina's invitation! The title of the paper would be "The Elementary Bipoles of Active Regions and Ephemeral Active Regions" (Martin, 1990c). For me this confirmed a personal paradigm shift - strong evidence that active regions were shallow in origin. If the small ephemeral regions were shallow as generally assumed, then I reasoned that active regions also had to be shallow, because they were formed from the very same elementary bipoles as the small active regions and the ephemeral active regions. I could see that sunspots resulted from the coalescence of the elementary bipoles of the same polarity and appeared to float on the photosphere. Sunspots seemed to be readily pushed around by supergranules because they lacked deep roots. My interest in the solar cycle was renewed. What a radical view I had acquired relative to the conventional ideas about the solar cycle! But when would I find the right time and circumstances to engage in a study so radical that it would be difficult to get funded? Would it not be better to let my ideas simmer and continue with my explorations of the quiet Sun?

Returning to the quiet Sun, I wish to thank Joseph Holweg for being the lone voice in early acknowledgment of my suggestion of a possible role for canceling magnetic features in the heating of the solar corona, which requires continuous or sporadic acceleration of particles into the corona. The most ubiquitous source is the magnetic reconnections between Intranetwork (I) and Network (N) magnetic fields which can be represented as I+/I-, $\mathrm{N}+/ \mathrm{I}-$, and $\mathrm{N}-/ \mathrm{I}+$ interactions. Much less common would be magnetic reconnection between ephemeral region magnetic fields, which can be represented as $\mathrm{ER}+/ \mathrm{N}-, \mathrm{ER}-/ \mathrm{N}+$, $\mathrm{ER}+/ \mathrm{I}-$, and $\mathrm{ER}-/ \mathrm{I}+$ interactions. The least likely to contribute to the corona are the $\mathrm{N}+/ \mathrm{N}-$ interactions, because these occur in filament channels with horizontal magnetic fields.

Since 1983, I have continued to think of canceling fields as the starting point for understanding the formation of fibrils and spicules, the generation of the solar wind in coronal holes, and the heating of the corona, both inside and outside of coronal holes. Intranetwork (I) fields are the most important in heating the corona, because they originate in supergranular convection cells distributed all over the Sun and interact continuously with network magnetic fields, mostly when they collide with the network fields at the boundaries and vertices of the supergranules. Here is a truly ubiquitous source of energy for accelerating particles along either closed or open fields. Even if the solar cycle disappeared, the solar wind and coronal heating would continue from the I+/I- interactions Simplistically stated, canceling fields represent photospheric magnetic reconnection; photospheric reconnection or any reconnection results in accelerated particles; accelerated particles result in waves and lead to collisions; both can result in heating.

A likely problem in recognizing the role of intranetwork/network magnetic reconnections in accelerating particles is that we are not able to detect low density streams of very fast 
particles. This tends to put the subject outside of the realm of ready observation leaving it mostly to theoretical work. It is reasonable to guess also that small-scale, granular magnetic reconnections, which can account for canceling magnetic fields, also produce waves and all the classical work on heating by waves is then also in the picture. But which yields more heating, the accelerated particles or the waves? Is it high heat flux over short intervals of time or low heat flux over long intervals of time?

What is now called the "interchange" reconnection seems to be the most likely magnetic reconnection mechanism for generating the solar wind from coronal holes; it should be continuously taking place between closed intranetwork and open network fields of coronal holes. The reconnections would primarily occur at intranetwork/network cancellation sites and primarily at the boundaries of supergranules and especially the vertices of all supergranules. Reconnections also would take place between many small closed ephemeral region bipoles and open network magnetic fields mainly in coronal holes. All other interactions would be between closed fields which would reconnect and reconfigure into other closed magnetic fields.

When the opportunities arose, I attended lectures by Gene Parker with great interest. I am especially glad to have had the opportunity to briefly discuss this subject and a few others with Gene. He was especially attentive to the work of observers and made it a pleasure to discuss questions with him.

Due to the lack of magnetograms with sufficient spatial resolution and magnetic sensitivity, I suspect that the energy of magnetic reconnection at or very near the photosphere is larger than currently thought and far more effective in accelerating particles than anyone has ever suggested. Has the true magnitude of both the strong and weak fields (Lin 1995a, 1995 b) been adequately considered in previous or current papers on the origin of the solar wind or the heating of the corona? Are not some waves and oscillations relatively gentle and steady compared to the energy that can be transferred to small amounts of mass by magnetic reconnection?

\subsection{Returning to the Topic of Emerging Magnetic Flux, Flares, and Related Dynamic Events}

Throughout my early years at Caltech, the development of major active regions and their ability to catalyze CMEs and the eruption of filaments had remained a topic of interest since our findings on that subject while at San Fernando Observatory (SFO). It became a topic of discussion with Joan Feynman when she began working at JPL. As Joan had been engaged in many studies of the interplanetary effects of flares and solar eruption events, we had a lot of common interest in any factors that could lead to eruptive solar events. Both of us also were deeply interested in the solar cycle. When I informed her of our yet unpublished results from SFO, she was keen to do a new study with a larger sample of data to see if we would get the same results. Indeed, we confirmed the earlier results. In addition, we could show that the orientation of the bipoles relative to the photospheric magnetic fields around filaments was also important. This was consistent with our guess that magnetic reconnection, between the magnetic fields of growing active regions and the coronal magnetic fields around filaments, was the likely change that lead to the eventual eruption of the filaments even at relatively large distances from the new active regions (Feynman and Martin, 1995).

Joan is shown in Figure 7 along with other colleagues. Not much later she married Alexander Ruzmaikin with whom it has been my pleasure to collaborate and also to discuss theoretical implications of various topics. Alexander and Joan are shown in the middle right of Figure 11. 
I might not have done any further research on solar flares after 1980 if Zdeněk Švestka (memoir by him, Švestka, 2010) had not continued, one by one, to present flare-related problems to me that he thought were solvable with high-quality observations in $\mathrm{H} \alpha$. After completing an early, brief, published article with Zdeněk and Roger Kopp, Švestka, Martin, and Kopp (1980) suggesting a minor modification to the Kopp and Pneuman model, for me the basic flare problem was solved. However, for the solar research community, the Kopp and Pneuman model (Kopp and Pneuman, 1976) was the beginning of numerous refinements and verifications which also brought new understanding of the coronal transients that later acquired the name, coronal mass ejections. Meanwhile, I thought that the tight relationships of filament formation and their subsequent eruption with flares was the area where research was most needed. I was much more eager to focus on erupting filaments, rather than the details of flares, with observers and students at San Fernando Observatory.

During that time, Zdeněk came for a visit specifically to discuss a series of papers he had initiated on a particular flare of 1973 July 29. Through our discussions, Zdeněk and I realized that this event was one in which it was possible to provide strong observational evidence that a major reconfiguration of local magnetic fields accompanied solar flares, a strong point in favor of the Kopp and Pneuman model. As this point had not yet been made in the literature, Zdeněk convinced me to write a paper to be published in the series on this event (Martin, 1979). It would be my task to provide the evidence that flare loops ascended through the same space that was previously occupied by a filament. This proof, of a dramatic change of the orientation of the coronal magnetic field during a solar flare, assumed acceptance of the observational deduction that all flows in solar structures were field-aligned. Given this assumption, a sudden change in plasma flow patterns in the same volume of space was proof of a change in magnetic field configuration. While Zdeněk's series of papers were readily published, the concept of filament mass motions being field-aligned met strong resistance, in spite of general acceptance that both chromospheric and coronal loops are being fieldaligned. Models in direct contradiction to the field-aligned evidence were still the touted models of the day.

I began to appreciate contradictions between observations and theory. Through them, I gained confidence that I needed - as an observer with a Bachelor of Science degree in physics - understanding that I was as capable as most in interpreting the physics of the Sun with the aid of the Sun itself and my faith wherein I learned: “. . . justice is My gift to thee.... By its aid thou wilt see with thine own eyes and not through the eyes of another and thou wilt know of thine own knowledge and not the knowledge of thy neighbor" (Baha'u'llah, 1923 translation).

Always with a new study or paper in mind, Zdeněk made infrequent visits at Caltech, a convenient trip from San Diego when he came to work periodically with Bernard Jackson and Paul Hick. Invariably, there was something new to learn. Zdeněk had become fascinated by both bright arches observed in the HXIS experiment on the Solar Maximum Mission (SMM) that he called flaring arches. He wanted to learn about their signatures in $\mathrm{H} \alpha$ and, indeed, new insight was in the offering. He pointed out that as the arch began close to the site of flare loops in HXIS, a second brightening occurred almost immediately in a distant location. Then a stream of X-rays filled in the path from the flare and base of the flaring arch, connecting it to the distant foot-point. The arch was then successively seen in lower temperature lines until it appeared in $\mathrm{H} \alpha$, the line with the lowest temperature. This cooling trend continued in $\mathrm{H} \alpha$ as the surge of emission gradually changed to absorption as mass was slowly falling back to chromosphere and disappearing.

Flaring arches were very different from flare loops in $\mathrm{H} \alpha$ in that the mass flows initially appeared near one end of the arch rather than at the apex of a loop (Martin and Švestka, 
1987). Additionally, flaring arches had different aspect ratios from flare loops: lower heights relative to the separation of their foot-points. The flaring arches turned out to be, in essence, giant, energetic surges (Martin and Švestka, 1988). Small energetic surges sometimes also traverse complete arches, while less energetic ones project outward from the chromosphere along a curved path and fall back along the same trajectory. If flaring arches have these super fast particles, then it is likely that surges and spicules also have analogous invisible high speed components.

The initial brightening of the second foot-point in the flaring arches provided evidence of initial particle travel times of a fraction of the speed of light. Subsequent mass flows through the arches decreased in speed, kinetic energy, and brightness until the slowest mass flows were seen only in absorption in $\mathrm{H} \alpha$, and were only tens of kilometers per second, like a common surge. This pattern of mass flows remains very instructive, and it is probably applicable to surges and spicules, similar events of lesser energies.

After Zdeněk invited me to join in a third paper on flaring arches (Švestka et al., 1989), he wanted to search for foot-points of giant arches also observed in X-rays. Our search paid off and we found low-intensity brightenings in $\mathrm{H} \alpha$ at the foot-points of a number of the arches in Big Bear full-disk data. We contacted Arvind Bhatnagar asking him to search his data at the Udaipur Solar Observatory for evidence of similar brightenings during the BBSO night-time and outside the Big Bear observing hours. Arvind's search was also successful in finding the subtle brightenings (Martin, Švestka, and Bhatnagar, 1989). In essence the giant arches turned out to be weak flare loops in the late phase of very large flares, often with a different orientation from the lower sets of flare loops. These results extended the known scale of two of the most common solar events, namely surges and flares. My several collaborations with Zdeněk were most enjoyable and fruitful.

These papers and the high quality of the images from the BBSO $25-\mathrm{cm}$ telescope inspired me to write a summary paper on the mass motions associated with solar flares. Using BBSO data for illustrations, I prepared a paper which, in essence, summarized some of what I had learned over the years at Lockheed, San Fernando, and Big Bear Solar Observatories (Martin, 1989).

In 1989, I was invited to present a paper at IAU Colloquium 117 in Hvar, Yugoslavia, on the Dynamics of Quiescent Prominences. However, my choice of topic applied to the dynamics of all filaments, not quiescent filaments alone. It was "Conditions for the Formation of Prominences Inferred from Optical Observations" (Martin, 1990b). By that time, I thought we knew the necessary and sufficient observational conditions for the formation of filament threads even if the mechanism of formation was not generally known. I felt that the conditions for the formation and existence of filaments needed to be stated and illustrated as a hypothesis as clearly as possible. That was my goal for my presentation at the Colloquium in Hvar. (It is also apparent at that time that I did not yet know about the chirality of filament channels and filaments, because I created a schematic of a filament in which the barbs have no chirality (Martin, 1990b, Figure 14).) While familiar with canceling fields and their close connection with filament formation, the question to me was: Could I show evidence or prove that cancellation represented upward motion of the magnetic field rather than the more popular interpretation that magnetic flux submerged? I thought downward mass flows should not necessarily imply downward moving magnetic flux. Erupting filaments already were showing us that upward bodily motions of erupting filaments were accompanied by large velocity down-flows within the legs of these eruptive events. Surely this could be the case for small-scale magnetic fields and flows, also. Would this be a sufficiently credible argument that canceling magnetic flux was resulting in an upward component of magnetic flux that was consistent with how filaments formed, while downward mass flows concurrently existed? 


\subsection{Gaining New Insights into Filament Formation}

Sometime around 1990, I had met Professor Cornelis (Kees) Zwaan of the University of Utrecht. A visit to his office in Utrecht, in conjunction with a meeting in Europe, is still memorable. He was already familiar with the work Karen Harvey and I had done on ephemeral active regions and with my papers with Jingxiu Wang and Silvia Livi on canceling magnetic fields. We discussed his various interpretations of how magnetic flux disappears in his earlier paper (Zwaan, 1987). In 1991 he invited me to do my doctoral thesis at the University of Utrecht, with him as my advisor. I accepted.

By the time of the IAU General Assembly (GA) in Buenos Aires and the IAU Colloquium 133 at Iguazú Falls on Eruptive Solar Flares (Švestka, Jackson, and Machado, 1992), I believed that we could link our picture of filament formation (Martin, Livi, and Wang, 1985; Martin, 1990b), to the evolution of filaments and to their eruption (Livi et al., 1989). One Saturday while preparing for the symposium in Iguazú, I was working alone in my office studying the details of high-quality images of filament channels, filaments and their association with magnetic fields seen in the BBSO videomagnetograph; I realized that filaments only grew longer when the opposite polarity fluxes merged together from the side instead of end to end as typically depicted in two-dimensional cartoons of magnetic reconnection. The motions involved in the merging of the fields from the side could only be understood in three dimensions! This was a key, new insight! Previously, I did not know why our observations did not fit the two-dimensional cartoons as illustrated by Zwaan (1987), but the answer was now obvious; the three-dimensional dynamic reconfiguring simply could not be represented in two dimensions. Thus, none of Zwaan's four suggested mechanisms correctly depicted a measurable two-dimensional cross section, although he had tried to imagine all possible configurations. His paper, however, was invaluable in arriving at this conclusion and at my greater understanding of magnetic reconnection as a viable mechanism for explaining canceling magnetic fields.

It was clear that the three-dimensional picture in my mind was completely consistent with the direction of the fibrils and the canceling fields merging perpendicular to the field direction, deduced as being along the fibrils. I was then fully convinced that the correct interpretation for canceling magnetic fields was magnetic reconnection in the photosphere. The parallel or nearly parallel fibrils in the filament channel represented a magnetic field configuration not favorable to reconnection in the chromosphere. It would, however, happen at the photospheric temperature minimum between oppositely directed components of the field, if they were forced together by photospheric flows. The reconnection would be side to side and not end to end, and would merely convert the line-of-sight component into a horizontal component. This magnetic reconnection would then result in a "net transfer of magnetic flux from the photosphere into the corona". I was elated! It was a personal moment of new understanding! The transfer of magnetic flux from the photosphere into the corona equaled the transfer of energy from the photosphere into the corona.

With that understanding, one could mentally leap forward. Since the imagined process could not reverse direction, the energy stored in the corona had to eventually exceed the amount held down by the overlying coronal loops and an eruptive event with a flare would necessarily occur. I recall my excitement in feeling that I was bestowed with the threedimensional geometric picture by which the Sun extracted energy from the photosphere and put it into the corona. At the IAU General Assembly (GA) in Buenos Aires before Colloquium 133 in Iguazú Falls, Argentina, I was very anxious to discuss my new picture with colleagues. One by one, I encountered Vic Gaizauskas, Terry Forbes, Oddbjorn Engvold, and Kees Zwaan and engaged with each in discussions. Vic was the most enthusiastic by 
far, accepting the idea with immediate enthusiasm. Terry and Oddbjorn were convivial in talking with me, but they seemed unconvinced that I was saying anything new. Kees, on the other hand, did not agree with anything I suggested. That meant my mental leaps would have to be reduced to smaller, well-supported steps.

I looked forward to spending time again with Silvia Livi at the Colloquium. We would have a marvelous time discussing our research details again. The paper presented at the Colloquium at Iguazú Falls (Martin and Livi, 1992) was not our first to connect the two concepts of filament formation, energy storage, and eruptive flares but presented the concept solidly and clearly with more examples than our initial paper (Livi et al., 1989) or the preceding foundation paper (Martin, Livi, and Wang, 1985).

For the 1991 IAU Colloquium 133 on Eruptive Solar Flares, I planned a second contribution more exciting to me than the careful clarification Silvia and I wrote on canceling fields and flares. The conditions necessary for the formation of filaments, in particular the canceling magnetic fields, had recently blossomed into the three-dimensional model that I had been discussing with friends at every opportunity during the preceding IAU GA meeting in Buenos Aires. The editors would allow a second contribution only as an extended abstract (Martin, 1992). The abstract melds the 1990 paper and the 1991 paper with Silvia Livi into a single picture of the stages in the build-up to CMEs. Both the extended abstract and the full paper with Silvia Livi interpret canceling magnetic fields as representing magnetic reconnection near the photosphere, which plays the important role of transferring magnetic field and, therefore, magnetic energy from the photosphere into the corona. This important point, however, is apparently lost in the extended abstract. I introduced too many complexities in describing the configuration of a filament channel.

At that time I was also intrigued about how the magnetic field configuration of filament channels is like a tangential discontinuity. A tangential discontinuity is a rotational configuration of a magnetic field in which the rotational part of the field is below the spatial resolution of the data. Therefore, in a data stream or measurement, the magnetic field appears to suddenly jump 180 degrees, from facing one direction to facing in the opposite direction. A trace across any polarity reversal boundary in low-resolution magnetograms would fit the definition of a tangential discontinuity. It is a common configuration seen in the solar wind and in the Earth's geomagnetic tail. It is the reason why solar and geomagnetism scientists have seen an analogy between the reconnection events in the geomagnetic tail of the Earth and solar flares.

If the above analogy is valid, then it follows that the center of a filament channel, above the polarity reversal boundary in the photosphere, corresponds to the center of a tangential discontinuity (rotational configuration). Each geomagnetic tail reconnection or each solar flare reconnection is a temporary breakdown of the tangential discontinuity. Once one recognizes this rotational magnetic field configuration existing in the middle of every filament channel, then one understands that the spine of filaments lies in the middle of such a rotational configuration. It follows that the spine is exceedingly narrow because the horizontal zone of the rotational configuration is exceedingly narrow; that narrow zone is the only place where mass of a filament spine can exist. In essence, the environmental field, the filament channel, dictates the space that a filament can occupy and explains why filament spines have the shape of long, extremely narrow ribbons rather than flux ropes. We deduced that the canceling magnetic fields are responsible for the thread structure and flows along the spine because the spine fits so closely to the polarity reversal boundary (Martin, Bilimoria, and Tracadas, 1994). But would others see canceling fields as disappearing upward into the spine instead of the popular interpretation - submerging below the photosphere? When would vector magnetograms become a practical means of testing this point? 


\subsection{The Discovery of Chirality in Filament Channels and Filaments}

My recognition of the rotational magnetic field configuration across filament channels was a personal elucidation of the configuration in a filament channel already shown in a schematic diagram by Peter Foukal (1971), based on early good quality $\mathrm{H} \alpha$ observations from the Big Bear Solar Observatory. Peter does not describe it as a rotational configuration, but it is the same configuration described by him. He also does not mention the possibility of the two configurations that differ by 180 degrees, but he came very close to making the discovery of chirality 22 years earlier than me. I was present at the solar neighborhood meeting where Peter first presented his initial paper on deducing the direction of the magnetic field along filament channels and filaments. I was impressed with the correctness of Peter's description, but the existence of the handedness of filament channels did not occur to either of us, nor to any of our colleagues.

My recognition of the two rotational configuration and chirality happened in the summer of 1991. I was able then to begin sponsoring Summer Undergraduate Research Fellows (SURF). In search of a sponsor and project, Rajesh Bilimoria, a student in aeronautical engineering, came to our department, and Hal Zirin agreed to his applying to do his project under my sponsorship. Rajesh's project was to collect statistics on the direction of the magnetic field along the long axis of filaments by applying the method of Foukal (1971) to high-quality $\mathrm{H} \alpha$ filtergrams from the recent BBSO archives. I independently made the same determinations to be certain of the chirality of the filaments and that any two people would arrive at the same conclusion for all classes of filaments, not just active region filaments. Because the fibrils are field-aligned, as depicted by Foukal (1971), their pointing and their systematically differing lengths across a filament channel represent the change in direction of the local magnetic field. The fibrils effectively reveal the rotational configuration for the average field direction. Relative to looking at a filament channel from its positive field side, the field can rotate either to the left or to the right.

One day I was wondering if the two possible rotational field configurations had anything to do with why the caterpillar-like "legs" of filaments (later named barbs) often statistically slanted in the same direction relative to the spine of filaments. I immediately started looking at convenient examples of filaments in the high-resolution BBSO images from the $25-\mathrm{cm}$ telescope. Every filament that I looked at had legs with the asymmetry in one sense or the other! They were either right-bearing or left-bearing on any given filament. That is, the mass from the spine to the chromosphere trailed downward to the right or to the left of vertical. The discovery of the handedness of filaments happened in that simple way.

As I further reviewed various examples of filaments, it quickly became clear that the filaments always have the same handedness as the fibril structure of their filament channels. My excitement grew as I had not previously noticed this pattern in spite of having written a review paper on filaments during the preceding year. I called Bill Marquette at BBSO to tell him the news as he would be able to see it for current filaments directly in the $25-\mathrm{cm}$ telescope. He was almost as pleased as I was to suddenly see a familiar subject in a completely different way. To most scientists, including me, there was no obvious significance to these discoveries of the chirality revealed in filament barbs and their filament channels. It was just a delightful, fun mystery that continued throughout the series of discoveries of chirality in many features.

One of our goals for Rajesh's project, was to find the direction of the magnetic field along the axis of polar crown filaments. It was already known from the previous studies (Rust, 1967; Leroy, 1978; Leroy, Bommier, and Sahal-Brechot, 1983) that the direction of the magnetic field along the polar crown filaments had reversed twice with the 11-year cycle. 
We had the opportunity to use our findings of chirality to confirm that the field direction along the polar crown filaments and channels for two more solar cycles. I proposed that Bill Marquette, Rajesh Bilimoria and I collaborate on a paper on this topic and present it as a poster paper at the Sacramento Peak Summer Workshop which was to be in the fall. This was the first opportunity to publish our findings of the handedness of filaments and filament channels in a paper (Martin, Marquette, and Bilimoria, 1992). The clarity of the handedness of quiescent or polar crown filaments was always marginal; it helped a lot to be able to use the handedness of filaments, even though this was also difficult because their barbs are close to perpendicular to the filament axis.

Subsequent to finding the chirality in filament barbs, further results on chirality of a variety of solar features came swiftly and were presented, published, and shared broadly with various colleagues (Martin, Bilimoria, and Tracadas, 1994; Rust and Martin, 1994; Martin and McAllister, 1996; McAllister et al., 2001). Papers on dynamic forms of chirality came later (Martin, 2003; Green et al., 2007). Numerous colleagues seemed to sense that the initial and ensuing discoveries were physically meaningful but few guessed its deeper significance beyond thinking that it was probably related to differential rotation. Dave Rust, however, saw great significance in the chirality of filaments from the outset of the first paper. It was he who first suggested using the term "chirality". He leaped ahead of us; he first anticipated the correlation of the sign of sunspot whirls with filament chirality (Rust and Martin, 1994). Shortly thereafter, he concluded it was the Sun's requirement to shed helicity that caused CMEs (Rust, 1994; Rust and Kumar, 1994). B.C. Low also concluded the same as Rust on the importance of this evidence of helicity (Low, 1994).

This handedness or "chirality" gives a kind of reason for why filaments and filament channels have such beautiful structure. The combination of some organization among some apparent randomness gives many aspects of Nature a lovely beauty. It reminds me of the saying by Keats, "Beauty is truth; truth, beauty". The beauty of the handedness of filaments and other structure has a subconscious appeal. A large number of people have volunteered to me that they are interested in working on the subject of handedness. Is it this aesthetic appeal combined with its mystery that so broadly attracts people to this subject?

\subsection{Discovery of the Hemispheric Pattern of Chirality}

When I returned from the IAU GA and IAU Colloquium in Argentina, Rajesh surprised me with the first tentative evidence of the hemispheric preference for each chirality in a small sample of data. I was extremely pleased, and I asked him to put his main project on hold and to focus on verifying that result using the bigger sample. Within a few days, he had confirmed the hemispheric preference for dextral filaments in the northern hemisphere and sinistral in the southern hemisphere but with a few noteworthy exceptions. The lack of one-to-one correlation as for chirality, meant that the hemispheric bias had a different cause from that of chirality in general. As expected at the end of the summer, Rajesh presented the marvelous results of his whole project at the SURF seminar day. His results pointed strongly to the likelihood that chirality might be caused by differential rotation. If so, however, how could exceptions to the dominance of one chirality per hemisphere be accounted for?

The finding of chirality and the hemispheric bias in 1991 caused me realize the need for systematic data sets on filaments recorded in the highest possible resolution with the biggest field of view. The 25-cm H $\alpha$ telescope was the best for that purpose. I asked Hal Zirin for one hour each day at BBSO to record successive fields-of-view over the whole Sun. Bill Marquette, as chief observer, had the responsibility for the observing part of the project and was eager to discuss the details. It was carried out systematically for about three months 
under good to excellent atmospheric seeing conditions. To increase our sample, we began carrying out a similar systematic observing program during the summer and fall of 1992.

For the summer of 1992, Philip Tracadas, a planetary science major from MIT, similarly applied to do a SURF project. I was impressed with his maturity and agreed to sponsor him. His project would be to follow on the work of Rajesh, beginning with the higher-resolution systematic data sets over the whole Sun that we had acquired in 1991. Bill Marquette had taken extreme care with the focus, and our images were among the best quality ever taken with the 10-inch telescope. I began assembling a paper on the results from our data on filaments, my understanding of the magnetic field configuration of filament channels, and the several results on chirality from the two summer SURF projects (Martin, Bilimoria, and Tracadas, 1994).

In 1994, I also decided to make a scale model of the magnetic field of a typical filament. It would show the chiral pattern in three dimensions along with the magnetic field configuration of filaments. It would include their relationship to canceling magnetic fields beneath the spine and at the foot-points of the barbs. It would also depict the chirality of the coronal loops systems high above filaments. The information for the model was already in hand from my sponsoring one more summer student in 1993, Chris Echols from Caltech. He had completed the task of calculating the height at regular intervals along the spine of classic filament. This and a number of auxiliary measurements, including the lateral extension and curvature of the barbs with respect to the spine, were adequate observational information to demonstrate the three-dimensional configuration of a typical filament. I considered the model to be a contribution to the field in the form of "food for thought". It differed radically from the most common belief in the field that prominence mass could only exist in the corona if it was supported in dips in magnetic field lines, assumed to connect the two polarities on opposite sides of a filament. It differed, also, from other popular theories of magnetic flux ropes or other magnetic field configurations where the mass is presumed to sit in concave upward locations in the magnetic field.

In contrast, the wire model (Martin and Echols, 1994) showed that filaments had separate rooting from the surrounding coronal magnetic fields. It was a means of providing evidence that prominences had their own magnetic fields separate from the surrounding coronal loops. The only assumption in the model was that filaments have field-aligned threads, a concept also well-based in indirect observations, because adequate direct observations were lacking. Although the model was necessarily static, being composed of wires connected to a copy of a real magnetogram for that day, it was consistent with all of the observations that invariably showed their mass to be moving along all of the prominence fine structures. The wires thus represented the form of the invisible magnetic field along which mass flowed. The studies with Jingxiu and Silvia had been enough evidence for them and me to learn that canceling magnetic fields were the source and driver of the well-known continuous mass flows in filaments. I was confident that the model had a solid observational and conceptual basis. My naïve feeling was that those who were well-versed in MHD modeling would find the wire model as a new and useful guide to figure out how to mathematically model the Sun's welldemonstrated configuration of filament magnetic fields. I felt my wire model was a sufficient culmination of my $\mathrm{Ph}$.D. thesis along with all of the supporting observational evidence that allowed me to conceive of the model.

A symposium on Solar Magnetic Fields was announced, to be held in honor of the retirement of Kees Zwaan. It was exciting to contemplate attending this symposium as I had such nice results to present from the model and from the results on chirality based on the Martin, Bilimoria, and Tracadas projects. I worked diligently by hand to complete the final color-coded version of the wire model representing a real filament. I thought it would be a 
wonderful surprise for Kees to see how far I had progressed with results towards my degree. I had succeeded with my intention to show him the basic structure of a real filament and the real magnetograms on which it was literally based. Thus, the model was to scale as much as the materials would allow and represented the magnetic field of a typical real filament including its chirality.

The results of the Martin et al. paper were well received at the Symposium and became a frequent topic of discussion. At the end of my talk I presented Kees with my carefully scaled, color-coded wire model of the chirality of a real filament on a color-coded magnetogram. I was completely wrong about what Kees' reaction would be. Instead of being pleased, he was highly embarrassed by the model and kept it hidden from view for the remainder of the symposium. Needless to say, we did not talk about it either. I was certain that I had unintentionally wiped out of existence any possibility of getting a Doctoral degree from Utrecht. Months later he told me my thesis should be a presentation of observations only. He also kindly invited me to consider joining himself and his former student, Piet Martens, in a model that excited him much more than mine. I regarded Piet as a respected friend and scientist also, but Piet was not present. I declined in all due respect. Silently, I knew I could not agree to be co-author on a paper that I felt to be in opposition to observations. I hoped future interactions would answer the question: What could be wrong with creating a threedimensional conceptual model when creating three-dimensional MHD models was not yet practically achievable?

Chirality remained fascinating from a number of perspectives but the physical significance of chirality, especially in the case of filaments and sunspot whirls, was not completely obvious at the time. Statistical relationships abound in nature but one-to-one relationships are rare. The latter invariably imply physical meaning, but their physical significance was not completely obvious at that time. I wrote a paper describing the full set of one-to-one relationships and the statistical association with the northern and southern hemispheres (Martin, 1998a). That same year, I received an invitation to write a review paper for the journal, Solar Physics (Martin, 1998b). This was a welcome invitation to update my 1990 review with the observations of chirality and to raise the interesting questions that remained about filaments and their environment: How do barbs evolve in relation to the pockets of minor polarity? Are continuous interactions with small-scale fields necessary to maintain filament barbs?

\subsection{The Relationship of Filament Chirality to the Chirality of Sunspot Superpenumbra}

Upon first learning about the handedness of filaments, Dave Rust, then at Johns Hopkins Applied Physics Lab, reminded me that chirality had already been found for sunspots by Richardson in the 1940s. Although I knew about the minor spiral patterns of superpenumbral fibrils around sunspots, the thought of sunspots having chirality related to filaments had not yet entered my mind. Dave suggested that there should be a unique association of the handedness of filaments and the handedness of the superpenumbral fibrils around sunspots. The gentle spiral pattern of superpenumbral fibrils had been called vortices or vortical patterns by Richardson (1941) and even earlier by George Ellery Hale (Hale 1908a, 1908b, 1908c). I thought about this and soon agreed with Dave. We each guessed the correct association but from different perspectives. We then verified the relationship that the counterclockwise spiral (from outer end to inner end of a fibril), or partial spiral pattern ( $<360$ degrees), related to dextral filaments, and clockwise spirals or partial spirals related to sinistral filament channels and filaments without exception (Rust and Martin, 1994). Dave suggested that we 
use the term chirality. We adopted his excellent suggestion in our brief paper on the chirality of sunspots and for the handedness of all solar features.

Long before our finding the chirality of filaments and filament channels (Martin, Bilimoria, and Tracadas, 1994), Burlaga (1988) had already discovered the chirality of magnetic clouds. With the handedness of interplanetary magnetic clouds well known, one could readily anticipate their source regions would exhibit chirality also and Gosling had already made a conceptual drawing of this for coronal loop systems (Gosling, 1990). Dave Rust was elated that we had established the dominance of one chirality per hemisphere, even though there were exceptions. He did an analysis and wrote the first paper on the handedness of magnetic clouds and their expected association with either the northern or southern hemisphere (Rust, 1999), with most left-handed ones coming from the northern hemisphere and most right-handed ones from the southern hemisphere.

At that time there was, and there still is, a shortage of the $\mathrm{H} \alpha$ Doppler images needed to understand the physics of eruptive solar events, which include erupting filaments, flares, and CMEs. Observing pre-eruptive Doppler shifts in $\mathrm{H} \alpha$ is one of the few means by which eruptive solar events might be forecast in the future. Because CMEs occur with erupting filaments but are not yet detectable against the disk, a forecast of an erupting filament is also a forecast for a CME. However, a major problem in implementing such research is equipping a high-quality telescope with multiple, tunable narrow band solar filters. Filters with adequately narrow passbands and the necessary tuning capability are a specialty item, custom-made by only a few manufacturers and costing from fifty to several hundred thousand dollars. Also, achieving high resolution over the whole Sun has been prohibitively costly. Funding of this magnitude through research grants is very limited; the cost of filters are a large fraction or all of the cost of typical funded research proposals. Most proposals could not be for equipment only but typically had to be focused on research which would require the use of the proposed equipment.

I had learned from Dave Rust of a new, narrow-band lithium niobate tunable filter known as a Fabry-Pérot Etalon, being manufactured for solar use by the Commonwealth Scientific and Industrial Research Organization (CSIRO) in Sydney, Australia. Dave showed me the excellence and purity of the spectral lines produced by one of these etalons in the spectrograph of the 60-ft tower at Mt. Wilson. I was also very much impressed that CSIRO was selling the etalon itself for only $\$ 30000$. We got Hal Zirin's consent for a 4-day test interval to try one out in the magnetograph at BBSO. Our less than perfect test setup, however, yielded only slightly better signal than the filter then in use. Hal was unimpressed, and not at all interested.

Dave was convinced we could do better, and he left an etalon in my care to try at a later time. I also wanted to test the etalon in taking $\mathrm{H} \alpha$ filtergrams. I was sure that we could get better ones than Dave had yet obtained at Sacramento Peak. Hal was amenable to Dave and I doing another observing test with the etalon when he was away on one of his trips. We succeeded, with the help of Bill Marquette and other BBSO observers, in taking images that were comparable in quality to those from the Zeiss filter at BBSO, except for some nonuniformity across the images. We knew that using the etalon in a telecentric beam, rather than on the 10-inch optical system in use, would eliminate the non-uniformity. Hal, however, was again unimpressed with the results, and refused any further time for Dave to come to BBSO.

Toward the end of 1994, I began talking with my husband about making a change in jobs; I could take early retirement from Caltech in 1995. Doug had retired several years earlier from his optics and filter manufacturing business. He enjoyed designing equipment, however, and thought - initially only to himself - that if he offered to build a telescope for 
me that I would be more inclined to retire early, as he knew very well how much I liked being the observer in my research on the Sun.

I had long dreamed of having my own personal solar telescope, and my ideal was modest. I thought one of the 5-inch $(12.5-\mathrm{cm})$ aperture, portable, telescopes like George Carroll formerly built would be just right. The big drawback was that a good-quality narrow band filter for it would cost at least five times as much as the telescope! That was far beyond our family resources for personal pleasure, so I did not speak much about this unrealistic dream. Doug completely surprised me when he offered to build my own solar telescope! I was ecstatic!! His innovative concept of a polar mount with a primary lens fed by a single mirror had several advantages. The telescope spar (bench) would be supported at both ends for stability, and it could rotate in synchronism with the Earth driven by a single small motor. Then one only needed an adjustment for declination north-south motion of the Sun in the sky, and a guider to hold it as rigidly as possible to the Sun. The aperture was to be 10 inches instead of 5, because we already had a 10 -inch $(25-\mathrm{cm})$ lens that Doug had ground, polished, and figured many years previously for a different telescope!

I was completely delighted! My dream was coming true in a way much better than imagined! My new telescope was going to be the same size as the telescopes I had used at Big Bear, and Lockheed! I still had to be true to my middle name, and have "Faith"; I would find a way to come up with $\$ 30000$ for an etalon or narrow-band filter, but, meanwhile, I would be satisfied to observe with a broad-band filter suitable for seeing prominences at a single wavelength. Why were my plans to retire from Caltech being augmented far beyond what I could possibly have imagined?

\subsection{Helio Research - A New Non-profit Research Institution}

Doug started building the $25-\mathrm{cm}$ solar telescope in 1995. At the same time, I took the lead in starting the non-profit corporation intended to be the institution through which I would apply for research grants. We chose to create a non-profit corporation, because this type of organization is eligible to apply for federal research grants, while ordinary businesses can only apply for contracts. Federal research agencies regard non-profit corporations akin to educational institutions, whereas for-profit corporations are "businesses". Also, there are clear state government regulations for non-profit institutions, which make administering research grants easier than contracts, hence favored by the agencies. It took more initial work, but after about six months of jumping through minor bureaucratic hoops and waiting, we received the document recognizing Helio Research as a non-profit Corporation in the State of California.

During this transition, Karen and Jack Harvey helped greatly by allowing a small grant for an educational movie on Solar Prominence Research, with me as PI, to be transferred from Caltech to their Solar Physics Research Corporation upon my "retirement" in December 1995 . This let me work remotely as a temporary part-time employee of their company. The movie-making project was completed with the able assistance of Philip Tracadas, who did most of the camera work. During the transition interval, I also had applied to the National Center for Atmospheric Research for a short-term Research Fellowship with sponsoring support of Boon Chye Low and Art Hundhausen. I worked with Alan McAllister, then a post-doc with Art, to determine the chirality of coronal loop systems and flare loop systems.

The key result of our study in Boulder was the finding that coronal loops and flare loops invariably had the opposite chirality to the associated filament barbs and fibrils in the same filament channels. Because all chiralities are defined in relation to either a polarity boundary, or a filament spine parallel to a polarity boundary, this meant that the field direction along 
the flares loops and coronal loops always had an oppositely directed component of magnetic field orthogonal to the polarity boundary relative to that of filament barbs and chromospheric fibrils. Yet all features also had a component in common parallel with the polarity boundary (Martin and McAllister, 1996). These key findings on the chirality of coronal loops and flare loops made it possible to summarize all of the patterns of chirality from photospheric, chromospheric, and corona data into one paper (Martin, 1998a). I was fortunate to be able to present this systematic picture at an IAU Symposium on "New Perspectives on Solar Prominences". No one yet knew the full significance of the finding that nearly all solar features had chirality (handedness). Nearly everyone thought it was significant, because it relates to helicity, and helicity is related to energy storage and release before and during eruptive events. It was intriguing because there was no mechanism or over-arching concept that yet explained the close, and elegantly simple, one-to-one inter-relationships of the chiralities of solar features.

Flux-rope models of filaments flourished in the field in the 1990s alongside the discoveries of chirality. It seems that every conceivable means for the Sun to generate flux ropes was proposed. To me, the pre-eruptive configurations of all features with chirality were clear evidence of helicity in the form of writhe rather than twist helicity essential to flux ropes. Was this propensity to favor twist an outcome of Burlaga's earlier discovery of flux ropes in interplanetary CMEs (Klein and Burlaga, 1982; Burlaga, 1991), and the tendency for a successful model to be followed by a flood of variations on a theme?

\subsection{The Martin Solar Telescope}

Another proposal I had recently written under the auspices of Caltech was pending. By the time it was approved, the grant could be awarded by NASA directly to Helio Research with the agreement with Caltech. That gave me the funds to work full-time for Helio Research. While I pursued new proposals and the grant work, Doug was putting our new telescope together in the small garden behind our house. The modest and innovative Martin Solar Telescope and its builder are shown in Figure 8.

Doug invented a novel way to make it structurally simple, rigid, and light weight with minimal flexure. He used a $15-\mathrm{ft}(4.5-\mathrm{m})$ aluminum tube surrounded by three $15-\mathrm{ft}$ aluminum plates screwed to the tube to create an exterior, triangular cross-section around the tube. A steel axle mounted on flexible bearings inside each end of the tube allowed rotation of the triangular structure at the solar rate using a very small motor that would not cause vibration in the structure. When not in use, the telescope bench rests in a horizontal position. For observing, the mirror end is raised by a manually operated winch until the end reaches an aluminum plate with anchoring pins that rest in slots in an aluminum block at the top of a large triangular fork. Until the telescope is locked to the fork, the fork is hinged at its base to allow north-south motion.

Doug attached crossbars on the top aluminum plate or "bench" of the telescope, to which rails attach for mounting optics, filters, camera and other equipment. After making the initial optical system, he redesigned the telescope to include dichroic mirrors to dump excess light and heat in a broad range excluding the $\mathrm{H} \alpha$ line. With reduced heat in the telescope beam before entering the filters, we then achieved satisfactory data. The data quality further improved upon inserting a pair of narrow prefilters in place of a single one. The field of view is $9 \times 9$ arc minutes, sufficient to include most long filaments. The first paper containing observations from Helio Research used images of an erupting prominence acquired on film before we were able to purchase a digital camera. By luck, Nandita Srivastava was studying the CME associated with an eruptive prominence that only Helio Research Observatory had 
Figure 8 Doug Martin stands by the $25-\mathrm{cm}$ aperture solar telescope he designed and constructed for me to observe the in La Crescenta, California, USA. The 25-cm lens is the dark circle at the upper end of the telescope in the top image. Left of the lens is the single mirror heliostat that feeds sunlight into the telescope. The path of the light beam coming from the lens is shown by the red dashed line in the lower image. The beam is reflected by two dichroic mirrors which serve to cool the beam by also passing the majority of unwanted light through the mirrors and out of the telescope. The dashed line ends at prime focus at the beginning of the light-tight lower end. The beam passes through lenses, a beam-splitter, prefilter, and a $1 / 10-\AA ̊$ narrow-band etalon before coming to focus at the $1024 \times 1024$ pixel digital camera at the lower end of the optical bench.
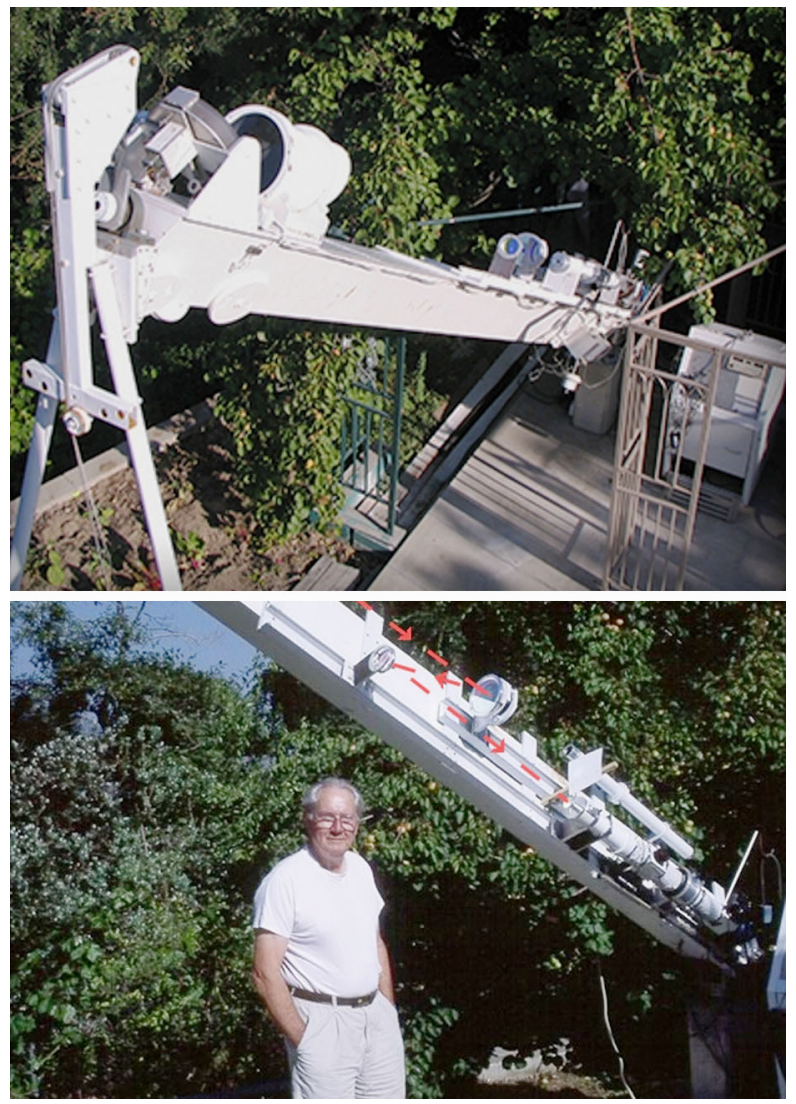

recorded in high resolution. Nandita had been the graduate student of our long-time friend, Arvind Bhatnagar. We met Arvind when he came as a post-doc to work with Bob Howard at Mt. Wilson. Arvind later became the manager of Big Bear Solar Observatory for a few years before deciding to return to India to begin a new solar observatory, the current Udaipur Solar Observatory. Naturally we had many interests in common.

Arvind was one of the persons who gave me the confidence to begin Helio Research. I too visited Arvind and his wife, Chitra, in India on four occasions in relation to attending different workshops. I recall with pleasure standing on the bare earth and rock which Arvind said would be the site of the new Science Building of the Udaipur Solar Observatory. Figure 9 shows us with Arvind and Chitra during their last visit with us about eight years after we had initiated Helio Research.

Our telescope was nearly up and running in 1998, when an opportunity opened with NASA to apply for funding for instrumentation, collaborative observing, and data analysis in support of the Solar and Heliospheric Observatory (SOHO). It was the perfect time for Helio Research to propose funding for the etalon, a prefilter, and digital camera for $\mathrm{H} \alpha$ Doppler observations. Doug would have to build the housing, oven, and power supply for the etalon, but that was well within his capabilities. He had already successfully built several birefringent filters as part of his business, Spectra Optics. Our proposal succeeded, partly because the telescope was already being built using our personal funds. We were planning for a unique capability for multi-wavelength observations across the $\mathrm{H} \alpha$ line, including the op- 
Figure 9 From left to right: Doug and Sara Martin with friends, Chitra and Arvind Bhatnagar, founder of the Udaipur Solar Observatory in Udaipur, India.

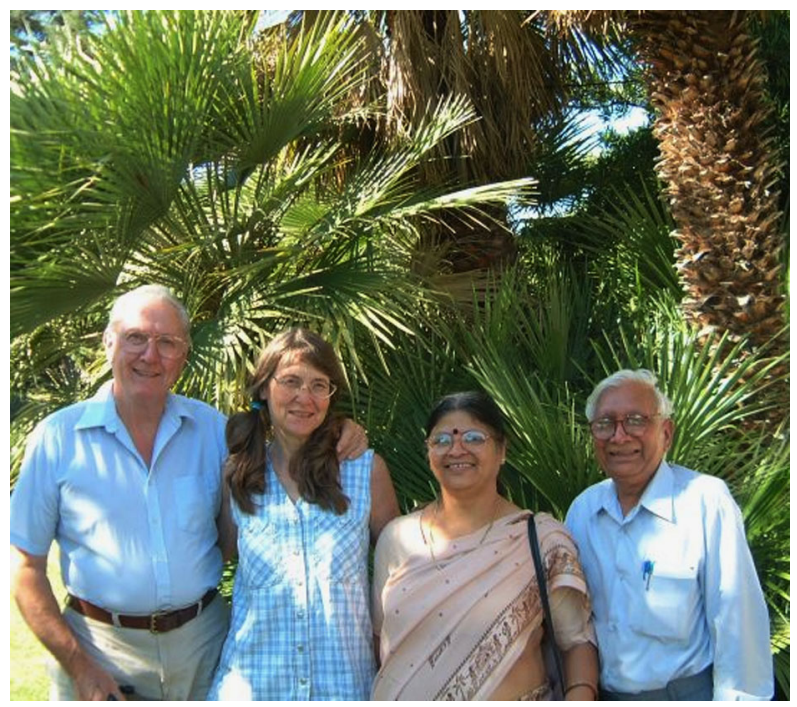

tion to acquire time-lapse images in other spectral lines. I also had the observing experience, the time needed to acquire the data, and the grant-writing expertise to compose a convincing proposal explaining the need for $\mathrm{H} \alpha$ Doppler and the merits of a lithium niobate etalon as our primary narrow-band filter. Due to Dave Rust's important role in testing Australian-made lithium niobate etalons, while a guest at different observatories, we happened to become the first in the American continents to employ one in daily research observations. Another colleague, Alan Kiplinger, at the University of Colorado, advised me about digital cameras and what would be the best choice for our research purposes.

I was pleased with the atmospheric "seeing" conditions at our small garden site in La Crescenta. Many instances of good seeing were comparable to what I had experienced at Lockheed, San Fernando, and Big Bear Observatories. I have also heard first hand from amateur astronomers of excellent daytime seeing at specific sites from Baja California in Mexico to central California. Mountain sites often have good seeing in the morning but are usually less desirable later in the day due to updrafts, with the exception of Big Bear Lake and possibly other lakes and valleys at high altitude. From first-hand experience, I knew well that low altitude observing sites in southern California had proven their exceptional worth. Would the convenient location of the Martin Solar Telescope in our little garden in La Crescenta be as good as the two former sites of the Lockheed Observatory and the San Fernando Observatory?

\subsection{PROM and Early Collaborative Research at Helio Research}

Around 1996, I accepted an invitation to speak on eruptive events on the Sun at a winter conference on solar and interplanetary physics at Yosemite, California. Eric Priest emailed me that he was going to the conference and would be coming through Los Angeles on his way to Yosemite. We drove to the conference together, which gave us ample time for discussions of observations and theoretical work. On the return trip, we began discussing the tendency of solar observers and theoreticians to work separately, and ways they might do more work together. We came up with the idea of forming a research team of observers and theoreticians to collaborate on a new proposal. A balanced team of scientists composed 


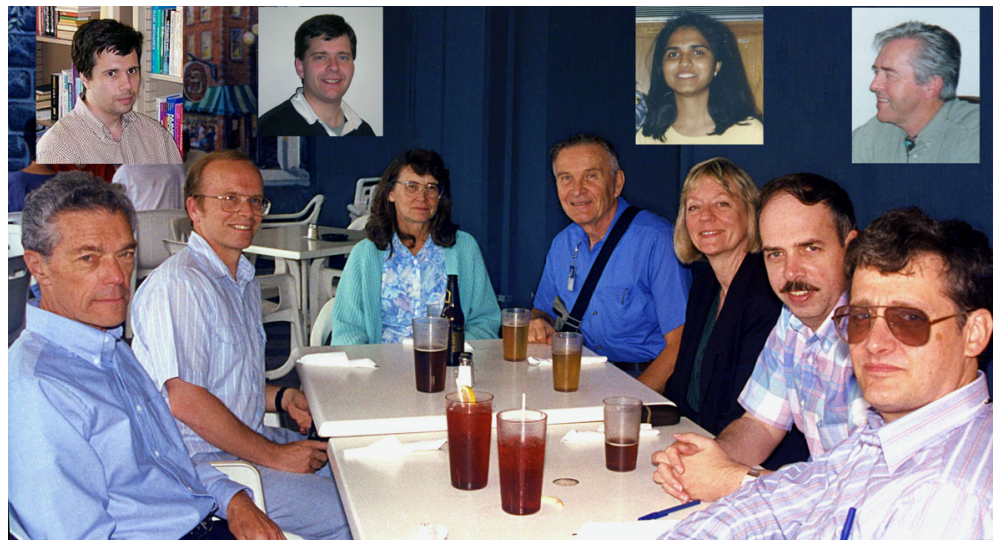

Figure 10 The Prominence Research Observations and Models (PROM) team in Ottawa, Canada. Seated, left to right, are Jack Zirker, Eric Priest, Sara Martin, Victor Gaizauskas, Karen Harvey, Terry Forbes, and Aad van Ballegooijen. Other early research team members not present but shown in the inserts are Yuri Litvinenko, Duncan Mackay (upper left), Nandita Srivastava (upper middle), and Oddbjorn Engvold (upper right). Original photo credit: O. Engvold.

of both observers and theoreticians could more effectively find research questions and answers alike. A strong team would aid us in getting funding to work together and allow us to meet for concentrated discussion a couple of times a year. We decided the team needed a name, and Eric came up with "PROM", for Prominence Research: Observations and Models. We proposed the concept to the colleagues we were already working with in smaller groups of two or three. Soon Terry Forbes, Karen Harvey, Vic Gaizauskas, Oddbjorn Engvold, Jack Zirker, Eric Priest, and I became the first PROM team to write and submit a proposal from Helio Research for a federal research grant. In Figure 10, we are meeting in Ottawa, Canada, with the addition of Aad van Ballegooijen. Oddbjorn Engvold, who took the picture, is shown in the upper right. The other inserts are the next persons who joined the team proposals and papers, Yuri Litvinenko, Duncan Mackay, and Nandita Srivastava. We could not propose salaries for those outside the US, but they would be co-investigators with salaries provided by their home institutions. The team composition gradually changed as some participants retired or dropped out while others joined new research proposals. The PROM team collaboration has been one of the most productive and enjoyable in my career.

The PROM team met at least once a year in various locations. In the spirit of our collaboration, we invited other scientists, in each locale where we met, to join in our discussions and presentations. This also broadened our association with others doing similar work, and enabled us to share our research with other scientists but kept our working group meetings small and easy to organize. We frequently received enthusiastic comments from local scientists about how much they learned by attending. We had neither the funding nor the intention to make our working group meetings into larger-scale "Workshops" in the current vernacular. Nevertheless, the later working group meetings evolved into larger attendance than the early ones as we did not turn down any requests by scientists who wished to continue attending after first meeting with us.

When I left Caltech, the new work of establishing Helio Research quickly absorbed all of my time. As a consequence, my work towards a doctoral degree with Kees Zwaan as my promoter did not result in a formal degree. I thought I could perhaps write my thesis to Kees' satisfaction after getting Helio Research under way. However, the early years of 
proposal writing, observing, and managing grant work whizzed by in intensive work weeks but without further work on the thesis; then Kees became ill with cancer of the stomach. He requested and I agreed to end our formal course of study. I did not see Kees again after that, but I recall with pleasure two occasions of being a house guest of Kees and his wife Prisca, and their being our guests. Discussions with him were delightfully challenging because he held alternative ideas to mine about how filaments should be modeled. Throughout the collaboration with Kees, I have to admit that my real goal was not ambition for a degree which, by that time, I did not need. For me it was an opportunity to interact with Kees and write a thesis. It was the experience of writing of a thesis that I thought I had missed in not previously being a graduate student and I truly wanted to write a thesis on the topic to which my research kept returning, solar prominences. Some years after Kees' passing, I realized that in effect, I had written the thesis. My ideas at that time of the key observational elements that needed to go into modeling filaments had all been expressed in published papers beginning with Martin, Bilimoria, and Tracadas (1994) and Martin and Echols (1994), and following on with Rust and Martin (1994), Martin and McAllister (1996, 1997), and Martin (1998a) with further clarifications appearing in my 1998 review paper (Martin, 1998b). Along with new conclusions about how prominences should be modeled, the common observational threads throughout these papers were findings on the chirality of filaments and related features surrounding them; the 1998 papers showed that all features with chirality belonged to one of two chiral systems.

Significant later research by and with PROM team colleagues more completely illustrated the detailed structure of prominences in high-resolution images from the Swedish Solar Telescope (Lin, Martin, and Engvold, 2008, and Martin, Lin, and Engvold, 2008). Essential mathematical modeling was carried out by Yuri Litvinenko (1999). But these and other new results, far beyond my realized thesis goals, need further mention later.

In 1996, after finishing his post-doctorate position at the High Altitude Observatory, Alan McAllister made a successful proposal and I agreed to have Helio Research serve as the administrative institution for his grant. As Jack and Karen Harvey had done for me with their corporation, Alan worked with us as a remote collaborator; he remained in Boulder, only making occasional trips to California.

Alan and I shared a high mutual interest in chirality and its dynamics in erupting prominences. He joined me in a two-part paper that followed up on my three-dimensional wire model of a filament magnetic field (Martin and McAllister, 1997). The first part of the paper shows a wire model of an erupting filament depicting what the sign of helicity would be if magnetic reconnection first took place under the filament between barbs on each side of it during the early stages as the hypothetical filament ascended. The model strongly resembles a well-known erupting prominence observed at Sacramento Peak in 1959 (shown in the paper). Our prediction was that the reconnection would produce twist over much of the length of the filament. Earlier, van Ballegooijen and Martens (1989) proposed the creation of shallow twist during filament formation. In contrast, our depiction produced twist only during an eruption. While both concepts seemed reasonable at the time they were proposed, neither has been verified. If twist is produced during filament formation, it would have to be destroyed as rapidly as produced because high-resolution images with excellent thread detail have not verified sustained twist. Is it possible that continuous magnetic reconnection takes place between the filament threads channel fine structure? The Martin and McAllister concept more obviously proved to be wrong; it has been completely replaced by observations showing that most or all of the twist observed in many erupting filaments is produced in a very different way, as discussed in Section 2.21 
A second part of the paper with Alan McAllister shows another wire model demonstrating what would happen if reconnection within the overlying arcade took place, as suggested earlier by Gosling (1990). In this case, the coronal arcade expands outward, leading to magnetic reconnection between adjacent stretched coronal loops. The result is a highly twisted magnetic flux rope consistent with helicity observed in interplanetary magnetic clouds (Burlaga 1988, 1991). But this excellent mechanism for creating flux ropes, to explain coronal clouds, was not proving to be satisfactory for filaments. Filaments needed a more complete and convincing description than that, of flux ropes. Yet it is well documented that, during eruption only, filaments often exhibit large-scale helical mass motion. The compelling question was, how do prominences develop helical motion in the clear absence of long-lived helical structure or long-enduring helical motion prior to their eruption?

\subsection{How the Ubiquitous Counterstreaming in Filaments was Discovered}

In 1998, as part of our grant research with the PROM team, I was analyzing the three wavelength Doppler observations of a filament that Jack Zirker, Oddbjorn Engvold, and I had acquired at BBSO in 1993. We had followed a typical filament from near the central meridian to the west limb of the Sun. At Helio Research, I digitized and aligned the center-line images from the original film. Then I repeated this for the red wing at $+0.3 \AA$ for just one day of our observations near the limb. My objective was to take these digitized movies to the 1998 PROM working group meeting so that Jack, Oddbjorn, and I could assess the potential for this data set and share it with the working group. We found it interesting but not unique that the red wing movie showed streaming mostly in one direction. After the Workshop, I digitized the blue wing, which also showed streaming in one direction - but within the same volume of space in the filament, the streaming appeared to be going in the opposite direction from the streaming in the red wing.

I played the red wing and blue wing movies one after the other again... and again... and again. The motions in the blue wing were in the southward direction along the filament spine and barbs, while in the red wing, the mass motions were going northward! Thinking I must be observing one of the movies backward in time, I checked and rechecked the hands of the clock face in the corner of each BBSO image. After several minutes, the reality of what I was seeing struck my consciousness like lightning. Jack and Oddbjorn should have been there to witness the comedy of my astonishment; my eyes must have been as wide open as my mouth. Many threads of mass were streaming both ways along the spine and barbs at the same time! I recalled seeing a few threads of counterstreaming mass along the top of a dense quiescent filament in another movie, but these movies were showing me threads of mass flowing both directions interleaved throughout all of the spine and barbs of this filament! And it was just an ordinary filament!

A flood of questions came to mind. How could this be? Were the threads the same in the two wings? I compared them. They were not. I checked the center-line film. It showed evidence of both motions, but the net visual effect was more like turbulence. Looking closely at individual center-line images, however, I could identify some of the same threads as in the corresponding wing images. It was really true! Mass in the interleaved threads was flowing in opposite directions in the filament by 180 degrees! Finally convinced of this astounding discovery, I sent a very excited email to Oddbjorn and Jack. They replied with the same enthusiasm. Via email and a few phone calls, we decided on a paper to Nature (Zirker, Engvold, and Martin, 1998). We discussed the meaning of continuous but steady upflows against gravity at length. Upflows were consistent with the Livi, Wang, and Martin (1985) interpretation of canceling magnetic fields as the driver of filament flows as summarized in 
Martin (1992), but these flows were not ballistic; they did not accelerate and decelerate as would a projectile governed primarily by gravity.

Of highest new significance to me was the confirmation of my longstanding impression, from my early days studying solar movies at Lockheed, that all visible flows in solar plasmas were field-aligned. This was still not accepted by most scientists in our field. To me, counterstreaming was a long-awaited proof that everyone would surely understand - that filament threads are field-aligned and, therefore, the magnetic field configuration in all filaments could be accurately modeled directly from observations of their mass motions. Jack, Oddbjorn, and I agreed that the greatest need was for higher-resolution observations that revealed the filament threads more clearly, accompanied by higher-quality magnetograms. Oddbjorn and Jack had been pursuing these goals already for many years through group and individual efforts in their use of the Dunn Solar Telescope (DST) at Sacramento Peak, and by promoting the Large European Solar Telescope (LEST) in Europe, and the Swedish Solar Telescope (SST). Although counterstreaming quickly became accepted, the corollary of mathematical modeling based on field-aligned threads has only received limited acceptance; few mathematical models based on observations of filament threads yet exist. Does it mean that the observations cannot be denied, but the implications of observations are strongly resisted if they require a complete change of mindset?

\subsection{Why Are Canceling Magnetic Fields Related to Filament Formation?}

Prompted by his participation in the PROM team, Yuri Litvinenko told me that he thought he could develop a theory of magnetic reconnection that would apply to canceling magnetic fields. I was overjoyed! He soon published his seminal paper on the interpretation of canceling magnetic fields as magnetic reconnection at the photosphere, and how it relates to filament formation (Litvinenko, 1999). However, his paper contained no observations. To illustrate the canceling-field association with the dynamics of a filament and associated magnetic fields, he and I wrote a short follow-up paper using a superb example from the $\mathrm{H} \alpha$ archives and videomagnetograms from BBSO (Litvinenko and Martin, 1999).

Our joint paper simply illustrates the consistency between the observations and the theory. It is still rare in solar physics that a theory fits the observations so closely. However, showing the correspondence well was a challenge. We had a single, clear example. Better magnetograms were needed in most cases. As with most new results, new questions were opened and remain open. How much mass might accompany the rising of the magnetic field into the corona? What makes the mass injections into filaments at some locations unidirectional instead of bidirectional? Later, together with colleagues, Yuri further developed the theory of canceling magnetic fields by qualifying that the reconnection was better characterized as a magnetic pile-up type reconnection (Litvinenko, Chae, and Park, 2007). A beauty of the Litvinenko filament models is their remarkable consistency with observations. Without any preconceived magnetic field configuration, the Litvinenko models allow for filaments to form thread-by-thread, and therefore, they are also consistent with counterstreaming everywhere in filaments. They bring to mind intriguing and significant new questions such as: What happens to the filament mass after it flows through a thread? Is it reflected by photospheric fields back into the corona, or is every filament thread a new thread?

\subsection{Filament Channels}

The magnetic fields of filament channels, whether of high or low flux density, must be stronger than the magnetic fields in associated filaments in order for them to control the 
structure of filaments. The papers of Vic Gaizauskas (1998, 2002, 2008), Gaizauskas et al. (1997), and Gaizauskas, Mackay, and Harvey (2001) discuss and/or illustrate various reasons why understanding filament channels is essential to understanding filaments. The established tight relationship between the chirality of filaments and their channels serves to clarify that the magnetic field of the filament channel determines the structure of filaments. Yet the majority of filament models, being published in the field, pay little or no attention to the structure of filament channels, or make incorrect assumptions about them. These are the main reasons there are few filament models that are consistent with observations of filaments. The magnetic field structure of filament channels can be used as a simple test of many of the magnetic field structures proposed in filament models. The test is a thought experiment. Imagine placing a modeled magnetic field in a filament channel as depicted by Foukal (1971). A model passes the test if all of its magnetic structure is aligned with the channel field. A model fails if any of its structure will reconnect with the channel field. Due to recent findings, the test now needs to include the coronal structure of channels as known from observations of coronal cells (Sheeley and Warren, 2012). It often takes a long time for observational knowledge to be generally accepted and integrated into models, although it can happen rapidly if a concept becomes popular.

The whole PROM team agreed that our work and research proposals should maintain as strong a focus on filament channels as on filaments. One of my favorite examples of that focus is our 2002 summer student project undertaken by Michael (Mike) Anderson, then ready to begin his senior year as a physics major at the University of California, Los Angeles (UCLA). He expressed a keen interest in how filaments evolved, so I showed him an exceptionally long filament that stretched almost a whole solar diameter across the Sun, from the active region belt to a polar crown filament channel. I asked him if he would like to study how it originated and evolved. He eagerly ran with the suggestion. The paper resulting from his project brings out the significance of filament channel evolution as a function of flux emergence, dispersal, cancellation, and differential rotation, all interacting to create an exceptionally long filament channel (Anderson and Martin, 2005). The paper also demonstrates how flux emergence and later dispersal were the dominant factors in the breakup of the long filament channel, hence its filament.

While none of the factors discussed in this paper were new, the study of the combination of these factors led to results that were truly illuminating. I was surprised one day when Mike showed me a filament spine in the corona that was partly visible above the limb in some 304$\AA$ images. Filament mass in the 304- $\AA$ line bridged a 15-20 degree gap between a nearly east-west polar crown filament and a more nearly north-south filament visible in $\mathrm{H} \alpha$. Only many days later did the connecting filament mass become visible in $\mathrm{H} \alpha$. A subsequent paper by our PROM team collaborator, Victor Gaizauskas, further broadened my understanding of how the formation of a quiescent filament channel and filament can evolve over much longer intervals than I previously thought possible (Gaizauskas, 2002). These examples illustrate how research is often a gradual unfolding of new knowledge punctuated by little leaps to new understandings. But they also bring to mind the question: How far can we stretch our thinking beyond that which is familiar?

\subsection{Discovery of Rolling Motion in the Top of Erupting Prominences}

When I was working at the San Fernando Observatory, I was intrigued by a $304-\AA$ image of an erupting prominence observed by NASA'a Skylab mission. In the 304- $\AA$ image, the top of the prominence appeared to be folded over in front of the lower part. This was consistent with the spine being a narrow sheet of threads stacked horizontally and consistent 
with our three-dimensional, field-aligned, observational model discussed previously. I was fascinated by apparent folding-over of the top in the same sense as the cresting of an ocean wave. I made an illustration comparing the single, early 304- $\AA$ image to the same erupting prominence seen in a full-disk $\mathrm{H} \alpha$ image. However, I found no data on the evolution of the eruption. Was the apparent "folding" real, and if so, how could that be?

After the beginning of continuous $304-\AA$ observations on board SOHO, I would occasionally see a movie in which the top of an erupting filament in 304- $\AA$ images would appear to gradually bend in front or back of other parts of its structure. The topic was worthy of a research paper. However, with only a single wavelength, I was not sure that I could provide evidence convincing to peer reviewers for scientific journals. I knew of no reason for such a development during an eruption. In fact, it seemed to oppose what one would expect. Why would a prominence, which follows a CME, do anything other than expand into the growing cavity beneath the CME?

Many years after my initial observation of the folded filament from Skylab images, my friend Arvind Bhatnagar reminded me of this little mystery when he brought me a movie from Udaipur in which he thought an apparently detached chunk of an erupting prominence was rolling over as it erupted outward. Was this related to the bending I had seen intermittently over the years? Without Doppler observations, there was no way to prove or disprove an erupting prominence mass could be rolling as it erupted. Again I shelved my questions for future consideration.

About 25 years after my original question arose, the mystery was resolved by our observation at Helio Research on 2002 July 29 of an erupting filament recorded using our $\mathrm{H} \alpha$ Doppler system. Luckily the eruption was a slow one, and we obtained nine full sets of nine images each at 0.2- $\AA$ steps across the $\mathrm{H} \alpha$ line during the eruption. Our summer student, Yashar Agah, colorized the $\mathrm{H} \alpha$ Doppler images to show the blue shifts as blue, blue-green, and green, and red-shifts as red, orange, and brown, respectively, with increasing wavelength across the line. He then combined each of these six sets into composite color images. (I was very happily aware that we were fulfilling Harry Ramsey's dream of using color Doppler movies to help us understand the Sun's phenomena.) Our observations, combined with $304-\AA$ images from SOHO/EIT clearly showed that the top of the prominence was rolling away and downward, while the bottom middle was moving into the foreground and upward. This rolling continued as one leg disappeared and the middle swung gradually above the other leg to create an ascending, nearly vertical structure. As the mass collected in this rising leg, the rotating motion continued such that it was nearly parallel with the limb; this remaining part of the prominence appeared to spin like a toy top but slowly. That same pattern of rotational motion continued while the whole structure gradually shifted to the blue wing and out of the passband of our filter. There in front of us was the confirmation that the folding or bending I had previously noticed was real! Finally I knew I could write a publishable research paper on the subject (Martin, 2003).

The proof of the roll effect at the top of erupting prominences turned out to be only a beginning step in a slowly accelerating process of unraveling some of the mysterious motions within erupting prominences. As shown in the first paper (Martin, 2003), the rolling motion propagates down each leg of the erupting prominence, whether the eruption is symmetric or asymmetric. Another fascinating aspect was realizing that the sign of twist is opposite in the two legs. A third was finding the direction of sideways roll to be correlated with the chirality of the prominences. Confident of the results, and considering the popularity of papers on erupting prominences, I expected high interest in our observations and planned to give a presentation at a next professional meeting.

When I gave my first oral presentation on the rolling motion and its thought-provoking details, several of my most highly respected colleagues could not accept these results and 
vehemently brought arguments for alternative interpretations. Their arguments were reasonable. One argument was: if twist were to develop in a prominence, it would have to begin at the foot-points, not at the top because there was no force in the corona that could make the motion start at the top; thus one colleague suggested that the motion would have to be induced at the photospheric foot-points and would rapidly collect at the top of a prominence. Another colleague said that our observations should be more correctly interpreted as a single sign of twist; if one bends a flux rope (by definition having a single sign of twist) into an arch like the symmetric erupting prominence, and looks down on the legs of the arch, we would see what appears as opposite senses of twist. The meeting ended with neither of their objections satisfied by my responses; nor was I dissuaded of the correctness of my results by the thoughtful objections of my good friends. Although these colleagues' arguments are answered with definite proofs in the details of the paper, only time would allow for more clarity on these mysterious motions during erupting prominences. Indeed, further studies would be necessary for the results to be accepted. Other questions that might have been raised which I would not have been able to answer at that time are: Why do only some prominences show the rolling motion as the prominence erupts? Why is there a relationship between the directions of roll and of chirality?

For me, the finding of the rolling in some erupting prominences was not just another finding - it was the beginning of my complete re-education on how prominence spines and barbs behave during an eruption. The $\mathrm{H} \alpha$ Doppler observations combined with high-cadence EIT 304- $\AA$ images made it clear that this sideways rolling of the ascending prominence ribbon in a symmetric eruption creates large-scale counterclockwise twist in one leg and clockwise twist in the other leg, as revealed by the mass flowing along the fields in the legs. Such a twisted ribbon with both senses of twist has quite a different structure from a magnetic flux rope. I took it to be the Sun's elegant confirmation that prominences are broad flat ribbons (or current sheets) that are readily distorted into a myriad of forms. As explained in Section 2.17, I previously thought it might be possible for filaments to develop flux-rope type twisted structures having the same chirality as their barbs. I am grateful the Sun proved my earlier conceptual picture to be wrong. Filaments could not turn into flux ropes in the process of erupting because that would be completely inconsistent with all of the observations of the rolling of the sheet-like spine during some erupting prominences, as later ascertained from STEREO observations as well as $\mathrm{H} \alpha$ Doppler shifts.

The Sun taught me that she reveals her secrets when and where she pleases, not according to our wishes. She was not at that time giving me any other clues about the reasons behind the mysterious rolling motion in erupting prominences. It was time for further reflection and simmering new questions. What could cause the roll effect in erupting prominences to begin at their top? Equally puzzling was the question: Was the correlation of the direction of roll really due to chirality or a happenstance of the strong association of chirality with hemisphere?

\subsection{Projects with Post-docs at Helio Research}

My generous friend and long-time colleague Karen Harvey passed on due to cancer in 2002. Her husband, Jack, quietly coped with the greatest sorrow in his life. It affected us all deeply; Karen was an integral part of the PROM team since the beginning (Figure 10). She was a coInvestigator on two of our team grants, but had been unable to complete the work due to her illness. My first thought was to complete her part myself, but I was intuitively uncomfortable with that choice.

Months drifted by with Karen's part of the funding unspent and the work undone, until the pressure to complete that part of our grant obligations finally prompted to me to ask 
myself: What would Karen have liked the most? Then, as so often happens when we arrive at the "right question", the answer was obvious: Karen liked to encourage young people, which I could easily do by creating internships or short-term post-doc positions at Helio Research. The other pieces to the solution were waiting to fall into place. After first getting approval from the grant agencies and announcing the position, Yong Lin, then finishing her Ph.D. at the University of Oslo, applied. Her thesis on prominences made her our best candidate. We offered her a 6-month position related to one grant. A 3-month position on the second, smaller grant was offered to Kasia Mikurda from Poland, who was finishing her Ph.D. in Germany. These first two post-docs at Helio Research arrived eager to learn to use the telescope and begin research projects.

Kasia Mikurda's project was to analyze how two filaments merged, and make movies of the process from both Helio Research images and 304- $\AA$ images from EIT on SOHO. She found the connection between the initially separate filaments was first visible in the $304-\AA$ images and later in $\mathrm{H} \alpha$ confirming an earlier observation (Anderson and Martin, 2005). In $304-\AA$ images and the $\mathrm{H} \alpha$ images, the connecting threads were seen in projection against the disk, first in the threads of the high spine, and last in the lower filament structure.

Yong brought data from observing runs on the Swedish Solar Telescope (SST) with her. Based on the SST observations, she had already begun a paper on the fine structure and mass motions in a filament and surge. This was also of great interest to me. We completed that study first for Yong to present at the coming COSPAR meeting in Beijing (Lin et al., 2006). She then undertook what I thought might be an impossible task, making a movie of a new large coronal cloud prominence. It was the first of that type of prominence recorded at Helio Research. The prominence was $200000 \mathrm{~km}$ high and so faint that it took $40 \mathrm{sec}$ exposures and use of an occulting disk at prime focus to adequately record it. Further, the telescope tracking was poor as it was so high above the limb. Nevertheless, Yong was able to align the frames and make a useful and enlightening movie. The topic of coronal cloud prominences was already one of mutual interest and discussion with her former advisor and our colleague, Oddbjorn Engvold. The movie confirmed that this coronal cloud prominence was not like the prominences and filaments we were analyzing and discussing in our PROM team research. It clinched our decision to continue searching for other examples of coronal cloud prominences while going on to pursue another paper that made more use of Yong and Oddbjorn's SST data.

The high-resolution SST images taken by Yong and Oddbjorn were the best ones available for showing how chirality is due to filament threads and is similar for active region, intermediate and quiescent prominences (Martin, Lin, and Engvold, 2008). We began a paper to answer questions about the filaments that often arose in discussions with colleagues: Do we think that active region prominences require a different model from quiescent prominences to explain their existence? How does one in practice distinguish between dextral and sinistral filaments? How do we determine the direction of the magnetic field along filaments from their chirality? We realized that answering this third question was the same as resolving the 180 degree ambiguity in magnetograms (Martin, Lin, and Engvold, 2008). We settled on writing a paper that would answer these questions and at the same time would show that finding the chirality of a filament channel or filament (or any other associated feature in the same chiral system), is analogous to resolving the 180 degree ambiguity in magnetograms. The $\mathrm{H} \alpha$ method of resolving the 180 degree ambiguity was not broadly known and had not been mentioned along with other ways of resolving this ambiguity using only magnetic field data (Metcalf et al., 2006).

Yong and Oddbjorn had enough varied examples of high-resolution SST H $\alpha$ images that we would be able to show how to identify chirality, and to also deduce the direction of the 
magnetic field along the prominence spine and barbs from the direction of their threads. We could do this for a range of filaments from active region, through intermediate cases, to quiescent ones. We could also clarify how errors can be made in determining chirality if the spatial resolution in $\mathrm{H} \alpha$ is not high enough to resolve filament threads. The high quality of the SST $\mathrm{H} \alpha$ images was sufficient to dispel the mistaken notion that the filaments that form in filament channels can have a mixture of dextral and sinistral barbs. The thread structure definitively reveals the sign of the chirality of barbs and that their ends are parallel with the chromospheric structure revealing the same sign of chirality. The mistaken alternative idea comes from observations of too low resolution in $\mathrm{H} \alpha$ to see the threads along with gaps in the visibility of threads. Such gaps are common between the spine and the more dense feet of barbs close to the chromosphere. In low resolution, a succession of adjacent foot-points and their partially visible threads can be mistaken as a barb. This results in the misinterpretation of field direction by about 90 degrees, enough that a dextral barb can be mistaken for a sinistral barb and vice versa.

We concluded that separate models are not required for active region and quiescent filaments because both, and all intermediate cases between these two extremes, have the same fundamental structure. However, we then needed to add: separate models are required for spines and barbs because spines can form without barbs but barbs could not form without a spine (although a spine can be invisible in $\mathrm{H} \alpha$ ). Therefore, barbs have a different starting condition, namely spine threads. Thus barbs do require a different model from spines. This paper was still in progress when Yong's post-doc term was finished.

After their respective post-doc intervals at Helio Research, Kasia went on to new work in Texas and Yong returned to Norway for her next post-doc position. Yong, Oddbjorn, and I followed through on the above paper and another paper based on the SST data. The next paper was focused on the three-dimensional structure of filaments and the field-aligned nature of filament threads (Lin, Martin, and Engvold, 2008).

As far back as 1971, Peter Foukal (1971) had shown that fibrils of filament channels in $\mathrm{H} \alpha$ were like little arrows pointing in the direction of the local magnetic field. The possibility that $\mathrm{H} \alpha$ chromospheric structure is an elegant kind of magnetograph was made early by George Ellery Hale (Hale 1908a, 1908b, 1908c) and Richardson (1941) for the superpenumbral fibrils around sunspots. Considering all of the studies that now confirm the field-aligned nature of filament threads one may ask: Why is it taking so long for this key information to be broadly used as the basis for modeling filaments?

\subsection{The Buildup to CMEs and Insights on the Roll Effect}

In 2006, our PROM team research grant for research on "The formation, evolution and chirality of filament channels: a physical basis to elements of space weather" was renewed. It specifically included a post-doc position. After the grant was in place, near the end of the year, we advertised the position, and in early 2007, I hired Olga (Olya) Panasenco, who had recently come to the US from Moldavia. She had earned a Ph.D. in the department of physics from Moscow State University, but she had not yet found a position in the US. We began our first paper and I introduced her to our system of acquiring research funding through the work of writing grant proposals.

The SOHO 20 Meeting in 2007 marked the 12th anniversary of the launch of SOHO, then 10 years beyond its expected lifetime. I especially wanted to attend this meeting because one of the topics, "The Build-up to Coronal Mass Ejections" was of particular interest relative to our grant work on the Development of Filament Channels and Filaments. I suggested to Yong, Oddbjorn, and Olya that we write an abstract on our research that was appropriate for 

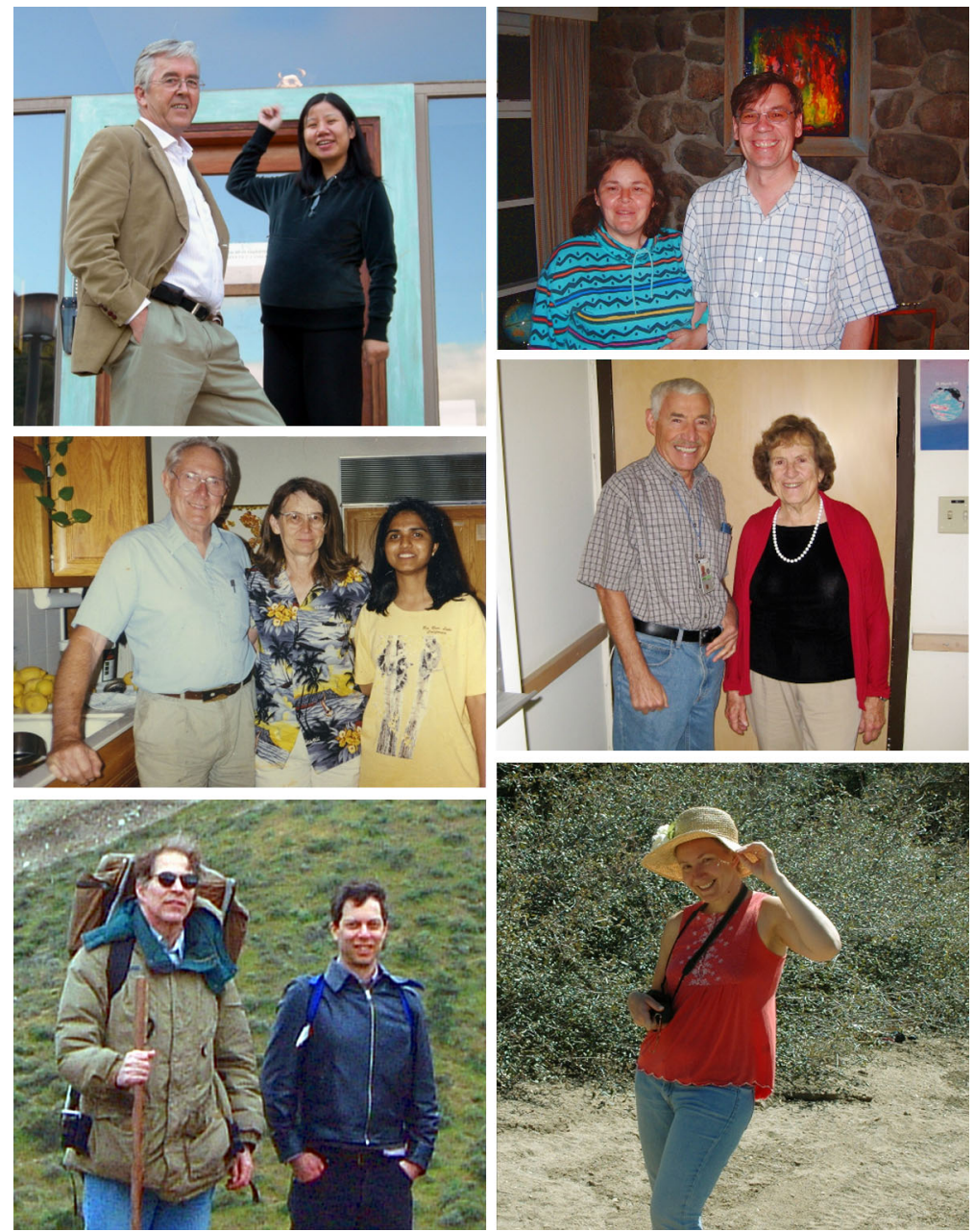

Figure 11 Some friends and collaborators who worked and/or visited at Helio Research. Upper left: Oddbjorn Engvold and Yong Lin, then working at Oslo University, Norway. Upper right: Alex Pevtsov from the Sacramento Peak Observatory, New Mexico, USA, with his wife, Elena. Middle left: Doug and Sara Martin in La Crescenta, California, USA with Nandita Srivastava from Udaipur, India. Middle right: Alexander Ruzmaikin and Joan Feynman both associated with the Jet Propulsion Laboratory, Pasadena, California, USA. Lower left: Martin Woodard, previously a colleague in the Caltech solar astronomy group, and Mitchell Berger from the Exeter College in England. Lower right: Olga Panasenco, then at Helio Research in La Crescenta, California, USA.

that session. Preparing for the SOHO 20 meeting put us on an expanded track of research going beyond our studies of filament channels and filaments. Our paper for the session on CMEs (Martin et al., 2008) became the foundation of our next PROM team research proposal.

The PROM team proposals and collaborations, as well as grant research funded by NASA, often provided reasons for work visits from colleagues or for me to visit them. Snapshots of various colleagues and friends are shown in Figure 11 from around 2004 onward. 
The 2008 PROM team proposal came at a critical financial juncture. Helio Research needed new funding if Olya was to continue with us. She and I spent a lot of time and effort together with the PROM team getting a new proposal done by the applicable NSF program deadline. After submitting it, however, I had many doubts about how well we had written it; the basic idea was good, but it seemed much too disjointed to get laudable reviews. After a few days of stewing about it - and for the first time in my career - I proposed to the team that we take the risk of withdrawing, rewriting, and resubmitting it as an unsolicited proposal. The extra effort paid off. The revamped proposal received excellent reviews and we received the award. However, we had not put all of our eggs into one proposal basket. Olya and I also had written a successful proposal for the SHINE program to seek evidence for physical links between emerging flux regions and active regions. We wrote another successful proposal to NASA to do research on the helicity of erupting prominences, in order to further explore our latest findings of the roll effect in erupting prominences. With these three projects including support for summer students, we were relieved of the necessity to submit new proposals for at least the next two years and could concentrate fully on our research.

By that time, Olya was also thoroughly intrigued by our earlier findings on chirality and my additional finding of the roll effect as a form of dynamic chirality (Section 2.21). She found a movie of the Grand Daddy prominence of 1946 June 4, and we looked up and read Pettit's report of his observations of it from Mt. Wilson (Pettit, 1946). A sequence of images of this erupting prominence is shown in Tandberg-Hanssen (1974, Figure II.2). Pettit clearly describes the sheet-like character of the prominence prior to its eruption and we could see that it is a typical polar crown filament. We knew that the sheet-like character of filaments was incompatible with the popular interpretation of the Grand Daddy prominence as a flux rope although the crossing thread structure in the line-of-sight gives the impression of a giant flux rope. Hence Olya and I studied the Grand Daddy movie carefully. Unfortunately, the movie starts after the eruption began. Hence, the prominence is already changed from the sheet-like appearance Pettit originally described. Therefore, the movie does not show the roll effect developing. However, near the edges of the movie, twist of opposite sign is revealed in the mass flows down the two legs of the erupting prominence, a key signature of the roll effect. However, as pointed out previously by Rust (Section 2.21), this is not an adequate test to distinguish a rolling sheet from a rope-like structure without spectra or Doppler observations of the mass motions. More observations revealing the three-dimensional structure of erupting filaments would still be needed to show that the rolling motion was typical of many quiescent prominences. We looked into old records as well as new observations.

In 1947, Ellison made a drawing of the opposite signs of twist in the mass flows down the two legs of another "eruptive arch" he observed but did not photograph on June 11, 1947 (Ellison, 1947, also mentioned in Ohman, 1969). While visually observing spectra of the prominence as it erupted, he was able to measure the velocity and direction of motions at the top of the prominence as well as in the legs. His drawing shows this eruption to be a superb example of the roll effect. Like other early observers, Ellison had the advantage of taking spectra or spectro-heliograms but the disadvantage of being unable to record at a sufficiently high cadence. Now, even with the increased use of filters for rapid imaging, it remains a challenge to obtain sufficient images at multiple wavelengths to correctly interpret the mass motions of many examples of erupting prominences.

We were able to find and verify more examples of the roll effect in erupting prominences in new observations from the STEREO satellites. Also we found evidence for additional cases in the EIT 304- $\AA$ data from the EIT experiment on board the SOHO satellite (Panasenco and Martin, 2008; Panasenco et al., 2011). By 2008, we felt the evidence was then sufficiently solid to propose a study to NASA in which we would search for the cause 
of this rolling in some erupting prominences. For expert assistance in interpreting the helicity of erupting prominences, we asked Mitch Berger (shown in Figure 11) if he would join us in this proposal and he agreed. Some of the key questions we would address were: Why was the roll effect correlated so perfectly with the other forms of chirality? Why did not all erupting prominences show this rolling motion? Was it like the hemispheric bias of chirality; i.e., would exceptions to this association with other forms of chirality be found?

Olya had also become fascinated with various coronal structures and configurations associated with adjacent filaments that erupt one after the other with varying intervals between them. She began applying Potential Field Source Surface (PFSS) modeling as a first approximation to large-scale coronal structures. Despite the limitations in this type of modeling, the answers to our questions about the roll effect in erupting prominences came tumbling out one after another. She found that the roll in erupting prominences was always away from a nearby coronal hole! Also it became clear that the rolling motion rarely occurs in active region prominences without adjacent coronal holes. Lastly, she found an exception to the one-to-one relationship of the direction of roll with the chirality of a filament. We concluded that the previous one-to-one relationship for these parameters was a happenstance occurrence related to the hemispheric bias (Panasenco et al., 2012). Olya also had confirmed the findings of others that the non-radial propagation of CMEs was away from coronal holes. However, it was new for us to learn that erupting filaments were non-radial in the same overall direction as CMEs but were substantially more non-radial than their counterpart CMEs.

\subsection{Preconceptions, Misconceptions, and Illusions}

What is often not stated is how key errors - unintentional ones - come about. Stated broadly, preconceptions create misconceptions. Viewing the Sun in single wavelengths can be misleading because what is invisible in one wavelength might be detectable in another. The idea one gets from one view or preconceived model can cause one to misinterpret what one sees in another case. The Grand Daddy prominence, often mistaken as large-scale magnetic flux tube or flux rope, is a prime example; the observer's description has been largely overlooked (Pettit, 1946).

In addition to the lack of more complete observations during the early development of the Grand Daddy erupting prominence, there were no spectra or Doppler observations in $\mathrm{H} \alpha$ which could have shown it was a partially rolled sheet of threads rather than a flux rope. The Grand Daddy prominence seemed a great confirmation of other examples of erupting prominences in which twisted structure was observed during their eruption. Belief that erupting prominences were flux ropes deepened because they were a means of explaining the observed twist and were relatively simple to visualize and model. With so many factors contributing to the entrenchment of the idea that erupting prominences are flux ropes, most investigators, who are already convinced that this idea is reality, will not think to look for evidence of two signs of twist in the same prominence, or evidence that filaments are not flux ropes. The veil of preconception blinds us to the natural process of questioning. Skepticism of alternatives to strongly held concepts then temporarily dominates full questioning. From observing these subjective human factors coming into play in ourselves, I anticipate very slow general recognition that erupting prominences are not flux tubes or flux ropes with a single sign of helicity.

As high-resolution observations of prominences accumulate, along with coronal structures in their immediate environment, there will be many future debates about the nature of prominences. The concept that prominences are flux ropes or become flux ropes during their eruption will not easily be dispelled. It would not be surprising if some believers in 
flux ropes would try to change the definition of a flux rope to fit observations rather than to acknowledge that filaments as a whole are not flux ropes nor do they become flux ropes.

A corollary to the idea of flux ropes is that the magnetic field of prominences unwinds during eruption. This conclusion has been drawn in quite a few published papers over the history of prominence research and often without discussion about whether this is possible or under what circumstances unwinding could be possible. Observations show that some filament ends are well anchored to the photosphere and remain well anchored throughout the visible phase of their eruption. Then, how could their magnetic structure unwind?

The expansion of the fields during eruption can also result in observed twist being misinterpreted as unwinding whereas the twist might only propagate to another part of the erupting event. Alternatively, twist in an erupting prominence could be amenable to interpretation as unwinding or partial unwinding if, or when, either or both legs reconnect with other coronal or chromospheric field. As a consequence of that form of reconnection, an erupting prominence would acquire different foot-points, and in so doing, could possibly lose (or gain) twist in exchange for helicity in the form of writhe. Examples of foot-point changing have been observed and described by Wang, Muglach, and Kliem (2009), but it is not yet known how common foot-point exchange is. The point here is that research papers are often both written and reviewed without either the authors or reviewers considering alternative possibilities for interpretation. One of the consequences is that graduate students often believe what is published and are seldom advised to question whether the conclusions of research papers are entirely valid.

The Grand Daddy prominence was not my only wake-up call about possible illusions in the observation of solar events. Counterstreaming in red and blue wing observations of a filament was already another prime example. My own strong impression, from center-line observations, that the mass motions in filaments were turbulent, prevented me from earlier recognition that counterstreaming was not just an occasional, but rather a fundamental property of prominences and filaments that have spines and barbs. The frequent impression of turbulence had become a working assumption. Looking for signs of a high degree of organization in the flows consequently never crossed my mind, and likewise, had not crossed the minds of many colleagues. The medium-resolution, 18-day movie of a solar prominence recorded at Helio Research reveals how counterstreaming in solar filaments and prominences can easily be mistaken for turbulence. In the sections of the movie that were recorded on days with good seeing conditions, the prominence clearly shows counterstreaming in its thread structure. When the seeing is poor, on the other hand, the same motions appear chaotic. Observing counterstreaming throughout a prominence for the first time had been a complete - and almost unbelievable - surprise. And little did I know that other astounding surprises from observing counterstreaming were yet in store!

There are other illusions in solar images and movies but, for me, these will remain for entertainment in life after writing a memoir, except to mention tornado prominences. Olya and I have found that prominences, recently claimed to be tornado prominences, are instead elegantly tricky illusions. The illusion of rotational motion is created by the interleaved counterstreaming threads in the giant barbs of quiescent filaments that have little or no visible spine (Panasenco, Martin, and Velli, 2014). Solar illusions are most entertaining and humbling after one has been trapped into erroneous belief by one; I was a long-term, faithful believer in tornado prominences until learning about counterstreaming threads throughout filaments and prominences. During post-memoir years, I will welcome the question: What other illusions is the Sun displaying in plain sight that we have yet to discover? 


\subsection{Lessons Learned from Exceptions to the Hemispheric Pattern of Chirality}

The question of why there are exceptions to the hemispheric pattern of chirality had often been raised in our PROM Workshops. The pattern is that most filaments in the northern hemisphere are dextral and most in the southern hemisphere are sinistral. Cases that are opposite are called exceptions. Jack Zirker gave an interesting report at one PROM working group meeting on earlier proposed explanations for the exceptions, and why each was not satisfactory. Eventually, answers were found, first by Yeates and Mackay (2009), and through a different method by our summer student, Alexander Wen and me (Martin and Wen, 2010). At another PROM working group meeting, Yeates and Mackay were first to say they had identified the reasons for the hemispheric pattern of chirality; they attributed it to a number of parameters. Although they could identify the exceptions in their modeling, they did not offer a means by which others could readily identify the exceptions. For me, the question remained: Could there be a simpler answer? This provided a timely project for our next summer student, Alexander Wen. Without referring to Yeates and Mackay, we started with data sets for which we had already identified the chirality. We created our own list of the parameters we could measure and which might provide clues to why the exceptions existed. Alexander also tabulated and measured our candidate parameters for a second, larger interval of filament data in a different phase of the solar cycle. Then we began testing each parameter for its importance. One after another failed to show a significant relationship to the exceptions versus the filaments that were consistent with the hemispheric pattern.

We had made some work prints of magnetograms and filtergrams to make it easy to compare many different examples side by side at a conveniently large scale. All else failing to give a correlation, we began putting the examples together into groups according to how the exceptions had evolved. Only then did it become clear that the filament channels and filaments that were exceptions to the hemispheric chirality had all evolved north or south of other active regions in the northern or southern hemispheres, respectively. Referring then to Yeates and Mackay's paper, the relative location of the exceptions was included in their list. Our independent confirmation of relative location as a key parameter and more specifically, relative north-south location, was nonetheless satisfying; we had arrived at that same conclusion with added clarity and by a different approach. I was just as happy as if we had been first to find the answer or the tenth to find the answer. By finding the answer ourselves and illustrating it in a different way, we had not only learned the reason for the exceptions but had learned the exceptions should be predictable directly from images.

In retrospect, Alexander and I had not initially included the key parameter in our investigation but still had found it. This is one of the fascinating things about research. In hindsight, it would have been possible for us, or anyone, to go directly to the answer with much less work than expended by either Zirker, Yeates and Mackay, or ourselves. However, we did not define the question that would have made that possible. If only any of us had thought to ask: Are the relative positions of adjacent active regions important in determining their chirality? Then a simple analysis could have yielded a direct "yes" or "no" answer. However, we all had asked enough questions to eventually find the answer. Thus I advise students that "Questions are just as important as answers".

Sometimes questions can be answered by a thought experiment. In the above case, imagine that active regions only formed in a longitudinal ring with their bipolar magnetic fields oriented north-south instead of east-west as observed. What would be the effect of differential rotation on filaments related to the polarity boundaries in or around these hypothetical active regions? The answer is that differential rotation, acting on filaments in and between these active regions juxtaposed north or south of each other, would result in a 180 degree 
reversal of the observed hemispheric pattern. In this hypothetical situation, filaments in the northern hemisphere would be dominantly sinistral instead of dextral and all of their chiral associations with other features would similarly be reversed. In this way we could also have arrived at the hypothesis that the relative juxtaposition and orientation of active regions together with differential rotation acting on them are factors needed to understand both the reason for hemispheric pattern and the exceptions. Testing this hypothesis, would have been much easier than the approach we took. However, no single approach to solving a problem (modeling, observational analysis, conjecture and testing, or other), is better or worse than the others. Each has its merits and each complements the other when the true answer is found. However, if complementary results are not achieved, are we willing to rethink and requestion?

\subsection{The DOT Prominence Project}

As we approached the second year of the latest PROM team grant in 2009, Olya and I were attending the annual Sacramento Peak summer Workshop, then held in the fall. Olya's talk was on spicules and prominences (Panasenco, 2010) and mine was a review of little understood properties of filament channels (Martin and Panasenco, 2010). As I was walking to lunch on the second day, Rob Rutten, from the University of Utrecht, joined me, and asked if I (representing the PROM team) would like to have essentially all of the observing time at the Dutch Open Telescope (DOT) on La Palma in the Canary Islands for the next season! (This was 2010 spring to fall.) Astonished by the offer, I wondered if he was joking - nowhere in the world could one group have so much observing time on a major solar telescope! Rob soon explained that his efforts to find funding for the DOT had not been sufficiently successful and the idea of our team using the DOT had just come to his mind during my talk as a possible solution to his dilemma. Settling into serious thinking, I could see that his timing synchronized amazingly well with our situation. We had a little over two years remaining on our current grants and had proposed the acquisition of data on other high-resolution telescopes for each year of the prime PROM team grant titled "Collaborative Research: Testing a New Concept for the Long-term Build-up to CMEs". Obviously, several months of continuous observing on one high-resolution telescope for our proposed research would be much better than a maximum of about three 10-14-day observing intervals on the DOT or other comparable telescopes. So I suggested that I next talk with our team members. Those of the team at the meeting enthusiastically agreed this was a great possibility and that we should continue to explore this with Rob Rutten. After several more discussions with the team members and with Rob, he and I each optimistically agreed to contact our other colleagues to see if all other affected persons, at our respective institutions and Co-Investigators on the PROM team, would also be in agreement with his new idea. Indeed, they were!

I knew we were eligible for a grant supplement, but the time was short. Our grants monitor at NSF, Paul Bellaire, readily caught the significance of this wonderful opportunity and called my attention to a relatively new special program called a Rapid Award. The Rapid Award program was designed to fund exceptional opportunities to augment a current research grant. We applied for and received this one-time-only auxiliary grant. This gave us just enough to cover the minimum operating costs for the DOT for six months, an initial three-week training program for observers new to the DOT, and travel and living expenses to maintain one scientist and one observer at the DOT for the duration of the project. We began observing at the DOT in May 2010. Paul Bellaire was good at keeping NSF grants lean and that was natural for us. We had already learned that the least expensive but reasonable accommodations for our training program on La Palma would be to rent three small houses 


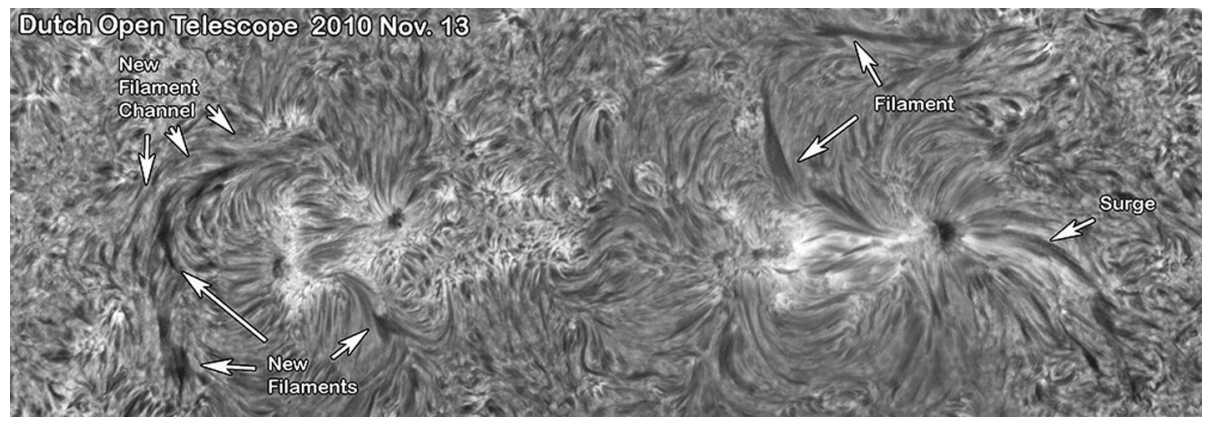

Figure 12 An $\mathrm{H} \alpha$ mosaic image from the Dutch Open Telescope on 2010 November 13. This image is a composite of an array of $6 \times 2$ spatially overlapping images taken consecutively between four other wavelengths in the wings of the $\mathrm{H} \alpha$ line.

for the training program at much less than the cost of staying at the professional astronomers residence building on La Palma. Of course, that meant cooking most of our meals ourselves. We continued to rent just one of the houses for the remainder of the project. Participating in our observer-trainee group were Eugene Romashets, Anand Joshi, Alena Kulinova, and Andrii Sukhorukov. The experienced training scientist for all of we observers was Vyacheslav (Slavik) Olshevsky. Alan Kiplinger, volunteered to implement his cloud removal algorithm for us. Marcia Knowlton was our volunteer cook and her husband, Prentiss Knowlton, a programming specialist, volunteered as a handy-man to help with any task needed to keep the focus of the group on the project. The volunteers contributed their time for the experience gained plus their airfare to and from La Palma along with accommodations. As project coordinator, I cannot thank everyone too much.

The technical logistics throughout the project were not easy. We were embarking, unknowingly, on a project that required more software and expertise than most of us yet had with observing at the DOT. Among the existing software was a sophisticated speckle reconstruction program written by Piet Sutterlin. Our goal was for all of the observers to learn how to take and implement the speckle reconstruction in addition to observing. There were few unbusy moments for any of us. Our Dutch colleagues, Guus Sliepen and Rob Hammerschlag, worked long hours and helped solve many small problems. I was highly pleased with the quality of the data, the broad range of data types that we could obtain, and with the sophisticated level of the observing software. Many days of 5-10 hours of observing were possible between shorter intervals when mountain top clouds, occasional rain storms, infrequent desert dust storms and rare high winds stopped all observing. We maintained the Dutch policy that the data sets are open and a list of the data and available movies are on the DOT website. A composite of a $6 \times 2$ array of images made into a single composite image is shown in Figure 12.

Seeing our need for additional software, Guus Sliepen began early in the project to write a new program to provide the quick-look movies which did not exist at the outset of the project. These were essential for any participant to evaluate the scientific merit of our long data sets at multiple wavelengths. After becoming experienced in the data acquisition, we were encouraged to use existing software to acquire "mosaic" data sets. In essence, creating the mosaics is giving the data sets a larger field-of-view than the telescope by successively pointing the telescope in a chosen pattern of adjacent fields-of-view.

How to handle the mosaic data sets was a tougher question. Quick-look movies which rapidly cycled through mosaic data sets of a succession of adjacent fields-of-view did not 
allow one to make any meaningful evaluation of these data sets. Fortunately, Guus figured out that he could use the information that had been stored about the telescope's guidance to combine the images. He brought the first freshly made mosaic movies to our Workshop on La Palma at the end of the observing phase of the project. The mosaic movies were seamless, remarkably well-aligned, and a tremendous success. The very first one he showed revealed spectacular counterstreaming in a filament on November 24, our last good day of observing before concluding the project. The techniques of movie-making from the mosaic data sets are described by Hammerschlag et al. (2012).

Weeks later after everyone was back at their home institutions, this same mosaic data set gave us a major novel result from our effort. While mass had long been seen flowing downward in prominence movies, the source sites of mass flowing into filaments had seldom been observed and details of the generation of counterstreaming remained a mystery. The data in the wings of the line cleared this mystery by revealing mass coming into the filament from source sites in canceling magnetic fields, and also going into sink sites, close to the source sites, where mass returned to the photosphere.

One of the most significant changes in observational research during my career has been the computer-enabled change-over to recording observations on digital media instead of film, and the subsequent relative ease and rapidity of digitally processing images to achieve similar results to that achieved from processing data on film. This change also enabled the acquisition of greater quantities of data, and in turn, the need and opportunity to develop ever more sophisticated software to sort and process the data for viewing, measurement and analysis. We used to have to wait for the lab to develop the film, and then spend hours viewing and reviewing it to extract the data "by hand". Now we work and wait to obtain funding for programmers to tailor the software as we increase our requirements for handling larger and more complex data sets. Much progress has been made in this regard, which not only facilitates our own work, but also facilitates the open exchange of observational data with our colleagues. Who knows what questions, and eventually answers, will come from this greater exchange of data and ideas?

\subsection{From Chirality to Chiral Systems}

The series of discoveries in the 1990s about the chiralities of solar features was for many years a novelty. No one completely understood their meaning and yet most scientists in our field believed that this handedness, of filament channels and filaments, represented helicity and thought it must be important. Aad Van Ballegoojen, Duncan Mackay, and Anthony Yeates were among the first scientists to purposefully seek to incorporate helicity into their modeling and to try to make their large-scale and global models consistent with the observed forms of chirality (Yeates, Mackay, and van Ballegooijen, 2007). One of the mysteries was: Why do filaments at high latitude not change their forms of chirality with time due to the action of differential rotation?

Some of the early PROM team papers address the question: What is the significance of the chirality of given solar features? The global modeling of van Ballegooijen, Mackay, and Yeates certainly gives clues about their significance while demonstrating that the question can be well addressed through modeling. These models are some of the best for understanding the long-term evolution of solar features. However, initial modeling of the semblance of features does not mean they are fully understood. If we are to make new discoveries, if we are to more fully understand, we always need to ask: Are the assumptions that go into such modeling correct? What information was left out in order to make a viable model? These questions need asking over and over again about any model or any concept developed by scientists. 
Our recent PROM team observers' paper - "The Significance of Chiral Systems from the Perspective of the Build-up to Solar Eruptive Events" (Martin et al., 2012) - addresses the broad question: What is the significance of chiral systems? The new term "chiral systems" follows from the earlier findings that there are one-to-one relationships between the chiralities of all solar features related to a given filament channel above a given polarity reversal boundary. More completely than my earlier paper (Martin, 1998a), this research team paper clarifies the definitions and verifies that there are two and only two sets of chiral systems within which the chiralities of all features fit to date. Without going into further details here, this paper presents an over-arching hypothesis composed of an array of lesser hypotheses for further evaluation. In summary, the Sun organizes solar activity such that each eruptive solar event is the result of one or more developing chiral systems. The paper presents the observable stages, or developments, that culminate in an eruptive event. Thus each stage entails also one or more smaller hypotheses that contribute to the overall concept. To bring the subject "down to Earth", we may consider that hypotheses are just questions phrased so as not to need a question mark at the end.

In hindsight, I could not see until polishing the above conceptual paper that the majority of my career, both individually and with colleagues, has been occupied with the development of this hypothesis. Numerous studies throughout my career along with many studies of my colleagues have somehow contributed to it, more in invisible than visible ways. Many thanks to my dear friends and colleagues who are co-authors. A peculiar feeling comes over me in realizing that most of a career can be summed up in the nutshell of a single hypothesis. It does seem fitting that the major hypothesis and the smaller hypotheses within it are questions left open at this closing of this memoir.

\subsection{In the End}

The satisfaction of working as a scientist for me has been as much in seeking questions as in finding answers. Indeed, the answers invariably are the spring board for new questions. In my view it does not matter if we are the first, or the tenth, or the hundredth to discover something. What matters is that we are involved in the inner joy of having our view expanded. Nor does it matter whether our discovery is small or big. The smallest thing might give the greatest joy. And the biggest we are likely not to ever fully comprehend.

This memoir unfortunately does not include all of the numerous people with whom I have collaborated or shared ideas. I hope you forgive me; so very much more has been skipped over than highlighted here! For example, in Figure 13 are friends and colleagues who have collected at the occasion of celebrating 100 years of observing at Mt. Wilson sponsored by Roger Ulrich in 2012.

I now wish I had a picture of each and every colleague not mentioned here who in many small or large ways helped me personally or through their insight into physical processes. Ideas and questions do not occur in a vacuum. The origin of the questions that occur to us probably come from a lot of processing of stored information from intermixed sources whose identity is long gone. Somehow we tend to think our questions are from our own minds. Better that we regard them as a gift because we do not really know how our minds work and are quite lucky to have been given one.

There has been much joy and intrigue in asking questions and seeking the truths along with colleagues who share, or oppose, or remain indifferent to our questions. At various times along this path, I have experienced delight, joy, frustration, exhaustion, and sobering lessons from asking questions. The most important things I have learned as a scientist are not the scientific facts and ideas but rather the lessons in life that have come while struggling 


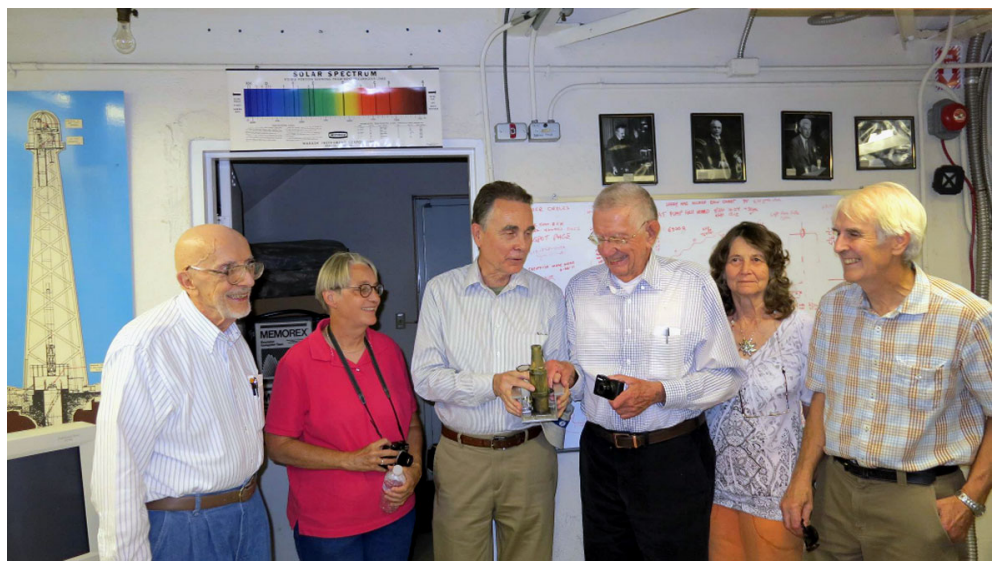

Figure 13 Discussing a historic piece of equipment in the observing room of the 100-ft Tower Telescope at Mt. Wilson. From left to right are: Bob Howard, Pam Gilman, Jack Harvey, Bill Livingston, Sara Martin, and Roger Ulrich. Photo taken during the Celebration of 100 years of Observing at Mt. Wilson in 2012 hosted by Roger Ulrich.

Figure 14 Doug and Sara Martin pausing in their sauntering through the wilderness of time.

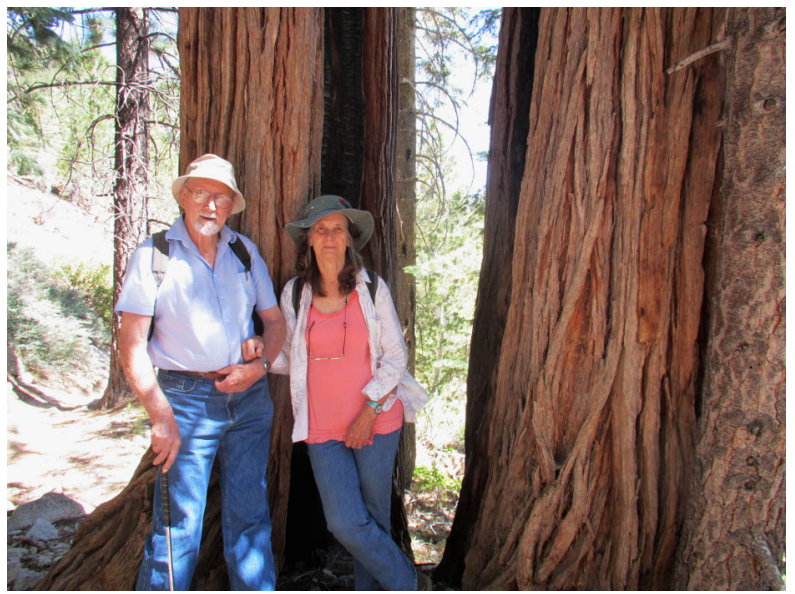

to become and then being a scientist: to greet with acceptance and determination all the unwanted tasks necessary to continue to work in science, to be unafraid to defend what my conscience tells me to do, and to love and appreciate without exception all of my colleagues and friends who have shared parts of my life journey.

Stepping into the future, I see myself sauntering at a slower pace (Figure 14), sharing science with friends, colleagues, students, and amateur astronomers, and all who are attracted to questioning many mysteries.

Acknowledgements I wish to express enormous appreciation to my family who are little mentioned here but who have been the most important part of my life. My brother, Alan Higgins, assisted with major editing of this memoir, while Doug Martin and cousin, Nola Almany, helped polish the final draft. I wish to give special thanks to the colleagues who have served as past and present members of the Board of Directors of Helio Research: Scott Carpenter, John Lawrence, David Hurst, Tony Heinzman, Wayne Rogers, Joan Feynman, and Doug Martin. I thank Joan Feynman also and her husband Alexander Ruzmaikin, each for many science discussions and joint work on research papers, proposals, and grants. 
Other persons, not yet mentioned, who contributed to the success of Helio Research are Eric McDonald and John Rogers, who successively helped with developing and interfacing telescope cameras and equipment to computers, Peter Zink, Rosalie Ewald, and Brittany McCrigler with observing and data analyses, Kay Meyer with book keeping, observing and data reduction and thereafter, Susan Keithly with bookkeeping. Full-time summer undergraduate or graduate observers and/or assistants were: Michael Anderson, Tokuo Nakamoto, Jason Geiger, Vlad Lazar, Yashar Agah, Paul Killam, and Mariam Mikhtarian. Aram Panansenco worked summers and part-time, primarily writing programs for data analyses. Jonathon Schiralli and Aparna Venkataramanasastry were interns for three months each in the Master's degree program at the University of North Dakota. Brigitte Ragot contributed as an independent scientist with proposals and grants in the area of interplanetary particles of solar origin.

Many thanks to colleagues and students who participated in the 2010 DOT prominence project and to Paul Bellaire at the National Science Foundation, who recognized the significance of this project.

Open Access This article is distributed under the terms of the Creative Commons Attribution License which permits any use, distribution, and reproduction in any medium, provided the original author(s) and the source are credited.

\section{References}

Anderson, M., Martin, S.F.: 2005, In: ASP Conf. Series 346, 201.

Athay, R.G., Moreton, G.E.: 1961, Astrophys. J. 133, 935.

Babcock, H.W., Babcock, H.D.: 1955, Astrophysics 121, 349.

Baha'u'llah: 1923, (date first published in English by the National Spiritual Assembly of the Baha' is of the British Isles), The Hidden Words, No. 2, Persian section, translated by Shoghi Effendi (the original text, circa 1850s, located at the Baha'i World Center, Haifa, Israel; currently published by the Baha'i Publishing Trust.

Bruzek, A.: 1951, Z. Astrophys. 28, 277.

Bruzek, A.: 1952, Z. Astrophys. 31, 99.

Bumba, V., Howard, R.F., Smith, S.F.: 1964, Astronomy 69, 535.

Bumba, V., Howard, R., Smith, S.F.: 1967, In: Cameron, R.C. (ed.) Magnetic and Related Stars, Mono Book Corporation, Baltimore 131.

Burlaga, L.F.: 1988, J. Geophys. Res. 93, 7217.

Burlaga, L.F.E.: 1991, Magnetic clouds. In: Physics of the Inner Heliosphere II. Particles, Waves and Turbulence, XI, Springer, Berlin. $352 \mathrm{pp}$.

Cliver, E.W., Laurenza, M., Storini, M., Thompson, B.: 2005, Astrophys. J. 631, 604.

Dodson, H.W.: 1949, Astrophys. J. 110, 382.

Dunn, J.M., Martin, S.F.: 1980, Bull. Am. Astron. Soc. 12, 904.

Ellison, M.A.: 1947, J. Br. Astron. Assoc. 57, 229.

Feynman, J., Martin, S.F.: 1995, J. Geophys. Res. 100, 3355.

Foukal, P.: 1971, Solar Phys. 19, 59.

Gaizauskas, V.: 1998, In: Webb, D., Rust, D., Schmieder, B. (eds.) New Perspective on Solar Prominences, IAU Colloquium 167, ASP Conf. Series 150, 257.

Gaizauskas, V.: 2002, Solar Phys. 211, 179.

Gaizauskas, V.: 2008, Astrophys. J. 686, 1432.

Gaizauskas, V., Mackay, D.H., Harvey, K.L.: 2001, Astrophys. J. 558, 888.

Gaizauskas, V., Zirker, J.B., Sweetland, C., Kovacs, A.: 1997, Astrophys. J. 479, 448.

Gosling, J.T.: 1990 In: Physics of Magnetic Flux Ropes, American Geophysical Union, Washington, 343.

Green, L.M., Kliem, B., Torok, T., van Driel-Gesztelyi, L., Attrill, G.: 2007, Solar Phys. $246,365$.

Hale, G.E.: 1908a, Publ. Astron. Soc. Pac. 20, 203.

Hale, G.E.: 1908b, Sol. Publ. Astron. Soc. Pac. 20, 220.

Hale, G.E.: 1908c, Astrophys. J. 28, 100.

Hammerschlag, R.H., Sliepen, G., Bettonvil, F.C.M., Jägers, A.P.L., Sütterlin, P., Martin, S.F.: 2012, In: Ground-Based and Airborne Telescopes IV. Proceedings of the SPIE 8444. Article id 844406, 18 pp.

Harvey, K.L.: 1993, The Solar Magnetic Cycle, Doctoral Thesis, University of Utrecht.

Harvey, K.L., Harvey, J.H., Martin, S.F.: 1975, Solar Phys. 40, 87.

Harvey, K.L., Martin, S.F.: 1973, Solar Phys. 32, 389.

Hermans, L.M., Martin, S.F., Marquette, W.H.: 1980, Factors related to the eruption of quiescent filaments. Bull. Am. Astron. Soc. 12, 914.

Howard, R., Bumba, V., Smith, S.F.: 1967, Atlas of Solar Magnetic Fields, Carnegie Institution, Washington. 
Klein, L.W., Burlaga, L.F.: 1982, J. Geophys. Res. 87, 613.

Kopp, R.A., Pneuman, G.W.: 1976, Solar Phys. 50, 85.

Leroy, J.L.: 1978, Astron. Astrophys. 64, 247.

Leroy, J.L., Bommier, V., Sahal-Brechot, S.: 1983, Solar Phys. 83, 135.

Lin, H.-S.: 1995a, In: Kuhn, J.R., Penn, M.J. (eds.) Infrared Tools for Solar Astrophysics: What's Next? World Scientific, Singapore, 397.

Lin, H.: 1995b, Astrophys. J. 446, 421.

Lin, Y., Martin, S.F., Engvold, O.: 2008, In: Howe, R., Balasubramaniam, K.S., Komm, R. (eds.) ASP Conf. Series 383, 235.

Lin, Y., Martin, S.F., Engvold, O., Rouppe van der Voort, L.H.M., van Noort, M.: 2006, Adv. Space Res. 42, 803.

Litvinenko, Y.E.: 1999, Astrophys. J. 515, 435.

Litvinenko, Y., Chae, J., Park, S.-Y.: 2007, Astrophys. J. 662, 1302.

Litvinenko, Y.E., Martin, S.F.: 1999, Solar Phys. 190, 45.

Livi, S.H.B., Wang, J., Martin, S.F.: 1985, Aust. J. Phys. 38, 855.

Livi, S.H.B., Martin, S., Wang, H., Ai, G.: 1989, Solar Phys. 121, 197.

Low, B.C.: 1994, In: Hunt, J.J. (ed.) Solar Dynamic Phenomena and Solar Wind Consequences, European Space Agency (ESA) SP-373, 123.

Malville, J.M., Smith, S.F.: 1963, J. Geophys. Res. 68, 3181.

Marsh, K.A.: 1978, Solar Phys. 64, 93.

Martin, S.F.: 1979, Solar Phys. 64, 165.

Martin, S.F.: 1980, Solar Phys. 68, 217.

Martin, S.F.: 1984, Small-scale dynamical processes in quiet stellar atmospheres. In: Keil, S.L. (ed.) Proceedings of the Conference Held in Sunspot, NM, USA, 25-29 July 1983, National Solar Observatory, Tucson, 30.

Martin, S.F.: 1988, Solar Phys. 117, 243.

Martin, S.F.: 1989, Solar Phys. 121, 215.

Martin, S.F.: 1990a, In: Stenflo, J.O. (ed.) IAU138, Kluwer Academic, Dordrecht, 129.

Martin, S.F.: 1990b, In: Rudzjak, V., Tandberg-Hanssen, E. (eds.) Dynamics of Solar Prominences, IAU Colloq. 117, 1.

Martin, S.F.: 1990c In: Societa Astronomica Italiana, Memorie 61, 293.

Martin, S.F.: 1992, In: Švestka, Z., Jackson, B.V., Machado, M.E. (eds.) Eruptive Solar Flares, IAU Colloq. 133, 331.

Martin, S.F.: 1998a, In: Webb, D., Rust, D.M., Schmieder, G. (eds.) IAU Colloquium 167, ASP Conf. Series 150, 419.

Martin, S.F.: 1998b, Living Rev. Solar Phys. 182, 107.

Martin, S.F.: 2003, Adv. Space Res. 32, 1883.

Martin, S.F., Bilimoria, R., Tracadas, P.W.: 1994, Solar surface magnetism. In: Rutten, R.J., Schrijver, C.J. (eds.) Proceedings of the NATO Advanced Research Workshop, Soesterberg, the Netherlands, 1-5 November 1993. NATO Advanced Science Institutes (ASI) Series C: Mathematical and Physical Sciences, Kluwer Academic, Dordrecht, 303.

Martin, S.F., Echols, C.R.: 1994, In: Rutten, R.J., Schrijver, C.J. (eds.) Solar Surface Magnetism, Kluwer Academic, Dordrecht, 339.

Martin, S.F., Harvey, K.L.: 1979, Solar Phys. 64, 93.

Martin, S.F., Lin, Y., Engvold, O.: 2008, Solar Phys. 250, 31.

Martin, S.F., Livi, S.H.B.: 1992, In: Švestka, Z., Jackson, B.V., Machado, M.E. (eds.) Eruptive Solar Flares, Springer, New York, 33.

Martin, S.F., Livi, S.H.B., Wang, J.: 1985, Aust. J. Phys. 38, 929.

Martin, S.F., Marquette, W.H., Bilimoria, R.: 1992, The solar cycle. In: Proceedings of the National Solar Observatory/Sacramento Peak 12th Summer Workshop, ASP Conference Series 27, 53.

Martin, S.F., McAllister, A.H.: 1996, In: Uchida, Y., Kosugi, T., Hudson, H.S. (eds.) Magnetodynamic Phenomena in the Solar Atmosphere; Prototypes of Stellar Magnetic Activity, Kluwer Academic, Dordrecht, 497.

Martin, S.F., McAllister, A.H.: 1997, In: Crooker, N., Joselyn, J.A., Feynman, J. (eds.) Coronal Mass Ejection, Geophysical Monograph 99, AGU, Washington, 127.

Martin, S.F., Panasenco, O.: 2010, Mem. Soc. Astron. Ital. 81, 662.

Martin, S.F., Švestka, Z.F.: 1987, Solar Phys. 113, 303.

Martin, S.F., Švestka, Z.F.: 1988, Solar Phys. 116, 91.

Martin, S.F., Švestka, Z.F., Bhatnagar, A.: 1989, Solar Phys. 124, 339.

Martin, S.F., Wen, A.: 2010, Small telescopes and astronomical research. In: Genet, R.M., Johnson, J.M., Wallen, V. (eds.) Proceedings of Galileo's Legacy, a Celebration of Small Telescopes and Astronomical Research Four Centuries Later, Collins Foundation Press, Santa Margarita 165. Chapter 14. 
Martin, S.F., Ramsey, H.E., Carroll, G.A., Martin, D.C.: 1974, Solar Phys. 37, 343.

Martin, S.F., Edberg, S.J., Hermans, L.M., Dunn, J.M.: 1979, Bull. Am. Astron. Soc. 11, 659.

Martin, S.F., Panasenco, O., Engvold, O., Lin, Y.: 2008, Ann. Geophys. 26, 3061.

Martin, S.F., Panasenco, O., Berger, M.A., Engvold, O., Lin, Y., Pevtsov, A.A., Srivastava, N.: 2012, In: Rimmele, T., Tritschler, A., Wöger, F., Collados, V., Socos-Navarro, H., Schlichenmaier, R., Carlsson, M., Berger, T., Cadavid, A., Gilbert, P., Goode, P., Knölker, M. (eds.) The Second ATST-EAST Meeting: Magnetic Fields from the Photosphere to the Corona, ASP Conf. Series 463, 157.

McAllister, A.H., Martin, S.F., Crooker, N.U., Lepping, R.P., Fitzenreiter, R.J.: 2001, J. Geophys. Res. 106, 29185.

Metcalf, T.R., Leka, K.D., Barnes, G., Lites, B.W., Georgoulis, M.K., Pevtsov, A.A., Balasubramaniam, K.S., Gary, G.A., Jing, J., Li, J., et al.: 2006, Solar Phys. 237, 267.

Moreton, G.F.: 1961, Sky Telesc. 21, 145.

Moreton, G.F.: 1964, H $\alpha$ shock wave and winking filaments with the flare of 20 September 1963. Astron. J. 69, 145 .

Nolan, B., Smith, S.F., Ramsey, H.E.: 1970, Solar Filtergrams of the Lockheed Solar Observatory, Lockheed Missiles and Space Co. printed by Rapid Blue Print Co.

Ohman, Y.: 1969, Solar Phys. 9, 427.

Ohman, Y., Lindgren, A., Lindgren, U.: 1962, U. Ark. Astron. 3, 121.

Ohman, Y., Ohman, N.E.: 1953, Observatory 73, 203.

Panasenco, O.: 2010, Mem. Soc. Astron. Ital. 81, 673.

Panasenco, O., Martin, S.F.: 2008, In: Howe, R., Balasubramaniam, K.S., Komm, R., Petrie, G.J.D. (eds.) Subsurface and Atmospheric Influences on Solar Activity, ASP Conf. Series 383, 243.

Panasenco, O., Martin, S.F., Velli, M.: 2014, Solar Phys. 289, 603.

Panasenco, O., Martin, S., Joshi, A.D., Srivastava, N.: 2011, J. Atmos. Solar-Terr. Phys. 73, 1129.

Panasenco, O., Martin, S.F., Velli, M., Vourlidas, A.: 2012, Solar Phys. 287, 391.

Pettit, E.: 1946, Publ. Astron. Soc. Pac. 58, 310.

Ramsey, J.: 1997, Sacramento Peak Observatory: In the Beginning, Morris Publishing, Kearney.

Ramsey, H.E., Smith, S.F.: 1966, Astron. J. 71, 197.

Richardson, R.S.: 1941, Astrophys. J. 93, 24.

Rust, D.M.: 1967, Astrophys. J. 150, 313.

Rust, D.M.: 1994, Geophys. Res. Lett. 21, 241.

Rust, D.M.: 1999, Geophys. Monogr. 111, 221.

Rust, D.M., Kumar, A.: 1994, Solar dynamic phenomena and solar wind consequences. In: Hunt, J.J. (ed.) Proceedings of the Third SOHO Workshop, Estes Park, Colorado, 26-29 September 1994, ESA SP-373, 39.

Rust, D.M., Martin, S.F.: 1994, In: Balasubramaniam, K.S., Simon, G.W. (eds.) ASP Conf. Series $68,337$.

Schrijver, C.J., Martin, S.F.: 1990, Solar Phys. 129, 95.

Sheeley, N.R., Warren, H.P.: 2012, Astrophys. J. 749, 40.

Smith, S.F.: 1968, In: Kiepenheuer, K.O. (ed.) Proceedings of IAU Symposium No. 35, Budapest, Hungary, 4-8 September 1967, Reidel, Dordrecht, 267.

Smith, S.F.: 1963, The Lockheed Solar Observatory, ASP Leaflet 413.

Smith, S.F., Harvey, K.L.: 1971, Physics of the solar corona. In: Macris, C.J. (ed.) Proceedings of the NATO Advanced Study Institute, Astrophysics and Space Science Library 27, 156.

Smith, S.F., Howard, R.: 1968, In: Kiepenheuer, K.O. (ed.) Structure and Development of Solar Active Regions, IAU Symposium 35, Reidel, Dordrecht 33.

Smith, S.F., Ramsey, H.E.: 1964, Z. Astrophys. 60, 1.

Smith, S.F., Ramsey, H.E.: 1966, Astron. J. 71, 399.

Smith, S.F., Ramsey, H.E.: 1967, Solar Phys. 2, 158.

Sturrock, P.A.: 1980, Solar Flares: A Monograph from SKYLAB Solar Workshop II, Colorado Associated University Press, Boulder.

Švestka, Z.: 2010, Solar Phys. 267, 235.

Švestka, Z., Jackson, B.V., Machado, M.E.: 1992, Eruptive Solar Flares, Springer, Berlin/New York. Also Lecture Notes in Phys. 399, Springer, New York.

Švestka, Z., Martin, S.F., Kopp, R.A.: 1980, Solar and interplanetary dynamics. In: Proceedings of the Symposium, Cambridge, Mass., 27-31 August, 217.

Švestka, Z., Farnik, F., Fontenla, J.M., Martin, S.F.: 1989, Solar Phys. 123, 317.

Tandberg-Hanssen, E.: 1974, Solar Prominences, Reidel, Dordrecht.

Tandberg-Hanssen, E.: 1995, The Nature of Solar Prominences, Kluwer Academic, Dordrecht.

Tandberg-Hanssen, E.: 2011, Solar Phys. 269, 237.

Tandberg-Hanssen, E., Hansen, R.T., Martin, S.F.: 1980, Solar Phys. 65, 357.

van Ballegooijen, A.A., Martens, P.C.H.: 1989, Astrophys. J. 343, 971. 
Wang, Y.-M., Muglach, K., Kliem, B.: 2009, Astrophys. J. 699, 133.

Webb, D.F., Cheng, C.-C., Dulk, G.A., Martin, S.F., McKenna-Lawlor, S., McLean, D.J., Edberg, S.J.: 1980, In: Sturrock (ed.) Solar Flares: A Monograph from Skylab Solar Workshop II, Colorado Associated University Press, Boulder, 471.

Wilson, P.R., Altrock, R.C., Harvey, K.L., Martin, S.F., Snodgrass, H.B.: 1988, Nature 333, 748.

Yeates, A.R., Mackay, D.H.: 2009, Solar Phys. 254, 77.

Yeates, A.R., Mackay, D.H., van Ballegooijen, A.A.: 2007, Solar Phys. 245, 87.

Zirker, J., Engvold, O., Martin, S.F.: 1998, Nature 396, 440.

Zwaan, C.: 1987, Annu. Rev. Astron. Astrophys. 25, 83. 